\title{
Preliminary Scaling Estimate for Select Small Scale Mixing Demonstration Tests
}

\author{
BE Wells \\ JA Fort \\ PA Gauglitz \\ DR Rector \\ PP Schonewill
}

September 2013

Pacific Northwest

NATIONAL LABORATORY

Proudly Operated by Battelle Since 1965 


\title{
DISCLAIMER
}

This report was prepared as an account of work sponsored by an agency of the United States Government. Neither the United States Government nor any agency thereof, nor Battelle Memorial Institute, nor any of their employees, makes any warranty, express or implied, or assumes any legal liability or responsibility for the accuracy, completeness, or usefulness of any information, apparatus, product, or process disclosed, or represents that its use would not infringe privately owned rights. Reference herein to any specific commercial product, process, or service by trade name, trademark, manufacturer, or otherwise does not necessarily constitute or imply its endorsement, recommendation, or favoring by the United States Government or any agency thereof, or Battelle Memorial Institute. The views and opinions of authors expressed herein do not necessarily state or reflect those of the United States Government or any agency thereof.

\author{
PACIFIC NORTHWEST NATIONAL LABORATORY \\ operated by \\ BATTELLE \\ for the \\ UNITED STATES DEPARTMENT OF ENERGY \\ under Contract DE-AC05-76RL01830
}

Printed in the United States of America
Available to DOE and DOE contractors from the Office of Scientific and Technical Information, P.O. Box 62, Oak Ridge, TN 37831-0062; ph: (865) 576-8401 fax: $(865) 576-5728$
email: reports@adonis.osti.gov
Available to the public from the National Technical Information Service 5301 Shawnee Rd., Alexandria, VA 22312 ph: (800) 553-NTIS (6847) email: orders $a$ ntis.gov $<$ http://www.ntis.gov/about/form.aspx> Online ordering: http://www.ntis.gov




\title{
Preliminary Scaling Estimate for Select Small Scale Mixing Demonstration Tests
}

\author{
BE Wells \\ JA Fort \\ PA Gauglitz \\ DR Rector \\ PP Schonewill
}

September 2013

Prepared for

the U.S. Department of Energy

under Contract DE-AC05-76RL01830

Pacific Northwest National Laboratory

Richland, Washington 99352 



\section{Summary}

The Hanford Site double-shell tank (DST) system provides the staging location for waste that will be transferred to the Hanford Tank Waste Treatment and Immobilization Plant (WTP). Specific WTP acceptance criteria for waste feed delivery describe the physical and chemical characteristics of the waste that must be met before the waste is transferred from the DSTs to the WTP. One of the more challenging requirements relates to the sampling and characterization of the undissolved solids (UDS) in a waste feed DST because the waste contains solid particles that settle and their concentration and relative proportion can change during the transfer of the waste in individual batches. A key uncertainty in the waste feed delivery system is the potential variation in UDS transferred in individual batches in comparison to an initial sample used for evaluating the acceptance criteria. To address this uncertainty, a number of smallscale mixing tests have been conducted as part of Washington River Protection Solutions' Small Scale Mixing Demonstration (SSMD) project to determine the performance of the DST mixing and sampling systems.

The purpose of the 2013 testing was to estimate scaling relationships for waste feed delivery tank performance metrics, in particular transfer UDS concentration. A statistically designed test plan was used to generate accurate and quantifiable correlations. These tests also used a simulant that better represented Hanford Site tank waste. The solids mixtures used in the base simulant for these tests is similar to the 2011 multicomponent Complex 5 simulant, however, the 2013 Base simulant has two variations, a typical and more challenging, high base loading. The liquid fraction of the simulant is tailored to provide corresponding typical and high viscosities, which better represent the Hanford Site tank waste supernatant. Water was used as the liquid fraction of the simulant in 2011 SSMD testing.

The purpose of this study was to take an independent look at the measurement data with an emphasis on estimating scaling exponents for performance metrics as a function of jet velocity. This study did not examine secondary variables such as capture velocity. Finally, since this study was limited both in terms of schedule and resources, only a subset of the data was examined. The selected data set had the largest number of jet velocities for otherwise constant conditions. Specifically, this was for the High Base simulant case with High simulant viscosity and the highest suction capture velocity, $11.3 \mathrm{~m} / \mathrm{s}$. In addition to transfer UDS concentration, consideration was given to scaling with jet velocity for additional metrics, including cloud height and effective cleaning radius to increase confidence in the transfer concentration test data scale-up. These additional performance metrics are of interest because they are available for small-scale and full-scale tests and predictions, whereas transfer UDS concentration is not. Therefore, these additional metrics provide a way to test scaling relationships and they present a means by which to relate expectations for other metrics to full scale.

There is general consistency in scaling behavior between test campaigns, full-scale data, and predictions using ParaFlow. The scale exponents are thus judged meaningful for different simulants and components as well as for full scale within the limited data and predictions considered. Depending on the performance metric evaluated and specific test conditions, different scale exponents are identified. The collective observations of test results with all SSMD simulants is that for transfer UDS concentration, stratified components (those components with varied vertical suspended concentration) scale with $\alpha=0$ to 0.1 . With these scaling exponents indicated by the test data, the jet velocities used in these tests are lower 
than the jet velocities required to relate performance to full scale. Improved performance is therefore estimated at full scale, as batch UDS concentrations are closer to the pre-transfer sample UDS concentrations at higher jet velocity.

Additional data, beyond what was specified for this study, is also available. Evaluation of these data, together with available data for the other metrics, would be a step to further increasing confidence in the scale-up performance of the SSMD waste feed delivery testing performance. One approach to using the different metrics in scaled testing would be to attempt to directly relate all of the metrics to the scaling of the UDS concentration at the transfer line. 


\section{Acknowledgments}

The authors thank DR Rector for his independent technical review, SA Suffield and LA Mahoney for their calculation reviews, and KR Neiderhiser for the document production. 



\section{Acronyms and Abbreviations}

CFR

DOE

DST

ECR

EM-31

PJM

PNNL

PPV

PSD

PSDD

SS

SSMD

UDS

WFD

WTP
Code of Federal Regulations

U.S. Department of Energy

double-shell tank

effective cleaning radius

U.S. Department of Energy Environmental Management Waste Processing Program

pulse jet mixer

Pacific Northwest National Laboratory

power per unit volume

particle size distribution

particle size and density distribution

stainless steel

Small Scale Mixing Demonstration

undissolved solids

waste feed delivery

Hanford Tank Waste Treatment and Immobilization Plant 



\section{Contents}

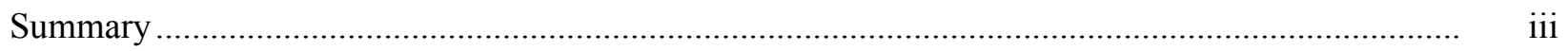

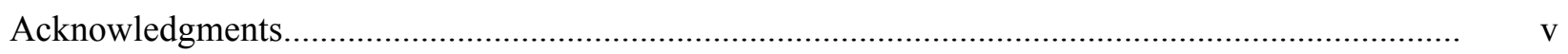

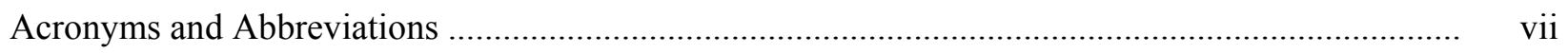

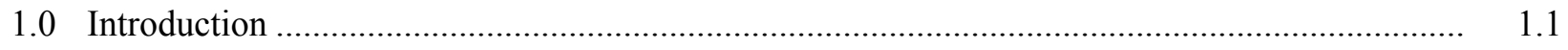

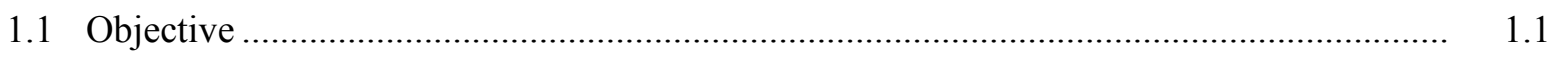

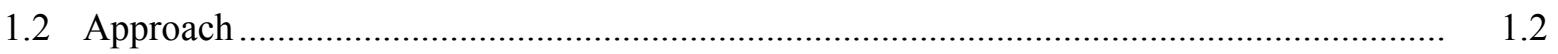

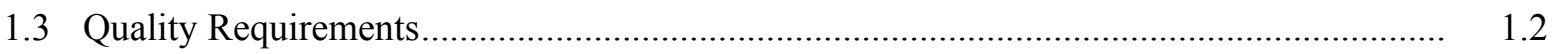

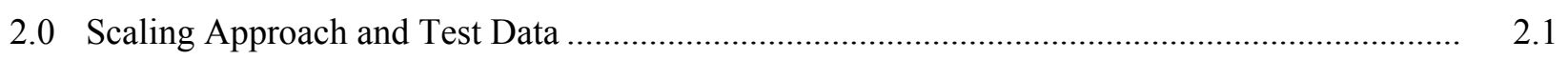

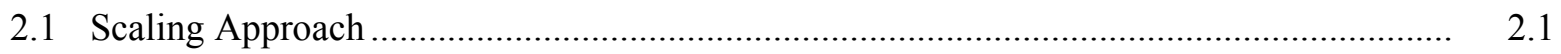

2.1.1 Criterion - Jet Velocities for Similar Concentration ............................................ 2.2

2.1.2 Example of Determining a Scale Exponent .................................................... 2.2

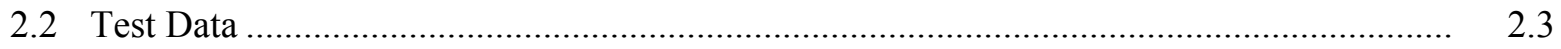

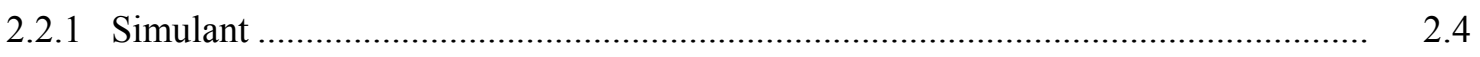

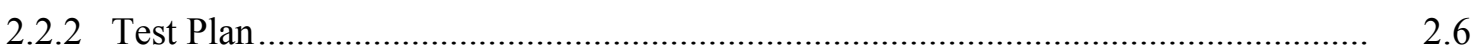

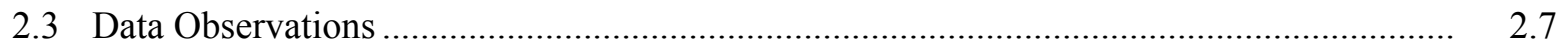

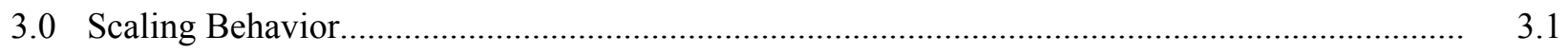

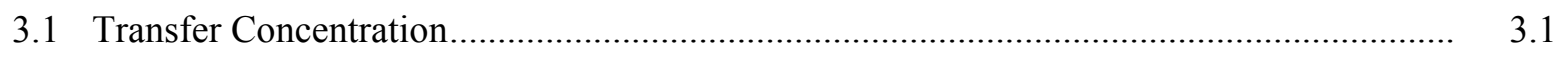

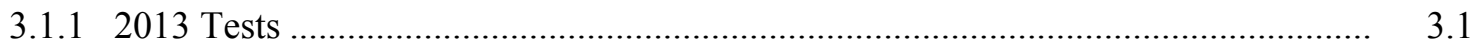

3.1.2 Transfer Concentration; Other Test Campaigns.................................................. 3.6

3.2 Cloud Height and ECR Performance Metrics ......................................................... 3.10

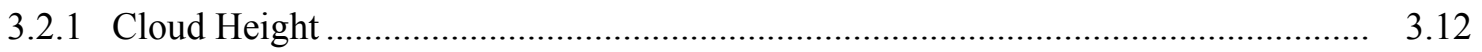

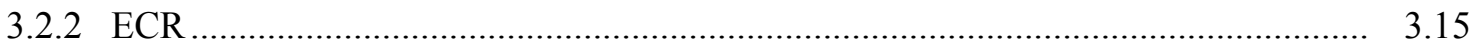

3.2.3 Summary of Scaling Behavior ................................................................. 3.22

4.0 Estimate of Full-Scale Performance …................................................................................ 4.1

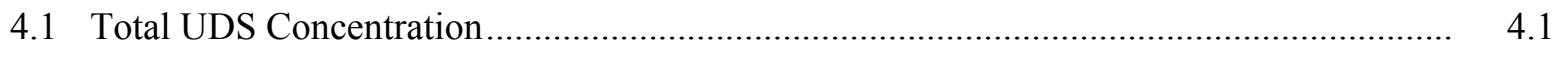

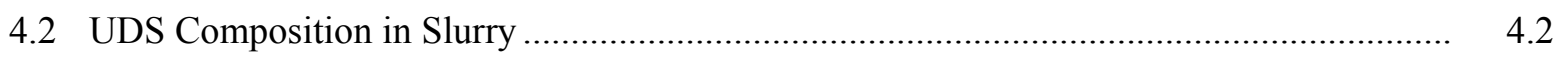

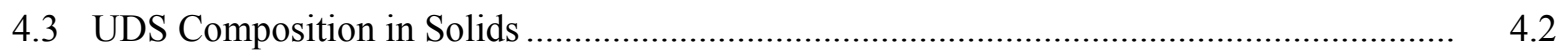

5.0 Conclusions and Recommendations ............................................................................ 5.1

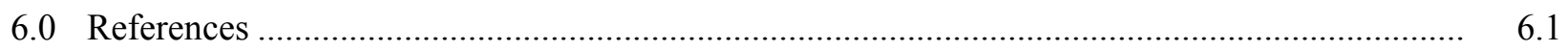

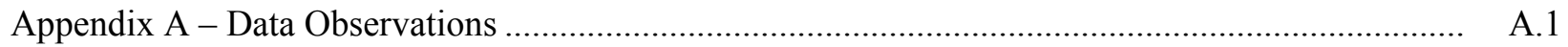

Appendix B - ParaFlow Predictions ..................................................................................... B. B 


\section{Figures}

$2.1 \quad$ DST Waste Feed Delivery System Example ...................................................................... 2.1

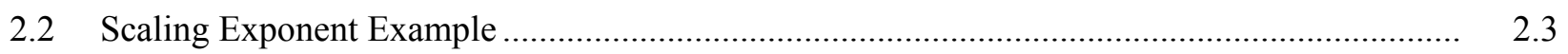

2.3 PSDD Metrics for Simulant Components - Settling Velocity ............................................. 2.5

2.4 PSDD Metrics for Simulant Components - Critical Stress for Erosion ................................. 2.6

2.5 Particle Transportation (Suspension) and Re-Suspension Velocity....................................... 2.8

3.1 Transfer UDS Concentration $-\mathrm{BS}=\mathrm{H}, \mathrm{SV}=\mathrm{H}, \mathrm{CV}=11.3$ - Gibbsite .................................... 3.1

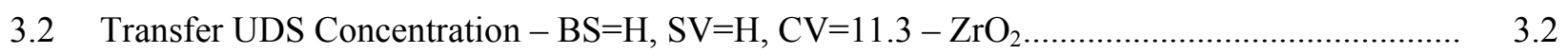

3.3 Transfer UDS Concentration - BS=H, SV=H, CV=11.3 - Sand....................................... 3.2

3.4 Transfer UDS Concentration $-\mathrm{BS}=\mathrm{H}, \mathrm{SV}=\mathrm{H}, \mathrm{CV}=11.3$ - Stainless Steel ........................... 3.3

3.5 Comparison of Transfer UDS Concentration Data for Normalized Jet Velocity [BS=H,

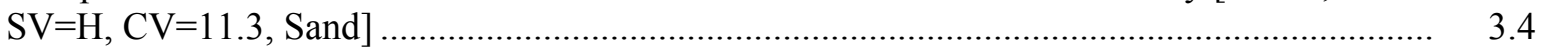

3.6 Comparison of Transfer UDS Concentration Data for Normalized Jet Velocity [BS=H,

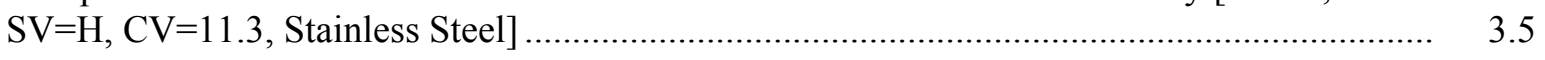

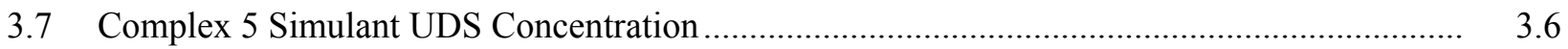

3.8 Transfer UDS Concentration - Complex 5 Simulant....................................................... 3.7

3.9 Comparison of Transfer UDS Mass Fraction Data for Normalized Jet Velocity Complex 5 Simulant - Stainless Steel ............................................................................ 3.8

3.10 Illustration of Transfer UDS Concentration Dependence on Cloud Height, Upper Image Low Jet Velocity, Lower Image High Jet Velocity...............................................................

3.11 Transfer UDS Concentration for $\mathrm{ZrO}_{2}$ Component of Complex 5 Simulant ........................... 3.11

3.12 Transfer UDS Concentration for $\mathrm{ZrO}_{2}$ Single Component Simulant.................................... 3.12

3.13 Cloud Height Measurements and Predictions for $\mathrm{ZrO}_{2}$ Simulant .......................................... 3.13

3.14 Cloud Height Measurements and Predictions for Complex 5 Simulant ................................. 3.14

3.15 ECR; SSMD Testing with Base Simulant and Mixer Pump Tests in AZ-101 ........................ 3.16

3.16 ECR, SSMD Testing with Base Simulant and Mixer Pump Tests in AZ-101 ........................ 3.18

3.17 Critical Shear Stress Calculated from PSDDs ............................................................. 3.19

3.18 Comparison of Normalized ECR Data for Normalized Jet Velocity ..................................... 3.20

3.19 ECR; SSMD Testing with Complex 5 Simulant and Mixer Pump Tests in AZ-101 ................ 3.21

3.20 ECR, SSMD Testing with Complex 5 Simulant and Mixer Pump Tests in AZ-101 ............... 3.21

3.21 Comparison of Normalized ECR Data for Normalized Jet Velocity - Complex 5

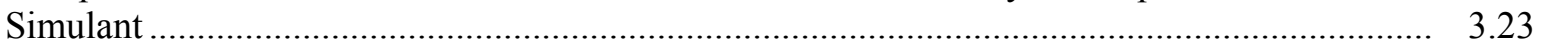

4.1 Transfer UDS Concentration, Total UDS, SSMD ............................................................

4.2 Transfer UDS Concentration - Composition in Slurry - SSMD ............................................ 4.4

4.3 Transfer UDS Concentration - Composition in Solids - SSMD ......................................... 4.5 


\section{Tables}

2.1 Performance Data Measured in 2011 and 2013 SSMD Tests................................................ 2.4

2.2 Base Simulant Solid Component Properties ........................................................................ 2.4

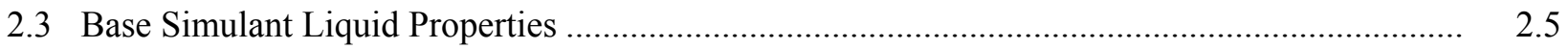

2.4 Newtonian Fluid Conditions for Scaled Performance Test Series ............................................ 2.7 



\subsection{Introduction}

The Hanford Site double-shell tank (DST) system provides the staging location for waste feed delivery to the Hanford Tank Waste Treatment and Immobilization Plant (WTP). Olson (2011) includes WTP acceptance criteria that describe physical and chemical characteristics of the waste that must be certified as acceptable before the waste is transferred from the DSTs to the WTP. Details of the activities associated with the initial development of data quality objective requirements to meet waste acceptance criteria for transfer of staged feed from tank farms to the WTP are provided in Arakali et al. (2011). One of the more challenging requirements relates to the sampling and characterization of the undissolved solids (UDS) in a waste feed DST.

The objectives of Washington River Protection Solutions' Small Scale Mixing Demonstration (SSMD) project are to understand and demonstrate the DST sampling and batch transfer performance at multiple scales using slurry simulants comprised of UDS particles and liquid (Townson 2009). WTP feed delivery requires that the DST sampling and batch transfer systems are capable of adequately mixing the waste feed tank contents and retrieving a representative sample. Waste feed delivery from a DST to the WTP proceeds generally as follows:

1. Waste from a DST feed tank is sampled while the mixing system is operated.

2. Upon WTP waste acceptance, the mixing system in the DST is again operated and batch transfers of the slurry are provided to the WTP.

The SSMD project utilizes geometrically scaled DST feed tanks to generate mixing, sampling, and transfer test data. The slurry simulants used in these tests have been undergoing continual refinement to provide representative physical properties of Hanford tank waste (Wells et al. 2011; Lee et al. 2012a). Results of testing over the last 2 years are described in Kelly et al. (2013). The present study is an assessment of the most recent tests in this series that examine transfer UDS concentration with the Base simulant as described in the test plan (Lee 2012; Lee et al. 2012b).

\subsection{Objective}

The objective of work documented in this report is to conduct an independent assessment of the recent Waste Feed Delivery Mixing and Sampling Program scaled/system performance test results and determine what these results imply for scale-up behavior ${ }^{1}$. The primary assessment activity was the statistical analysis (Piepel et al. 2013) as described in the revised test plan (Lee et al. 2012b). The time frame for this assessment was limited; therefore, the scope was limited to the data set that had the maximum likelihood to reveal scaling trends for performance metrics of interest as defined in Section 2.

\footnotetext{
${ }^{1}$ This independent analysis was completed and presented at the June 3-5, 2013, SSMD Mixing Performance Results Review at Richland, Washington (Wells et al., "Observed Scaling Behavior: Implications for Full Scale Performance," PNNL-SA-95989). The results documented in this report are identical to those presented at that review.
} 


\subsection{Approach}

Jet nozzle velocity has been shown to have the greatest impact on mixing performance metrics for a given tank loading and this study was limited to estimating its effect in 2013 test results. The primary performance metric examined in the current study was transfer UDS concentration with some consideration also given to cloud height and effective cleaning radius (ECR). Data were evaluated for scaling behavior, how to increase confidence in extrapolations to full scale, and implications for full-scale performance.

\subsection{Quality Requirements}

Pacific Northwest National Laboratory's (PNNL's) Quality Assurance Program is based on requirements defined in U.S. Department of Energy (DOE) Order 414.1D, "Quality Assurance," and Title 10 of the Code of Federal Regulations Part 830 (10 CFR 830), "Energy/Nuclear Safety Management," Subpart A, "Quality Assurance Requirements" (a.k.a., the Quality Rule). PNNL has chosen to implement the requirements of DOE Order 414.1D and 10 CFR 830, Subpart A, by integrating them into the laboratory's management systems and daily operating processes. The procedures necessary to implement the requirements are documented through PNNL's How Do I? (HDI) standards-based management approach.

The performed calculations as well as the documentation and reporting of results and conclusions were reviewed in accordance with HDI. Internal verification and validation activities were addressed by conducting an independent technical review of the final data report. This review verifies that the reported results are traceable and that inferences and conclusions are soundly based; review materials are documented in project records. 


\subsection{Scaling Approach and Test Data}

The accuracy of the estimated full-scale mixing performance in a DST necessarily depends on the accuracy of the model(s) used to predict the full-scale performance. A summary discussion of scaling approaches is provided, and the specific approach and example are discussed. Test data and observations of that data are summarized.

\subsection{Scaling Approach}

The accuracy or uncertainty of a scaling model can only be established by comparing the scaling model predictions with the actual performance of the full-scale system. A schematic representation of the waste feed delivery system is provided in Figure 2.1. The phenomena of jet mixer pump mobilization, suspension, subsequent particle settling, and transfer pump withdrawal are depicted together with test metrics describing aspects of these phenomena. Extrapolating on the basis of data taken at only two sizes provides no basis to confirm that the scaling relationship is constant with size beyond the test scales. Thus, in the absence of full-scale data specific to the waste(s) and performance metric(s) of interest, some other estimate for full-scale data or phenomenological quantification are required. Physical reasoning based on first principles and supporting analyses is required to evaluate the implications of an extrapolation approach.

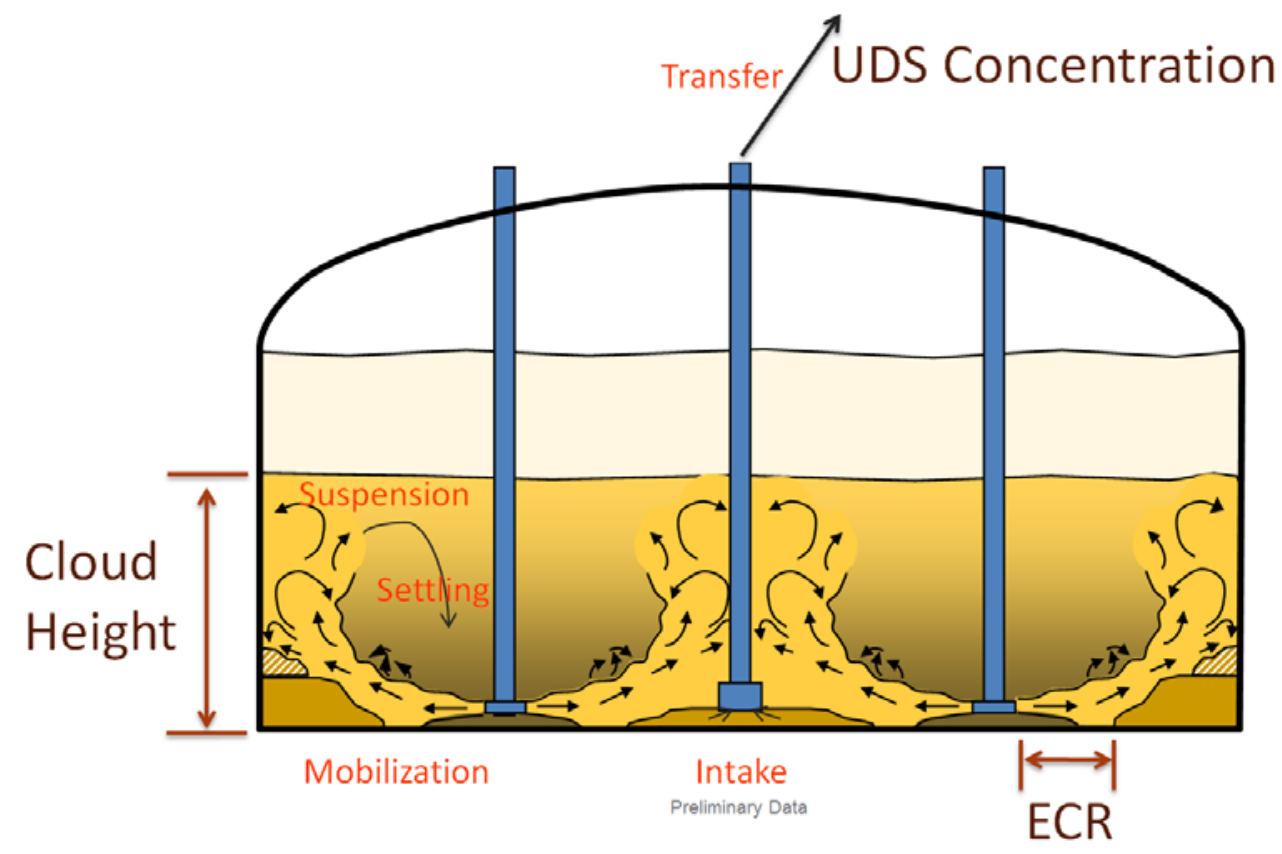

Figure 2.1. DST Waste Feed Delivery System Example

Physical reasoning of the complex phenomena of the capability of the full-scale mixing and transfer system to deliver feed batches that are consistent with pre-transfer samples collected to characterize the feed is not feasible without the aid of computational tools. Thus, without computational tools, the approach must be to address aspects of the process separately through simple models of fluid mechanics or assessment of the simple models via comparison to data wherein the individual processes can be 
considered. Therefore, the simplest model forms that address the data must be considered and then, after applying physical reasoning to evaluate the credibility of the fit of a simple model, the results can be judged physically reasonable or not.

For the current work, simple power-law models are applied to the SSMD test data for the specific metric of interest, DST sampling and batch transfer performance, and confidence in the accuracy of these test results relative to full-scale DST mixing is judged via full-scale mixing performance data and predictions for related performance metrics. The DST sampling and batch transfer performance scaling is described in Section 2.1.1.

\subsubsection{Criterion - Jet Velocities for Similar Concentration}

Transfer concentration is the primary metric used for DST sampling and batch transfer performance (Lee 2012). The scaling of this metric can be evaluated from scaled data using concentration data with similar performance at different velocities. For this approach, velocities that provide equivalent concentration at both test scales are identified. The scaling exponent can be obtained from the geometrically scaled tests using the common approach,

$$
\frac{\mathrm{U}_{\mathrm{L}}}{\mathrm{U}_{\mathrm{S}}}=\left(\frac{\mathrm{D}_{\mathrm{L}}}{\mathrm{D}_{\mathrm{S}}}\right)^{\alpha}
$$

where

$$
\begin{aligned}
\alpha & =\text { scale exponent } \\
\mathrm{U} & =\text { jet velocity } \\
\mathrm{D} & =\text { tank diameter } \\
\mathrm{L} & =\text { large vessel size } \\
\mathrm{S} & =\text { small vessel size. }
\end{aligned}
$$

This is a power law model, which can be expressed in the more convenient logarithmic form for data analysis. Taking the log of both sides of Equation (2.1) gives a linear relationship where $\alpha$ is the slope of data on a plot having $\ln \left(\mathrm{U}_{\mathrm{L}} / \mathrm{U}_{\mathrm{S}}\right)$ on the ordinate and $\ln \left(\mathrm{D}_{\mathrm{L}} \cdot / \mathrm{D}_{\mathrm{S}}\right)$ on the abscissa.

\subsubsection{Example of Determining a Scale Exponent}

What velocities provide equivalent concentration at both test scales? An example is shown in Figure 2.2, wherein blue colored symbols are small tank test data and red and orange symbols are large tank test data. The multiple data points at each velocity are the pre-transfer and batch concentration values. The green symbols and curve represent a scale-up of the small tank data using $\alpha=0.2$ which is shown in Figure 2.2 to give concentration variation with jet velocity very close to those of the large scale tank measurements. Therefore, for this example, a scale-up exponent of 0.2 gives similar behavior. This indicates that test scale jet velocities need to be less than full-scale jet velocities to achieve equivalent performance for this example. A scale-up exponent of zero would indicate that the scaled jet velocities would be the same as full-scale jet velocities for equivalent performance. 


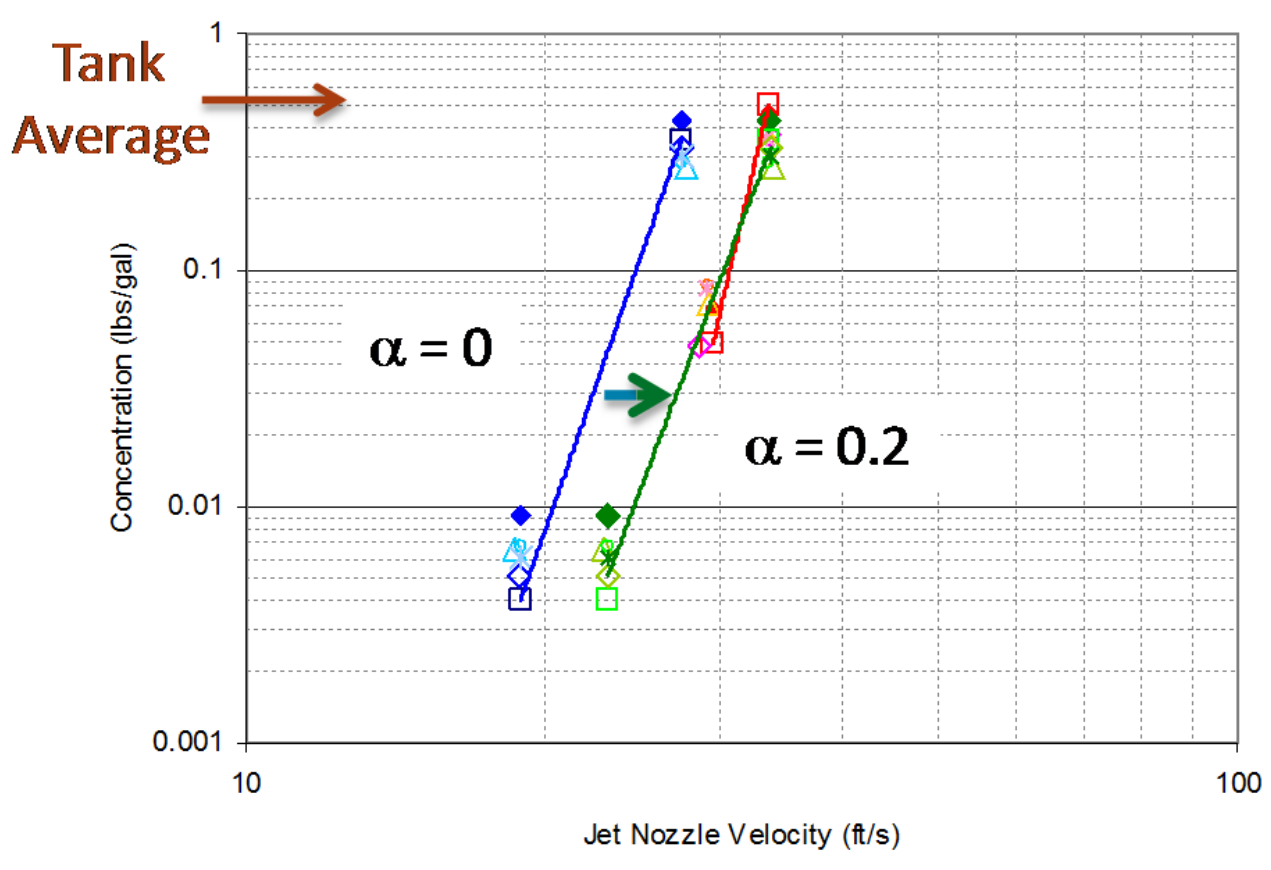

\begin{tabular}{|c|c|}
\hline & Small \\
\hline$\diamond$ & Pre-Transfer \\
\hline$\square$ & Batch 1 \\
\hline$\diamond$ & Batch 2 \\
\hline$\triangle$ & Batch 3 \\
\hline 0 & Batch 4 \\
\hline * & Batch 5 \\
\hline & Large \\
\hline$\bullet$ & Pre-Transfer \\
\hline$\square$ & Batch 1 \\
\hline$\diamond$ & Batch 2 \\
\hline$\triangle$ & Batch 3 \\
\hline 0 & Batch 4 \\
\hline * & Batch 5 \\
\hline & alpha $=0.2$ \\
\hline$\diamond$ & Pre-Transfer \\
\hline$\square$ & Batch 1 \\
\hline$\diamond$ & Batch 2 \\
\hline$\triangle$ & Batch 3 \\
\hline 0 & Batch 4 \\
\hline * & Batch 5 \\
\hline
\end{tabular}

Figure 2.2. Scaling Exponent Example

\subsection{Test Data}

Initial SSMD testing focused on mixing and transfer performance with a simple single component simulant as well as one representing AY-102 (RPP-49740, RPP-RPT-53101, and RPP-47557). More recent SSMD testing builds on that initial work and explores three areas: 1) limits of performance, 2 ) solids accumulation, and 3) scaled performance (Kelley et al. 2013). The present report is directed at the recently completed scaled performance testing, which examined the relationship between a pretransfer sample of a mixed tank to the five discrete batches in the simulated waste feed delivery process, and thus specifically consider one of the more challenging Waste Feed Delivery (WFD) requirements; sampling and characterization of the UDS in a waste feed DST. These tests were conducted in the two SSMD scaled tanks, 43 and 120 inches in diameter, with the goal of building correlations to estimate fullscale behavior. The 2013 testing uses a statistically designed and simulants that represent a range of Hanford waste. A summary of performance measurements and simulants used in SSMD tests is given in Table 2.1. Also included in this table are full-scale tests in AZ-101 and model predictions for a full-scale DST with $\mathrm{ZrO}_{2}$ simulant properties. As will be described in more detail below, these full-scale results are included to increase confidence in the scale-up predictions of transfer concentration. 
Table 2.1. Performance Data Measured in 2011 and 2013 SSMD Tests

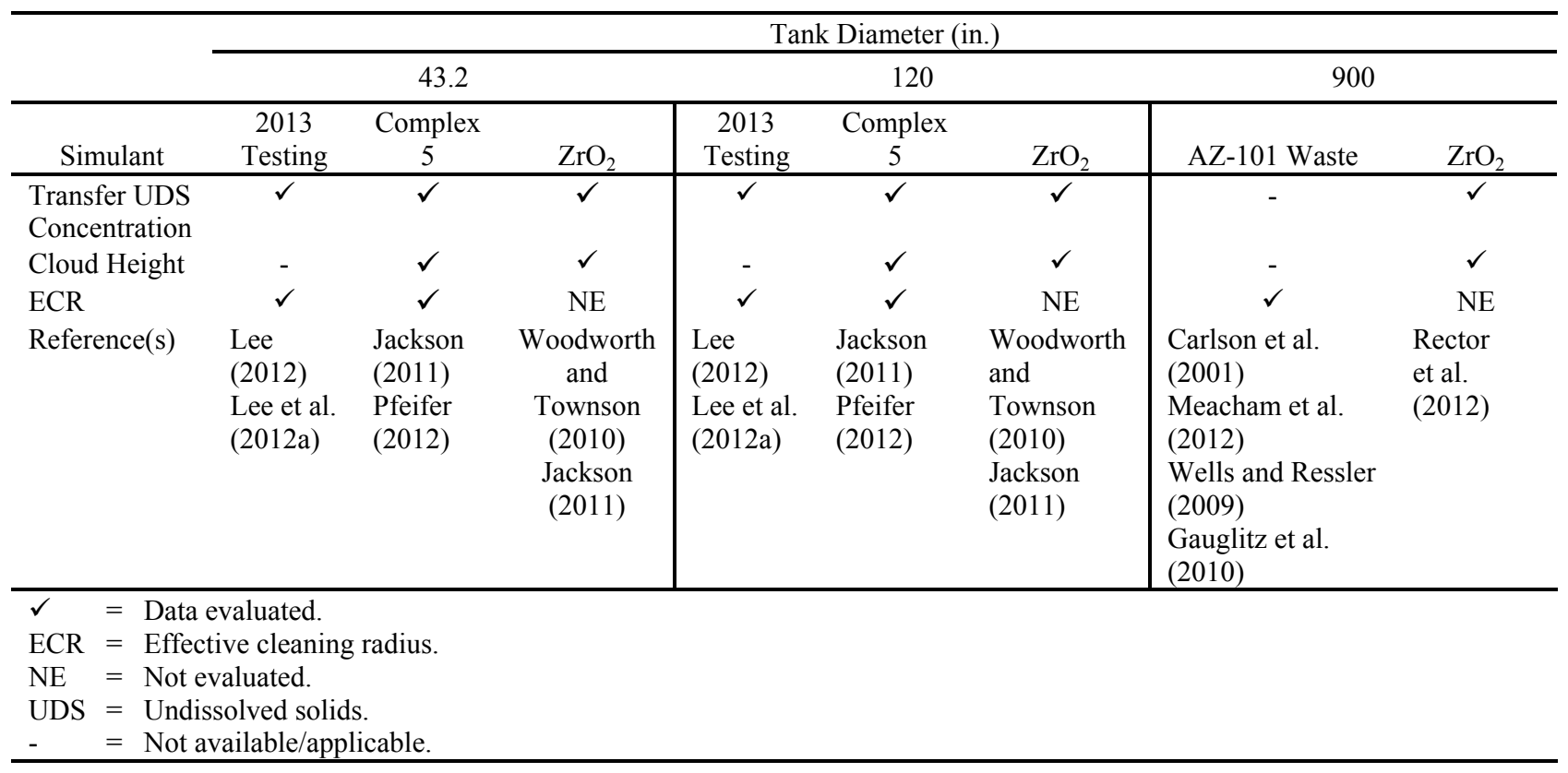

\subsubsection{Simulant}

The 2013 simulant uses a base solids mixture of gibbsite, sand, zirconium oxide, and stainless steel particulate to represents the bulk solids in the tank waste. Three base simulant compositions were developed representing Low, Typical, and High Hanford tank waste particle size and density distributions (PSDDs). The base simulant component properties and simulant mass fractions are given in Table 2.2. A range of liquid base simulant recipes were also developed for SSMD testing. Their composition and properties are shown in Table 2.3. Figure 2.3 and Figure 2.4 compare settling velocity and critical shear stress for the range of solid particulates that have been used in these and 2011 SSMD simulants (following the methodology of Wells et al. 2012). In each case, water is the liquid phase. These figures demonstrate that the simulant components represented a range of performance significant to aspects of waste feed delivery depicted in Figure 2.1 (particle settling and mobilization).

Table 2.2. Base Simulant Solid Component Properties (Lee 2012)

\begin{tabular}{lccccl}
\hline & Solid Density & Median Particle & \multicolumn{3}{c}{ Mass Fraction } \\
\cline { 4 - 6 } Compound & $(\mathrm{g} / \mathrm{ml})$ & Size (micron) & Low & Typical & High \\
\hline Small gibbsite & 2.42 & 1.3 & 1.00 & 0.27 & 0 \\
Large gibbsite & 2.42 & 10 & 0 & 0.44 & 0.03 \\
Small sand & 2.65 & 57 & 0 & 0 & 0.35 \\
Medium sand & 2.65 & 148 & 0 & 0.13 & 0 \\
Large sand & 2.65 & 382 & 0 & 0 & 0.21 \\
Zirconium oxide & 5.7 & 6 & 0 & 0.10 & 0.08 \\
Stainless steel & 8.0 & 112 & 0 & 0.06 & 0.33 \\
\hline
\end{tabular}


The base simulant recipes were developed for the range of SSMD tests. Only a subset was used for scaled performance testing, specifically the typical and high base solids and the typical and modified high base liquids.

Table 2.3. Base Simulant Liquid Properties (Lee 2012)

\begin{tabular}{|c|c|c|c|c|c|}
\hline \multirow[b]{2}{*}{$\begin{array}{c}\text { Supernatant } \\
\text { (density/viscosity) }\end{array}$} & \multicolumn{2}{|c|}{$\begin{array}{c}\text { Target Simulant } \\
\text { Properties at } 20^{\circ} \mathrm{C} \\
\end{array}$} & \multicolumn{2}{|c|}{$\begin{array}{c}\text { Simulant Properties } \\
\text { at } 20^{\circ} \mathrm{C} \\
\end{array}$} & \multirow[b]{2}{*}{ Simulant Composition } \\
\hline & $\begin{array}{c}\text { Density } \\
(\mathrm{g} / \mathrm{ml})\end{array}$ & $\begin{array}{l}\text { Viscosity } \\
(\mathrm{cP})\end{array}$ & $\begin{array}{c}\text { Density } \\
(\mathrm{g} / \mathrm{ml})\end{array}$ & $\begin{array}{l}\text { Viscosity } \\
(\mathrm{cP})\end{array}$ & \\
\hline Low/Low & 1.1 & 1 & 1.098 & 1.62 & $12 \mathrm{wt} \%$ sodium thiosulfate \\
\hline Low/High & 1.1 & 8 & 1.135 & 8.03 & $53 \mathrm{wt} \%$ glycerol \\
\hline High/Low & 1.37 & 1 & 1.370 & 2.00 & $37 \mathrm{wt} \%$ sodium bromide \\
\hline High/High & 1.37 & 15 & 1.368 & 14.6 & $\begin{array}{l}33.4 \mathrm{wt} \% \text { sodium thiosulfate and } \\
19.5 \mathrm{wt} \% \text { glycerol }\end{array}$ \\
\hline Typical/Typical & 1.29 & 3.3 & 1.284 & 3.60 & $31.5 \mathrm{wt} \%$ sodium thiosulfate \\
\hline $\begin{array}{l}\text { High/Modified } \\
\operatorname{High}^{(a)}\end{array}$ & 1.318 & 8 & TBD & TBD & $\begin{array}{l}\text { TBD wt } \% \text { sodium thiosulfate and } \\
\text { TBD wt } \% \text { glycerol }\end{array}$ \\
\hline
\end{tabular}

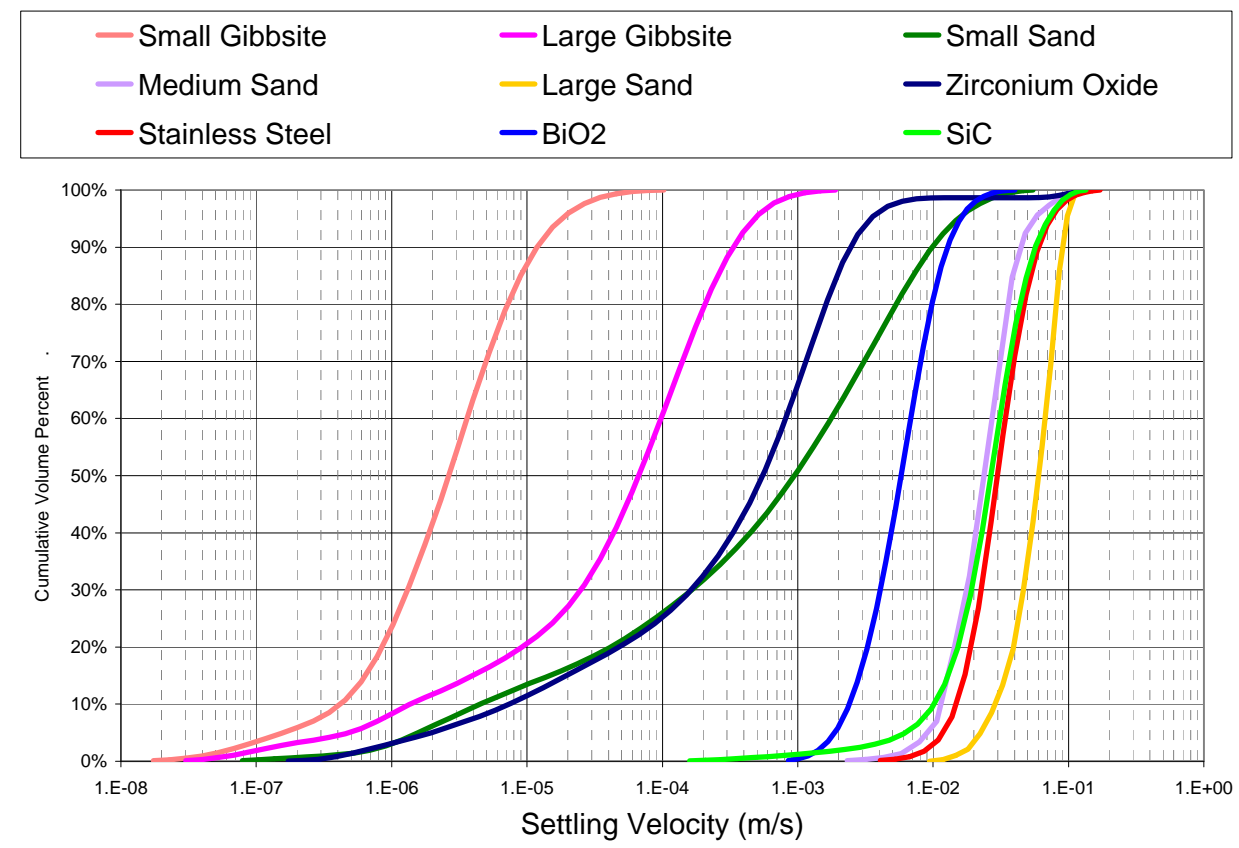

Figure 2.3. PSDD Metrics for Simulant Components - Settling Velocity 


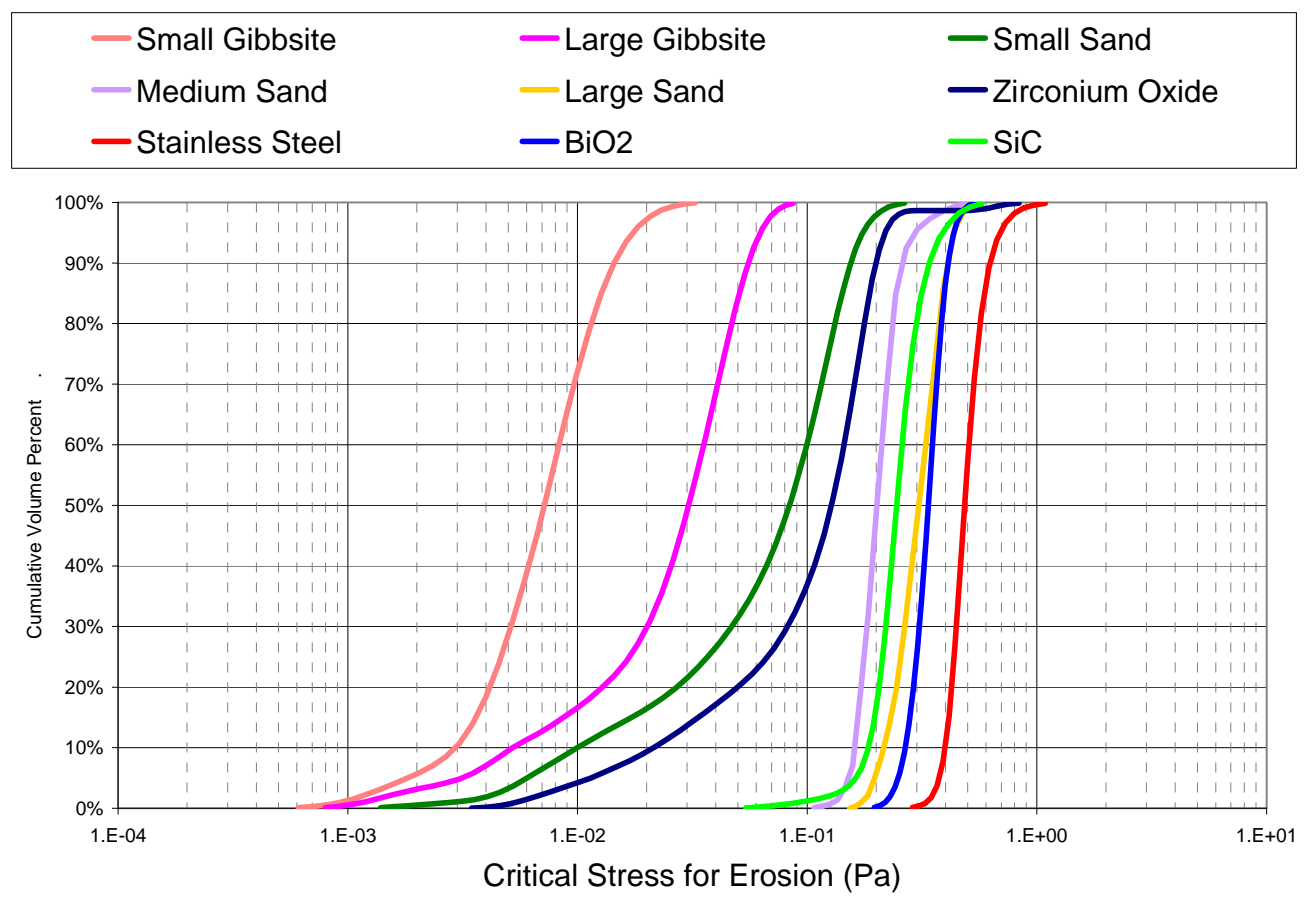

Figure 2.4. PSDD Metrics for Simulant Components - Critical Stress for Erosion

\subsubsection{Test Plan}

From Lee et al. (2012b), the test conditions used for the scaled performance test series are shown in Table 2.4.

This study will focus on the four test cases with constant properties except varying nozzle velocity (Test Conditions 18-21 in Table 2.4). Using these test conditions provides highest range and resolution of metric response to test jet velocity. Test Conditions 18-21 include four different jet velocities compared to at most three different jet velocities for any other set of test conditions in Table 2.4 with nonjet velocity test parameters held constant. Test Conditions 18-21 use the high Base simulant loading condition, the high supernatant viscosity and the highest capture velocity, $11.3 \mathrm{~m} / \mathrm{s}$. This test condition will be referred to through the remainder of this report as $[\mathrm{BS}=\mathrm{H}, \mathrm{SV}=\mathrm{H}, \mathrm{CV}=11.3]$.

As indicated in Section 2.0, metrics that are common to the entire range of scales are needed to assess whether behavior observed in the small-scale tanks is consistent with full scale. Transfer UDS concentration is not available for any full-scale tests; however, data do exist at full and reduced scales for cloud height and ECR. These related performance metrics (see Figure 2.1) are therefore used to increase confidence in transfer concentration performance predictions for full scale. To restate, a favorable comparison of available related performance metrics between test scales and full scale increases confidence in full-scale transfer UDS concentration performance predictions based on test scale data. 
Table 2.4. Newtonian Fluid Conditions for Scaled Performance Test Series (Lee et al. 2012b)

\begin{tabular}{cccccc}
\hline $\begin{array}{c}\text { Test } \\
\text { Number }\end{array}$ & $\begin{array}{c}\text { Nozzle Velocity } \\
1: 21-\text { Scale ft/s } \\
(\mathrm{gpm})\end{array}$ & $\begin{array}{c}\text { Nozzle Velocity } \\
1: 8-\text { Scale ft/s } \\
(\mathrm{gpm})\end{array}$ & $\begin{array}{c}\text { Base Simulant } \\
\text { Constituent }\end{array}$ & $\begin{array}{c}\text { Supernatant/ } \\
\text { Non-Newtonian } \\
\text { Simulant Properties }\end{array}$ & $\begin{array}{c}\text { Capture } \\
\text { Velocity } \\
(\mathrm{ft} / \mathrm{s})\end{array}$ \\
\hline 1 & V21-1 & V8-1 & High & Typical & 7.3 \\
2 & V21-3 & V8-3 & High & Typical & 7.3 \\
3 & V21-2 & V8-2 & Typical & Typical & 7.3 \\
4 & V21-5 & V8-5 & Typical & Typical & 7.3 \\
5 & V21-5 & V8-5 & Typical & Typical & 7.3 \\
6 & V21-2 & V8-2 & High & Modified High & 3.8 \\
7 & V21-2 & V8-2 & High & Modified High & 3.8 \\
8 & V21-4 & V8-4 & High & Modified High & 3.8 \\
9 & V21-1 & V8-1 & High & Modified High & 7.3 \\
10 & V21-5 & V8-5 & High & Modified High & 7.3 \\
11 & V21-3 & V8-3 & High & Modified High & 11.3 \\
12 & V21-3 & V8-3 & High & Modified High & 11.3 \\
13 & V21-3 & V8-3 & Typical & Modified High & 3.8 \\
14 & V21-1 & V8-1 & Typical & Modified High & 7.3 \\
15 & V21-5 & V8-5 & Typical & Modified High & 7.3 \\
16 & V21-3 & V8-3 & Typical & Modified High & 11.3 \\
17 & V21-3 & V8-3 & Typical & Modified High & 11.3 \\
18 & V21-1 & V8-1 & High & High & 11.3 \\
19 & V21-3 & V8-3 & High & High & 11.3 \\
20 & V21-5 & V8-5 & High & High & 11.3 \\
21 & V21-2 & V8-2 & High & High & 11.3 \\
22 & V21-4 & V8-2 & Typical & High & 11.3 \\
\hline
\end{tabular}

\subsection{Data Observations}

It follows that predictions based on test data are only as valid as the test data themselves. For example, sampling during a periodic operation, such as with the rotational mixer pumps, needs to be conducted at an appropriate frequency. Therefore, transient operational data for the data set of interest $\left[\mathrm{BS}=\mathrm{H}, \mathrm{SV}=\mathrm{H}, \mathrm{CV}=11.3\right.$ ] was examined as part of this study. ${ }^{1}$ The following observations can be made from the transient operational data plots included in Appendix A:

- Jet mixer pump flow rates are elevated relative to the target flow rate prior to the start of a test for all eight tests (as planned).

- In some tests, there is a relatively short period where the flow rate is either below the target or zero.

- Six of the eight pre-transfer samples in this test series were taken before steady state was achieved.

- More evident in 120-in. vessel tests

- Less evident in 43-in. vessel tests

- Oscillations in the density and transfer flow data are well behaved.

\footnotetext{
${ }^{1}$ Email communication from RX Milleret, Washington River Protection Solutions, to BE Wells and PP Schonewill, Pacific Northwest National Laboratory, May 2013.
} 
From the conclusions made in Section 4 on the test data relative to steady-state test conditions during sampling, it can be inferred that the pre-transfer samples are at higher solid concentrations than the batch transfer data resulting from the test operation. This occurrence would necessarily cause the batch and pre-transfer sample concentrations to be more different. Thus, if performance, i.e., batch UDS concentration relative to the pre-transfer sample UDS concentration (see Section 4), is deemed acceptable for the test data, the result is likely conservative.

Conversely, the issue with steady-state test conditions can also negatively impact the implications of the test results. As summarized, the jet mixer pump rates are elevated above the test flow rates following the planned test operation. It is well established in the literature that the flow velocity required to suspend a particle (re-suspension velocity) is greater than the velocity required to keep that particle in suspension (e.g., transportation velocity), Figure 2.5 (Schwuger 1996). This result is, of course, dependent on the nature of the solids in the flow. Thus, a particle that may not be suspended and transferred out of the test vessel at the test flow rate could, with relatively short periods where the flow rate is either below the target or zero, remain in suspension from the elevated flow and therefore the transfer performance would be elevated over the actual test performance. However, as will be subsequently described in Section 4, the concentration of the more challenging components approaches homogenous concentration at higher test velocities over the batches after the test data indicates that steady state (with acknowledgment that there may be transfer effects) has been reached.

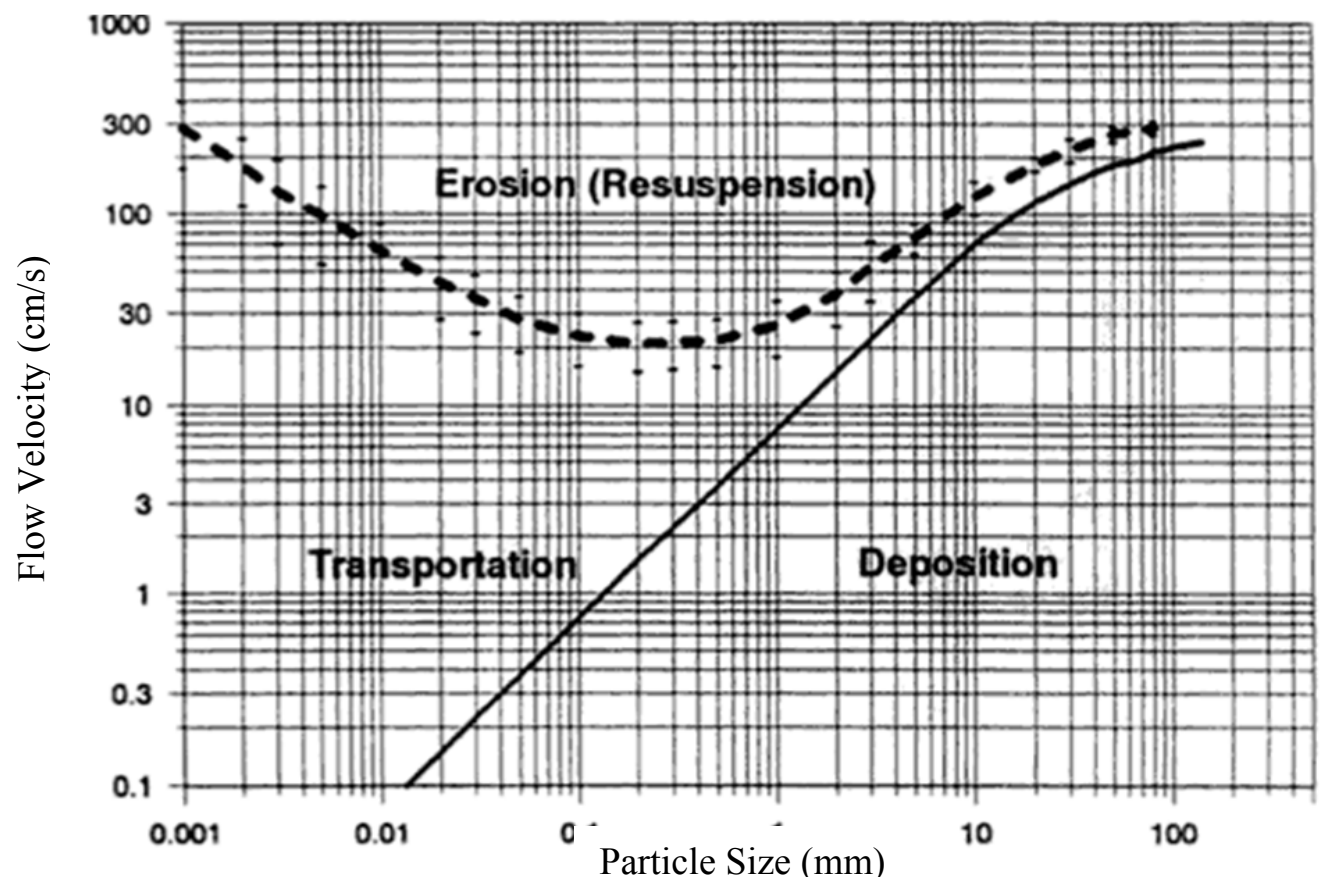

Figure 2.5. Particle Transportation (Suspension) and Re-Suspension Velocity (from Schwuger 1996) 


\subsection{Scaling Behavior}

The primary focus in examining scaling behavior will be in terms of the measured transfer UDS concentration and this is discussed in Section 3.1. As discussed in Section 2.2.2, there is also interest in examining scale behavior in other performance metrics to relate 2013 testing results to existing predictions and data at full scale. These additional performance metrics are discussed in Section 3.2.

\subsection{Transfer Concentration}

Transfer UDS concentration is discussed first for the 2013 testing with Base simulant in Section 3.1.1 and then for 2011 SSMD testing with other simulants in Section 3.1.2.

\subsubsection{Tests}

As stated previously, the examination of the 2013 tests is limited to those test conditions with four different jet velocities. These are the $\mathrm{BS}=\mathrm{H}, \mathrm{SV}=\mathrm{H}, \mathrm{CV}=11.3$ cases (Test Conditions 18 through 21 in Table 2.4). Figure 3.1 through Figure 3.4 show component transfer UDS concentration as a function of jet nozzle velocity for this test condition in the two test scales. In each figure, the pre-transfer homogeneous mixed concentration is indicated with an arrow pointing to that value on the ordinate.

For the slower settling and easier to suspend components, gibbsite and $\mathrm{ZrO}_{2}$ (see Figure 2.3 and Figure 2.4) concentration is generally independent of scale and constant with velocity, Figure 3.1 and Figure 3.2, respectively. For the faster settling and harder to suspend components sand and stainless steel (see Figure 2.3 and Figure 2.4), the data is essentially coincident which implies that the scale coefficient, $\alpha$ in Equation (2.1), is roughly zero, Figure 3.3 and Figure 3.4, respectively. In these figures, the blue colored symbols are the small tank test data and the red and orange symbols are the large tank test data. The multiple data points at each velocity are the pre-transfer and batch concentration values. In contrast to the gibbsite and $\mathrm{ZrO}_{2}$, the transfer UDS concentration increases with velocity over the test range for sand and stainless steel.

Gibbsite: $B S=H, S V=H, C V=11.3$

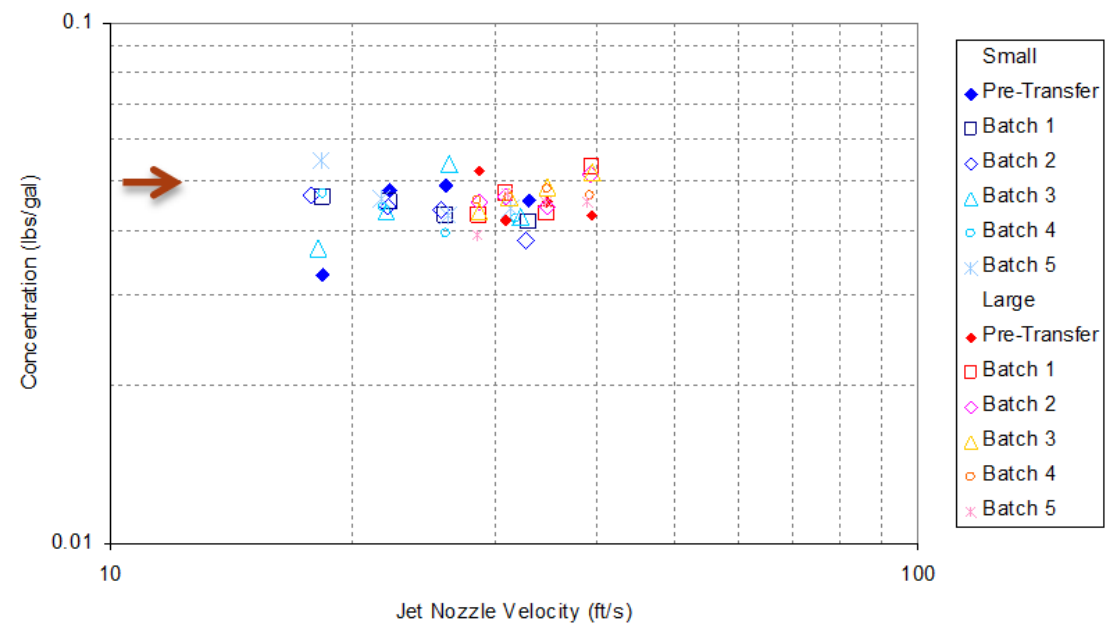

Figure 3.1. Transfer UDS Concentration $-\mathrm{BS}=\mathrm{H}, \mathrm{SV}=\mathrm{H}, \mathrm{CV}=11.3-$ Gibbsite 
ZrO2: $\mathrm{BS}=\mathrm{H}, \mathrm{SV}=\mathrm{H}, \mathrm{CV}=11.3$

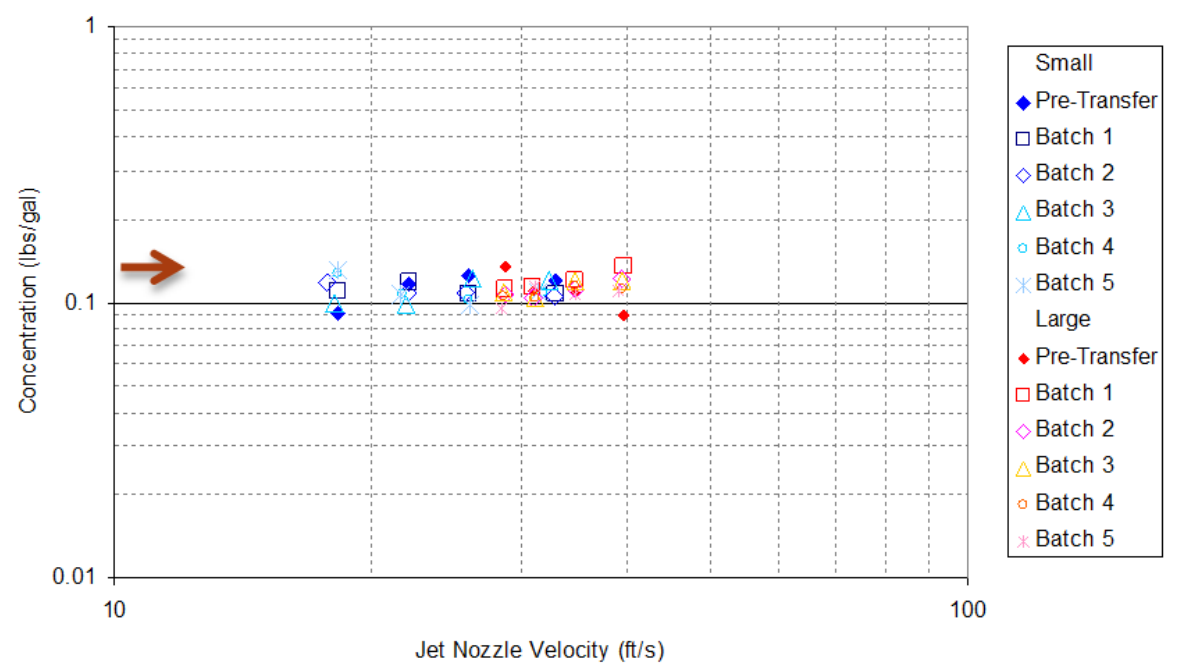

Figure 3.2. Transfer UDS Concentration $-\mathrm{BS}=\mathrm{H}, \mathrm{SV}=\mathrm{H}, \mathrm{CV}=11.3-\mathrm{ZrO}_{2}$

Sand: $B S=H, S V=H, C V=11.3$

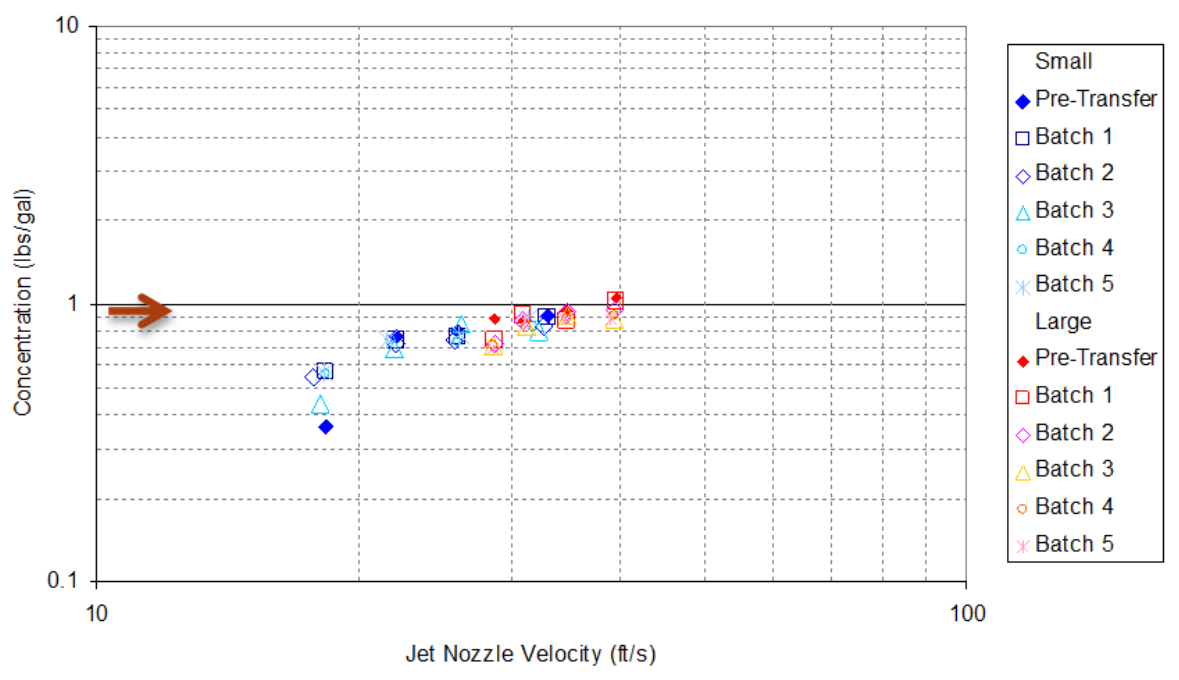

Figure 3.3. Transfer UDS Concentration $-\mathrm{BS}=\mathrm{H}, \mathrm{SV}=\mathrm{H}, \mathrm{CV}=11.3-$ Sand 


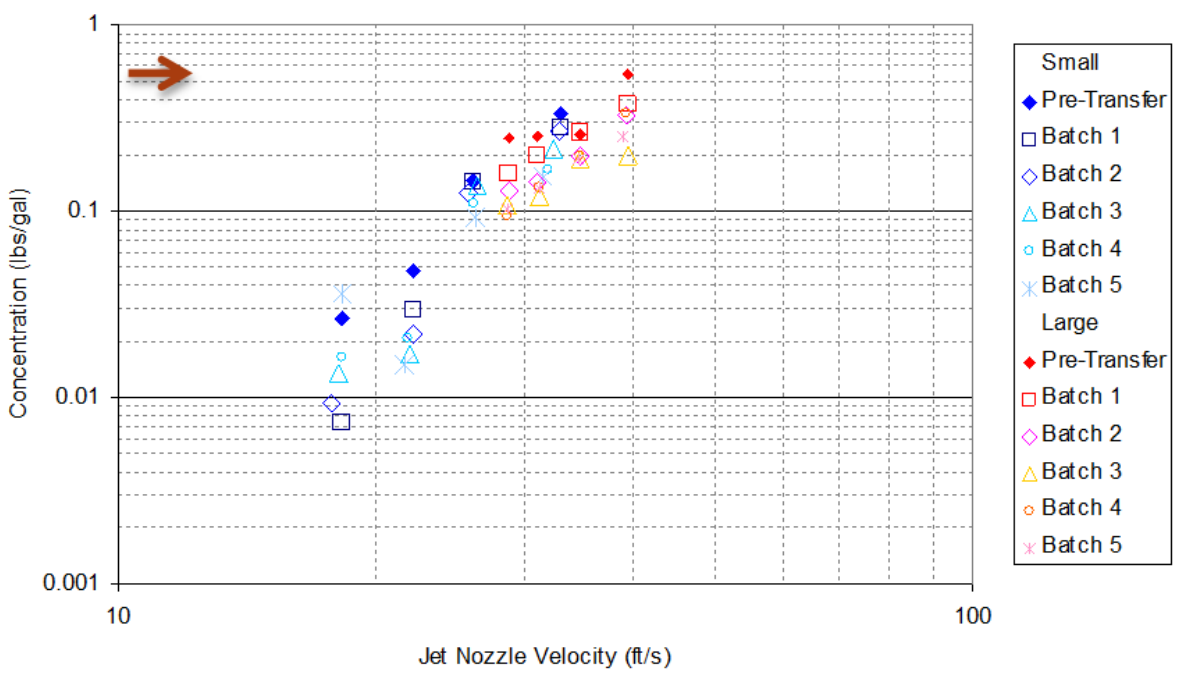

Figure 3.4. Transfer UDS Concentration $-\mathrm{BS}=\mathrm{H}, \mathrm{SV}=\mathrm{H}, \mathrm{CV}=11.3-$ Stainless Steel

For the two components that showed a dependence on jet nozzle velocity, sand, and stainless steel, the procedure introduced in Section 2.2 for determining the scale exponent is applied next. The test results are expressed in normalized form to the full-scale velocity and tank diameter so that the scale exponent is included in the representation of the data. This is done by normalizing Equation (2.1) to the full-scale conditions as

$$
\text { Normalized Velocity }=\left(\frac{U_{i}}{U_{F S}}\right)\left(\frac{D_{F S}}{D_{i}}\right)^{\alpha}
$$

where $U$ and $D$ are jet velocity and tank diameter as defined previously (Equation (2.1)) and subscripts $i$ and FS refer to test values and full-scale values, respectively.

First for sand, Figure 3.5 shows the transfer UDS concentration data scaled by various $\alpha$ (see Equation (2.1)). The lines shown on the figure are power law fits to the respective datasets, as denoted by the color. Coincidence of these lines indicates agreement with the scale exponent value indicated in the plot legend. Also included on the plots is an $\mathrm{R}^{2}$ value for a power law fit to the combination of the small and large tank data. This $\mathrm{R}^{2}$ value provides a qualitative means to judge the coincidence of individual tank's data sets; a larger $\mathrm{R}^{2}$ value indicates better coincidence. By visual inspection of the power law fit lines and by the $\mathrm{R}^{2}$ values, $\alpha=0$ to $\alpha=0.1$ provides the best agreement. Next consider the same process for stainless steel. Figure 3.6 shows that, although there is a stronger dependence of concentration on jet velocity, $\alpha=0$ to $\alpha=0.1$ also provides the best agreement. The power law fits to the stainless steel datasets have a more significant difference in slopes for the small and large-scale tests. The reason for this difference is not clear; uncertainty in the measured data is one possibility, but a likely cause is flattening of the data at the higher jet velocities in the large tank as transfer UDS concentration approaches the homogeneous mixed condition. 
Sand $B S=H, S V=H, C V=113$

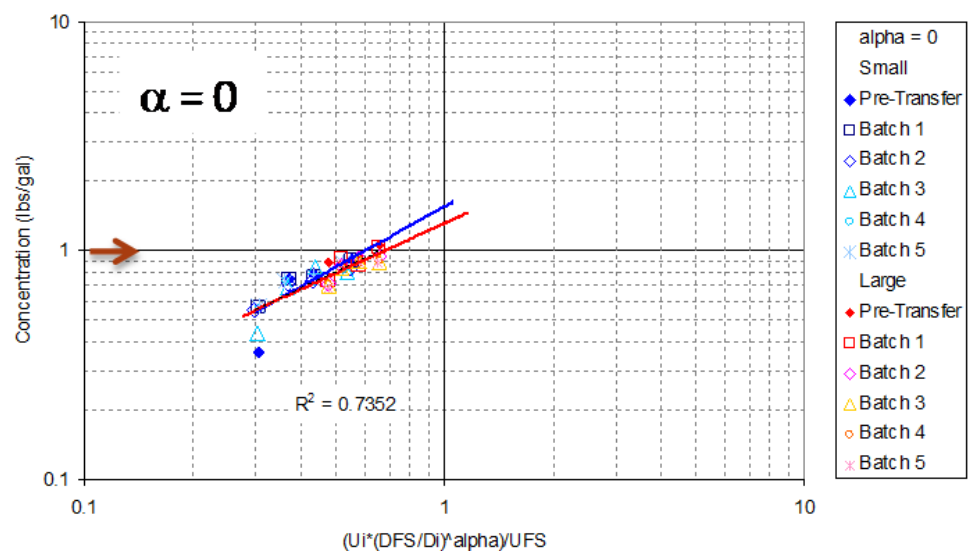

Sand $B S=H, S V=H, C V=11.3$

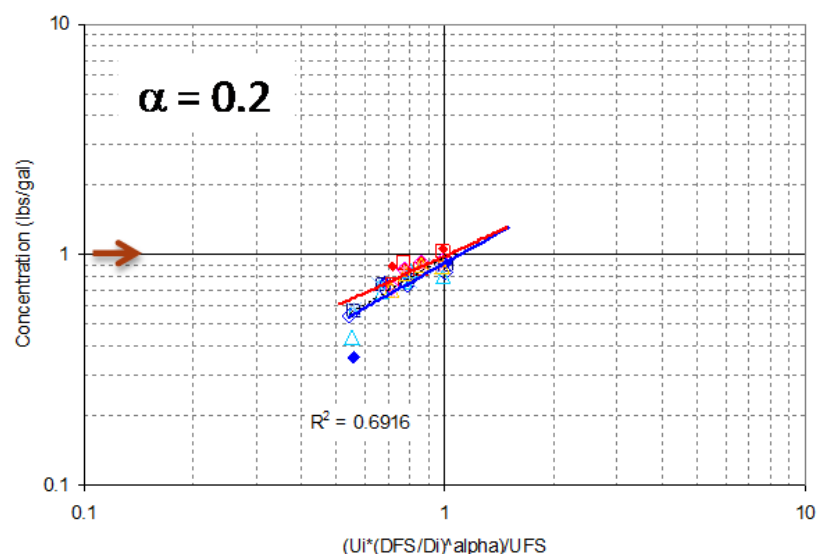

Sand: $B S=H, S V=H, C V=11.3$

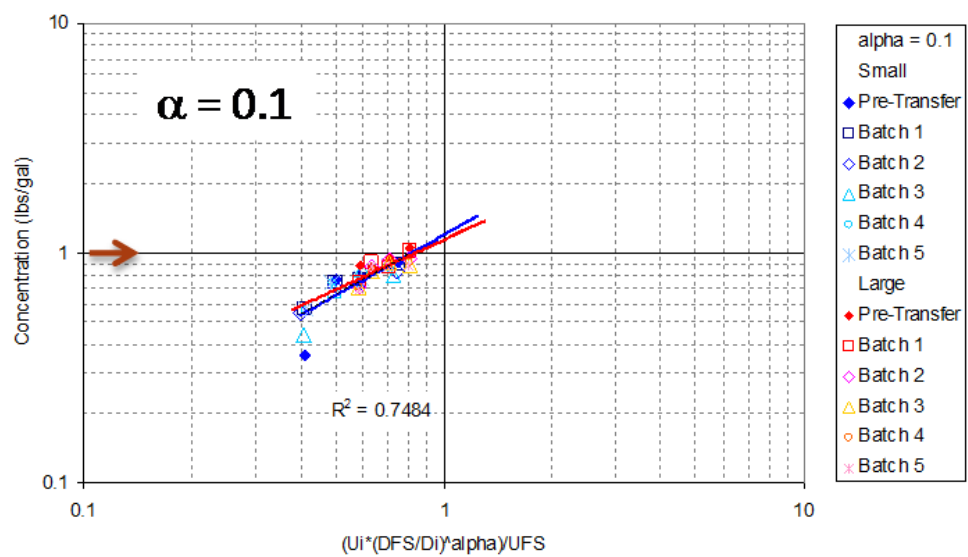

Sand: $B S=H, S V=H, C V=11.3$

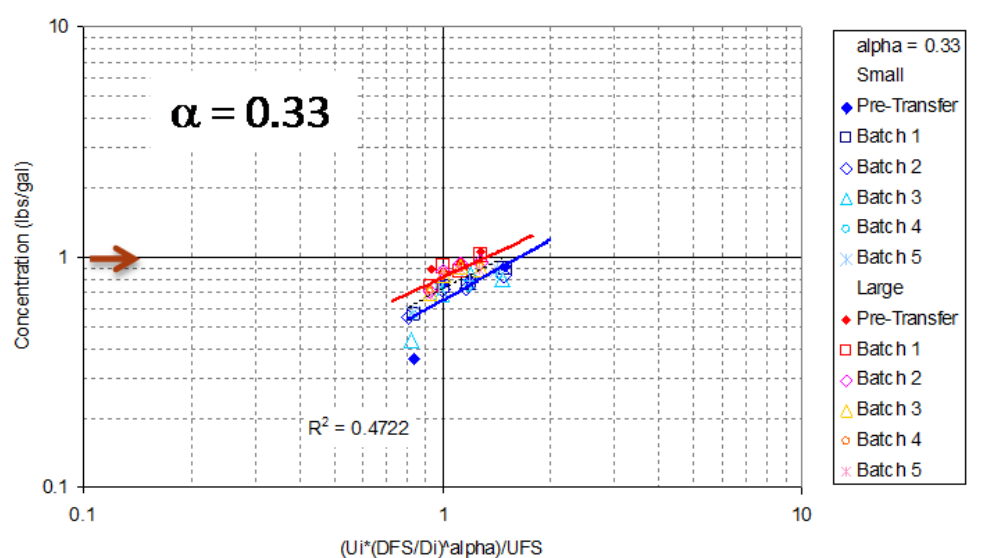

Figure 3.5. Comparison of Transfer UDS Concentration Data for Normalized Jet Velocity [BS=H, $\mathrm{SV}=\mathrm{H}, \mathrm{CV}=11.3$, Sand] 
SS: $B S=H, S V=H, C V=11.3$

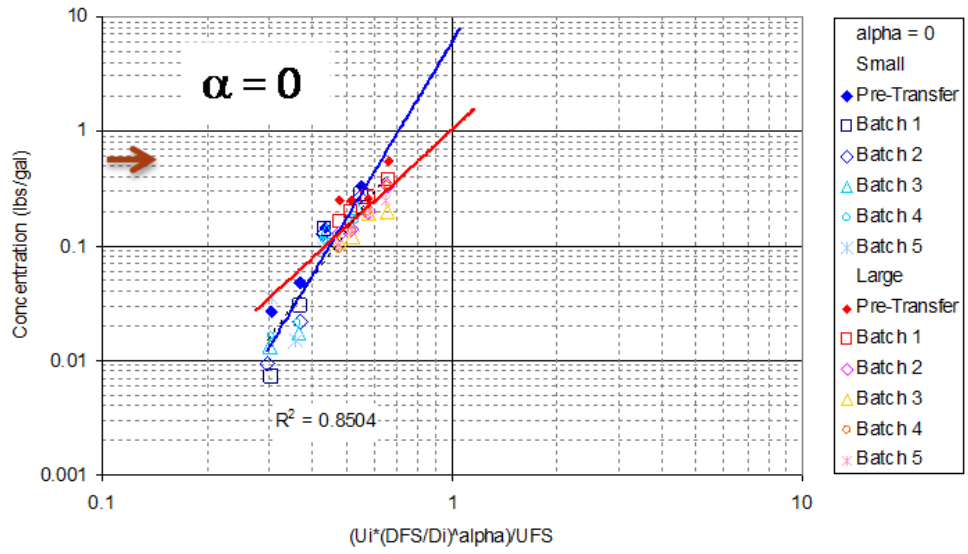

SS: BS=H, SV=H, CV=11.3

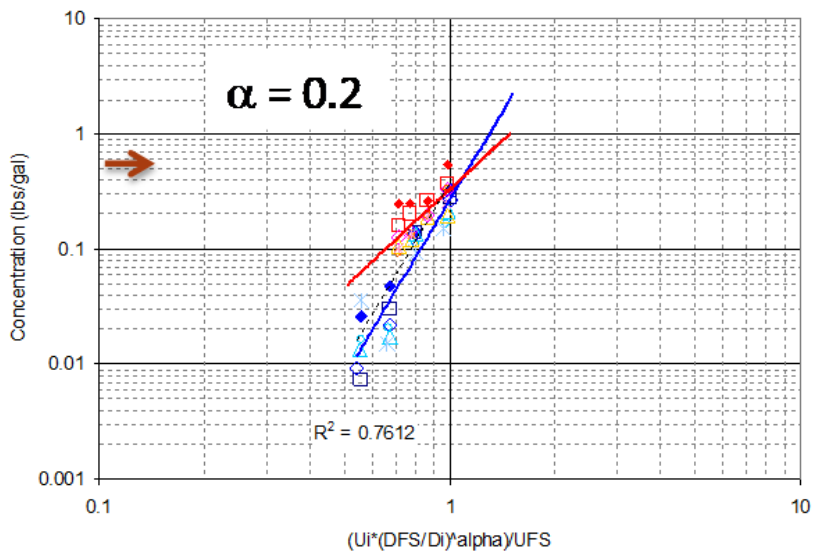

SS: $B S=H, S V=H, C V=11.3$

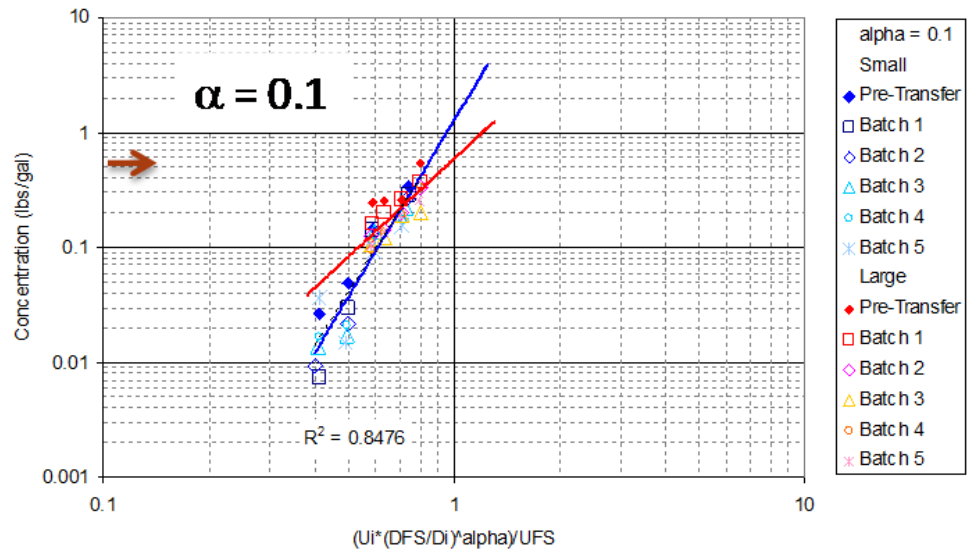

SS: $B S=H, S V=H, C V=11.3$

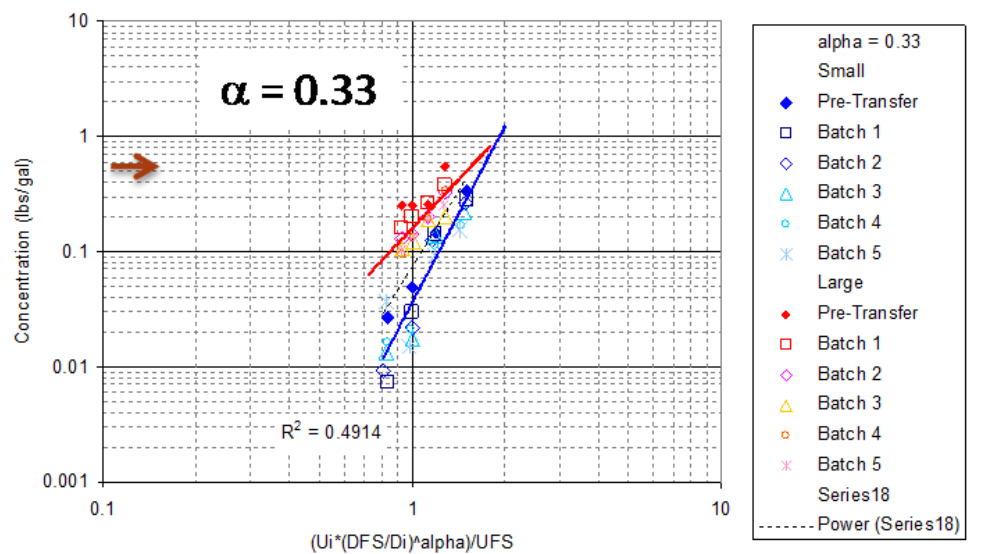

Figure 3.6. Comparison of Transfer UDS Concentration Data for Normalized Jet Velocity [BS=H, SV=H, CV=11.3, Stainless Steel] 
To summarize, transfer UDS concentration increases with velocity for both sand and stainless steel with best fit scaling exponent of $\alpha=0$ to 0.1 . These results are similar for other cases and for other simulants. For example, this is observed in Figure 3.7 for the fraction of total UDS mass transferred in 2011 SSMD tests with the Complex 5 simulant. Also depicted in Figure 3.7 is the performance that should have been observed in the 43.2-inch vessel if the total UDS mass transferred scaled as power per unit volume (PPV, scale exponent of 0.33). Comparisons of scale-up coefficients for the simulant components are shown in the next section.

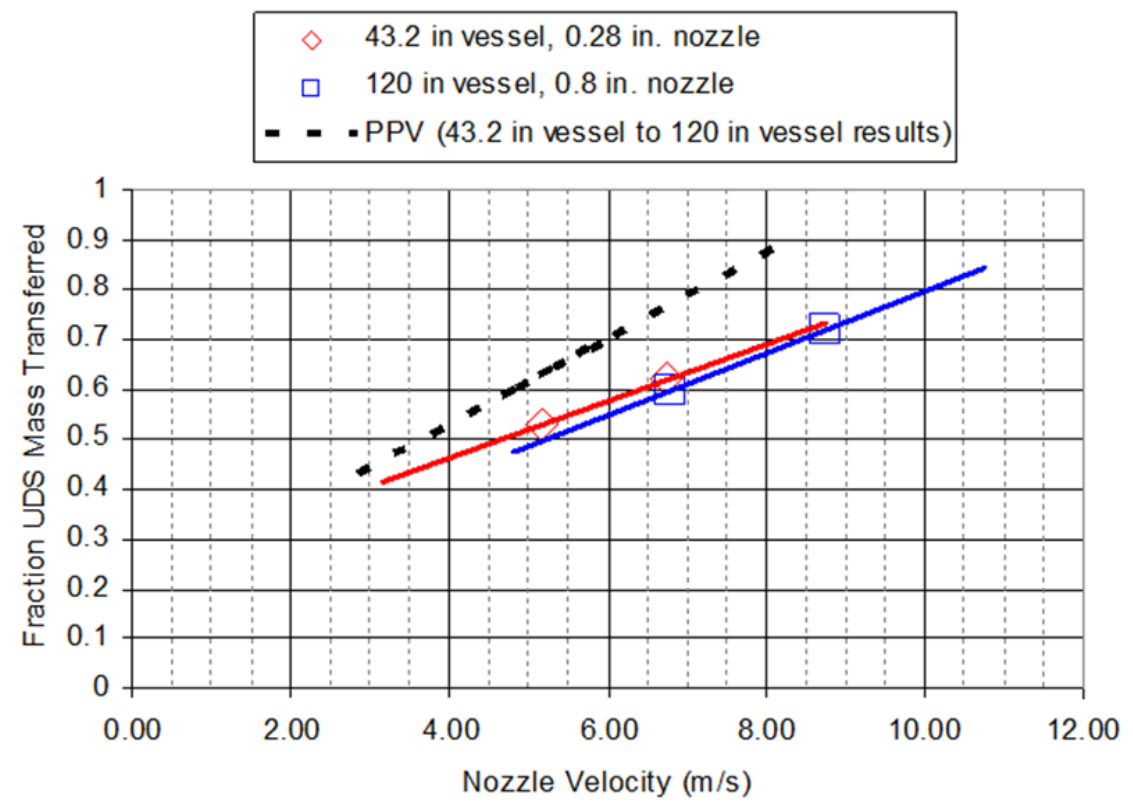

Figure 3.7. Complex 5 Simulant UDS Concentration ${ }^{1}$

\subsubsection{Transfer Concentration; Other Test Campaigns}

Transfer UDS concentration versus jet velocity is shown by constituent for components of the Complex 5 simulant in Figure 3.8. These tests are described in RPP-49740 and RPP-RPT-53101. As in the 2013 test results shown in Section 3.1.1 for the slower settling and easier to suspend components, there is no apparent dependence on jet velocity for gibbsite, however, $\mathrm{ZrO}_{2}$ shows a negative dependence (decreasing concentration with increasing jet velocity). This behavior is discussed further below. The faster settling and harder to suspend components stainless steel, bismuth oxide and silica carbide show an increase in transfer UDS concentration with increased jet velocity. Transfer UDS concentration as a function of jet velocity for stainless steel is shown as the top left plot in Figure 3.9. The remaining plots in Figure 3.9 show the normalized velocity (Equation (3.1)) at various $\alpha$. Following the approach described in Section 3.1.1, $\alpha=0.1$ provides the best agreement.

\footnotetext{
${ }^{1}$ 3/11 SSMD Workshop Informal PNNL Follow-on Presentation to Washington River Protection Services, DOE.
} 
Gibbsite: BS=Complex 5, SV=water, CV=11.3, TL=Riser 30, L

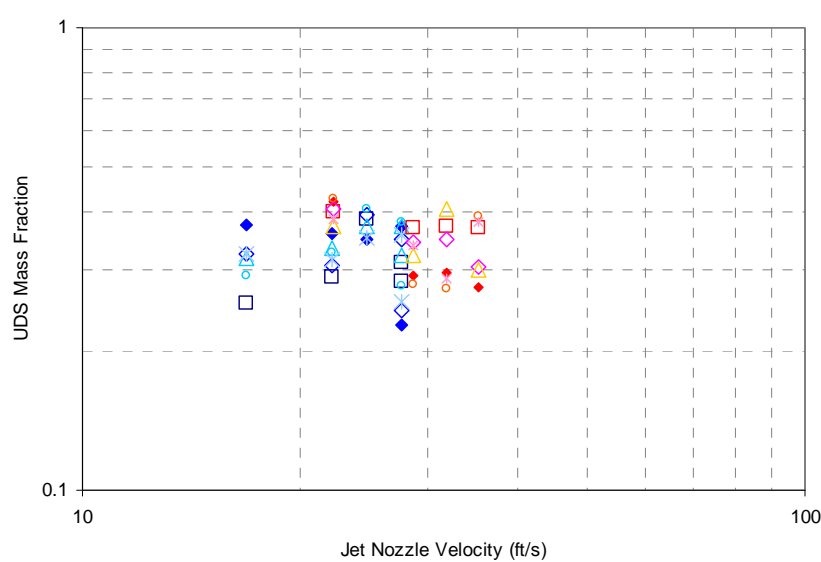

Bi2O3: $B S=$ Complex $5, \mathrm{SV}=$ water, $\mathrm{CV}=11.3, \mathrm{TL}=\mathrm{Riser} 30, \mathrm{~L}$

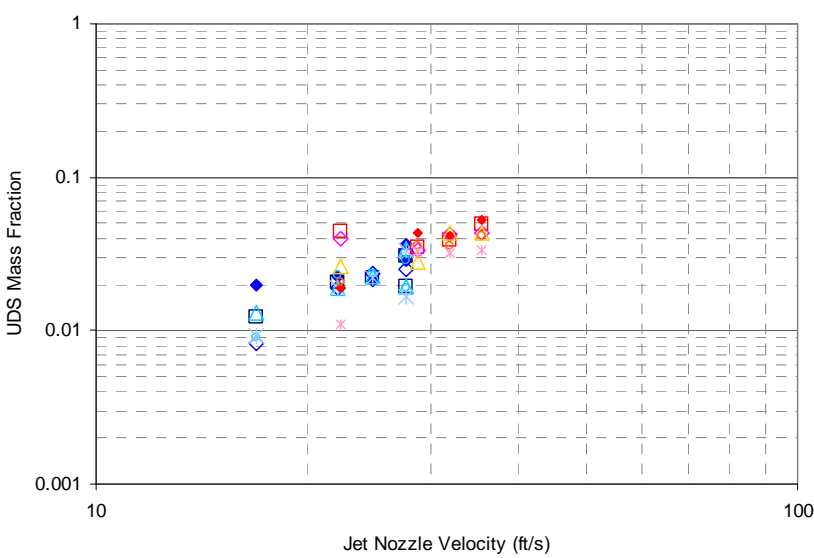

ZrO2. BS=Complex 5, SV=water, $C V=11.3$, TL=Riser $30, L$

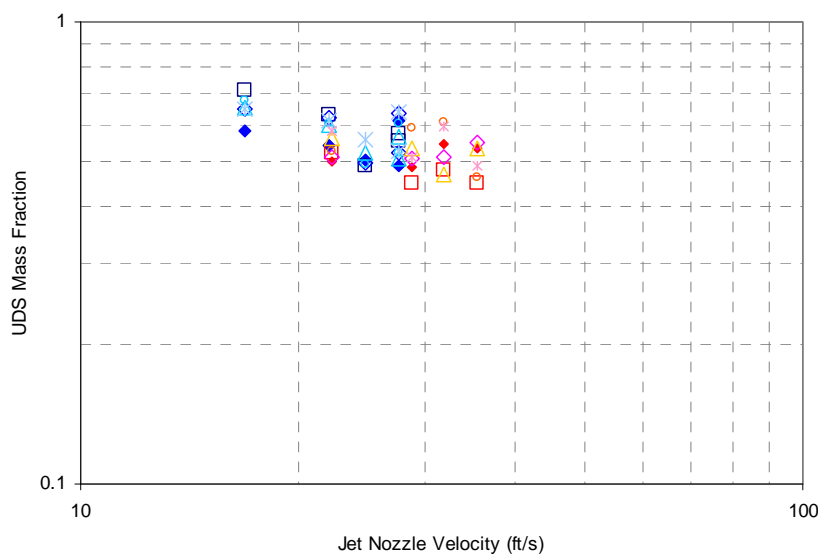

SiC: BS=Complex $5, \mathrm{SV}=$ water, $\mathrm{CV}=11.3, \mathrm{TL}=\mathrm{Riser} 30, \mathrm{~L}$

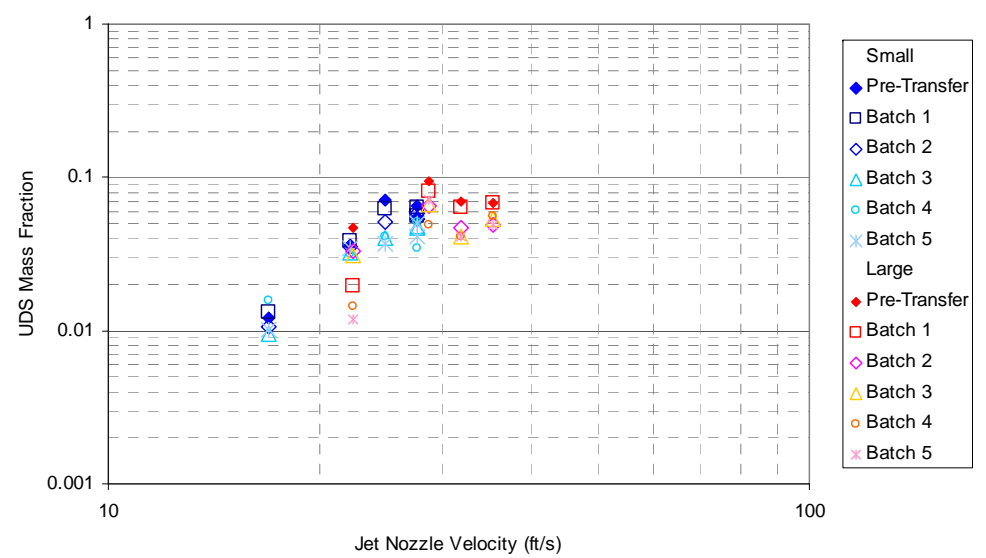

Figure 3.8. Transfer UDS Concentration - Complex 5 Simulant 
SS: BS=Complex 5, SV=water, $C V=11.3$, TL=Riser 30, L

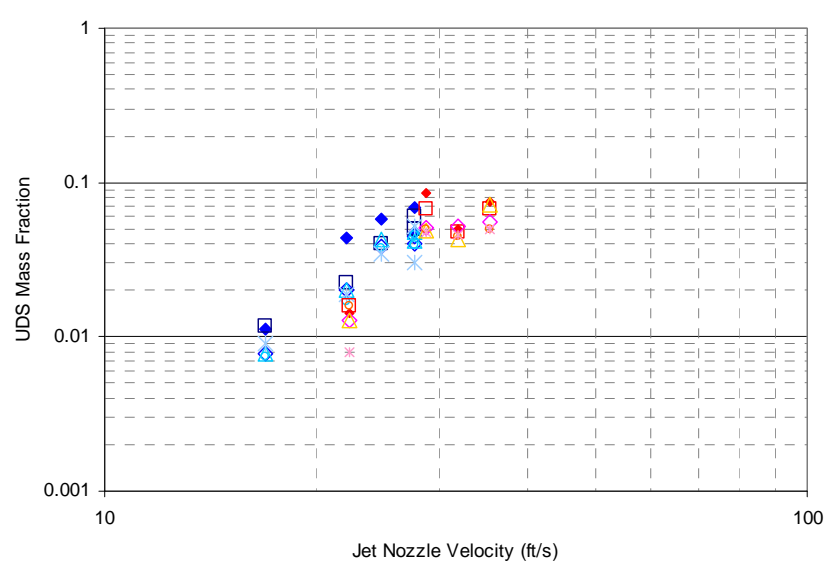

SS: BS=Complex $5, S V=$ water, $C V=11.3, T L=R i s e r ~ 30, L$

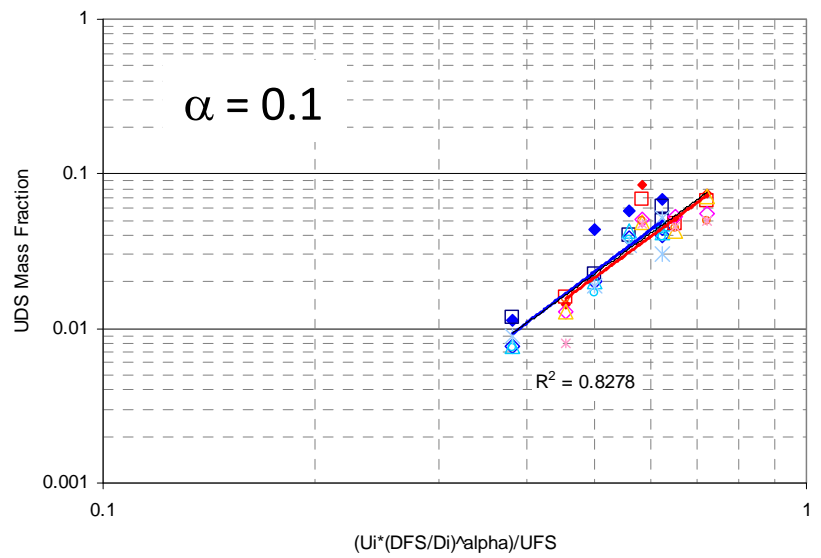

SS: BS=Complex 5, SV=water, $\mathrm{CV}=11.3, \mathrm{TL}=$ Riser $30, \mathrm{~L}$

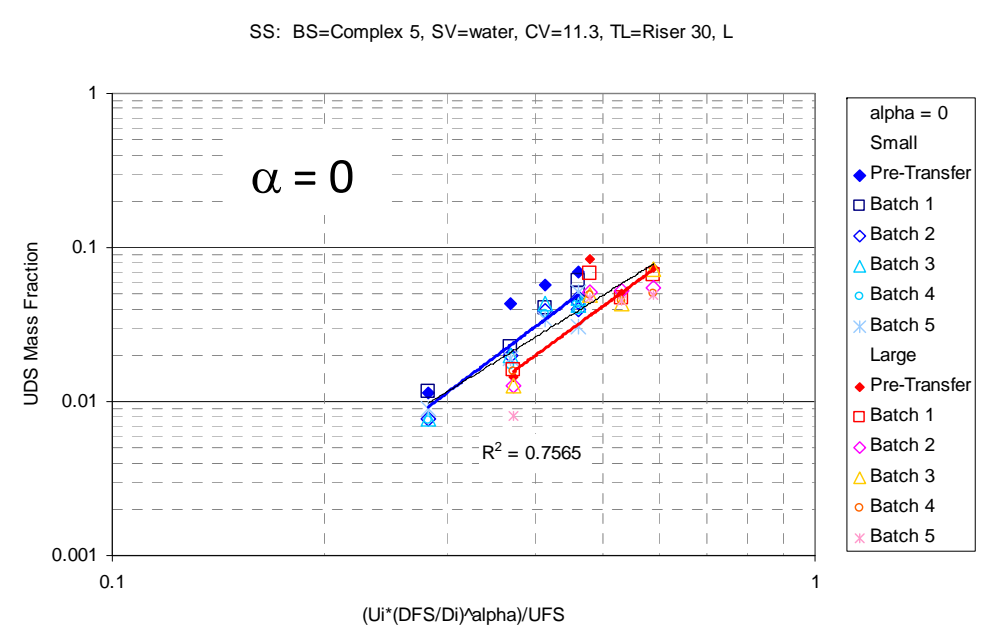

SS: BS=Complex 5, SV=water, CV=11.3, TL=Riser 30, L

\begin{tabular}{|l|}
\hline alpha $=0.1$ \\
Small \\
$\bullet$ Pre-Transfer \\
$\square$ Batch 1 \\
$\diamond$ Batch 2 \\
$\triangle$ Batch 3 \\
$\circ$ Batch 4 \\
$\times$ Batch 5 \\
Large \\
- Pre-Transfer \\
$\square$ Batch 1 \\
$\diamond$ Batch 2 \\
$\triangle$ Batch 3 \\
$\circ$ Batch 4 \\
$\times$ Batch 5 \\
\hline
\end{tabular}

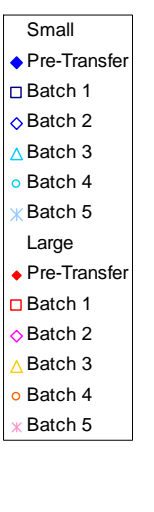

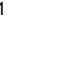

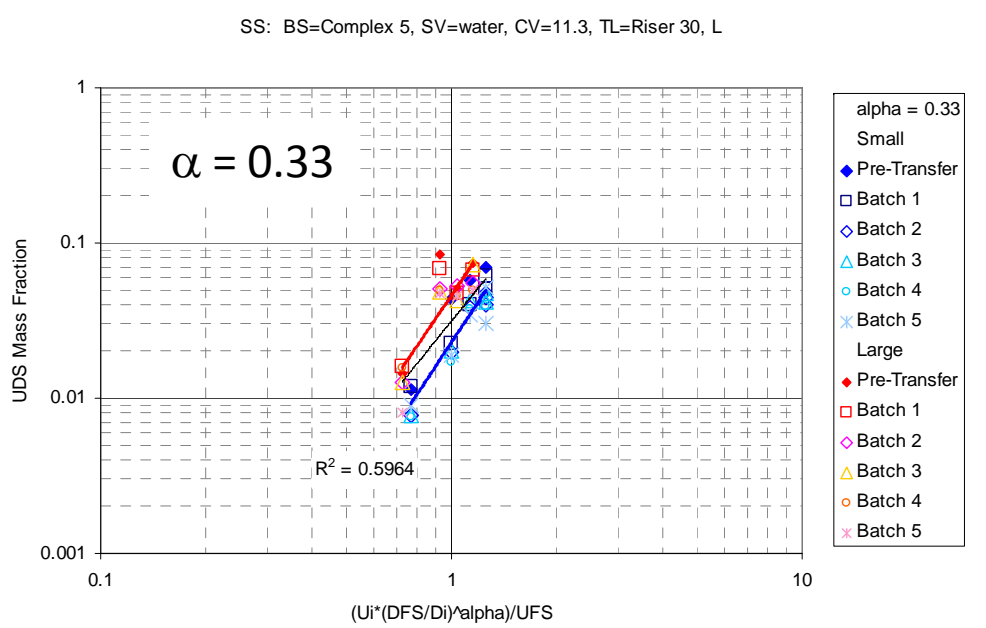

Figure 3.9. Comparison of Transfer UDS Mass Fraction Data for Normalized Jet Velocity - Complex 5 Simulant - Stainless Steel 
Looking again at Figure 3.8, the negative dependence of $\mathrm{ZrO}_{2}$ transfer concentration with jet velocity may seem counterintuitive. Increasing jet velocity would be expected to erode and mobilize more of any settled solid, thereby presenting higher concentration of that constituent at the suction nozzle. This is the case with a fast settling solid like stainless steel over the jet velocity range tested. The obvious limit to this phenomenon is the homogenous concentration.

On the opposite end, a slow settling particle like gibbsite or $\mathrm{ZrO}_{2}$ is relatively insensitive to jet velocity because it is easily suspended throughout the tank to the cloud height. However, as was shown in Figure 2.3 and Figure 2.4, $\mathrm{ZrO}_{2}$ is faster settling and has a higher critical stress for erosion than the gibbsite. For a relatively easy-to-suspend solid like this, it is reasonable to expect a decreasing concentration with increasing velocity as the cloud height is increased as depicted in Figure 3.10. At a low jet velocity, the cloud height is low and the homogenously suspended solid concentration is high (upper image in Figure 3.10) relative to a high jet velocity where the cloud height is increased and the concentration is decreased (lower image in Figure 3.10) via conservation of mass. With this example factor of two difference in the cloud height, the solid concentration in the homogeneous cloud for the high jet velocity case is half by volume that of the lower velocity homogenous cloud.
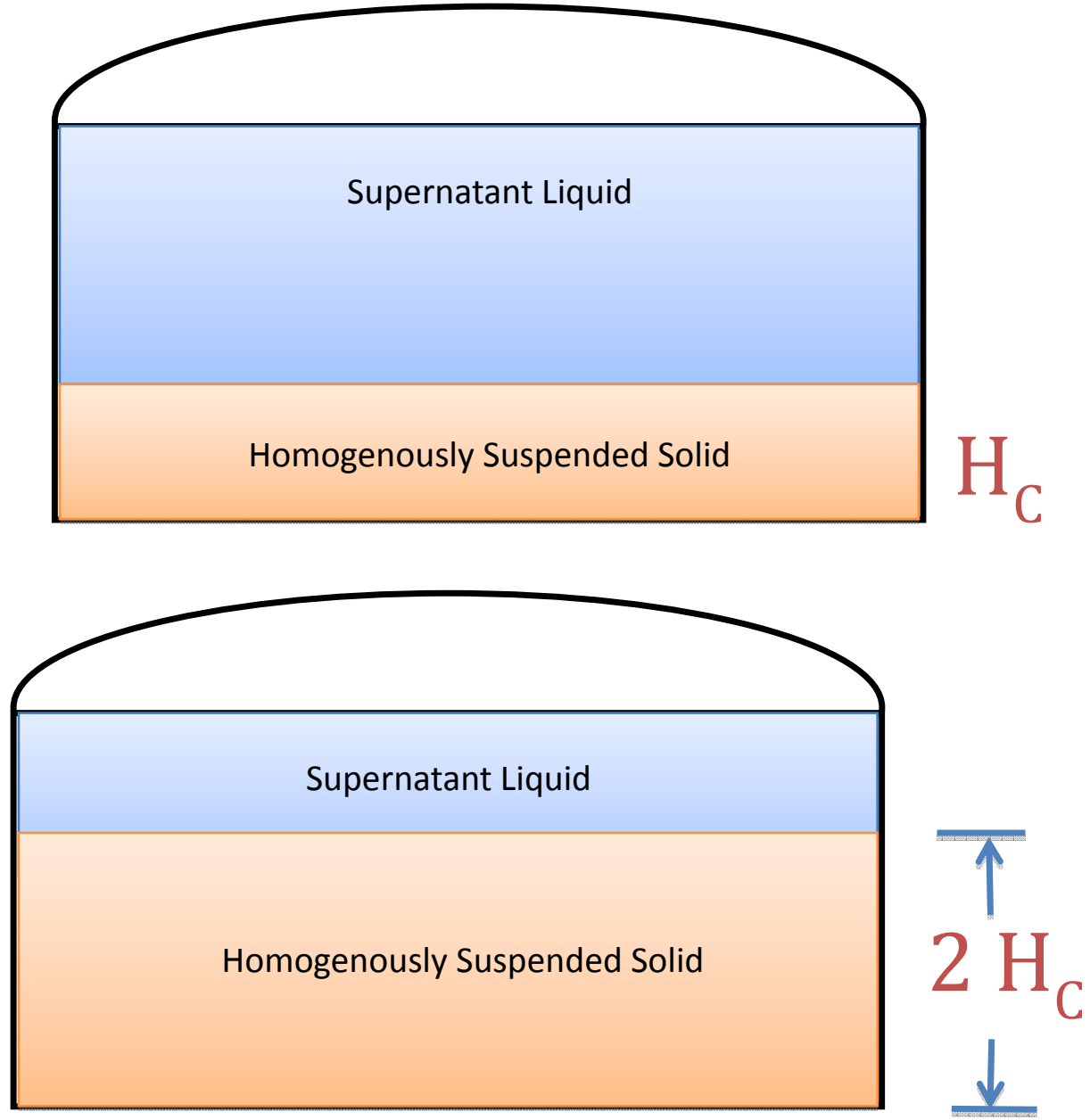

Figure 3.10. Illustration of Transfer UDS Concentration Dependence on Cloud Height, Upper Image Low Jet Velocity, Lower Image High Jet Velocity 
The scaling exponent for $\mathrm{ZrO}_{2}$ transfer UDS concentration can be estimated next. The upper panel of Figure 3.11 shows the $\mathrm{ZrO}_{2}$ component of the Complex 5 simulant normalized with $\alpha=0$ from Figure 3.8 along with curve fits. The lower panel of Figure 3.11 shows the same normalized with $\alpha=0.33$. From these plots, it is not clear what the scaling exponent for the $\mathrm{ZrO}_{2}$ component of the Complex 5 simulant transfer UDS concentration is, but it is not 0.33 . This result is in contrast with test results with single component $\mathrm{ZrO} 2$ simulant.

In Figure 3.12, the solid symbols and lines are for ParaFlow CFD code predictions (green denotes the full-scale predictions), which are described in more detail in Appendix B. Depending on the test samples considered ("vertical profile" or "prior to batch xfer", Figure 3.12), the $\mathrm{ZrO}_{2}$ concentrations have varied performance with normalized velocity. The ParaFlow predictions compare well with the "prior to batch xfer" 120 -inch test results, $(\alpha=0$, Figure 3.12), and the full-scale predictions are shown to align with the scaled predictions $(\alpha=0.33$, Figure 3.12). Figure 3.12 shows the same presentation of data for the single component $\mathrm{ZrO}_{2}$ simulant as Figure 3.11 for the $\mathrm{ZrO}_{2}$ component of the Complex 5 simulant and it is clear that $\alpha=0.33$ is a good representation of the scaling exponent, as indicated by coincidence of the respective data fit lines, for the single component case.

To summarize for the Complex 5 simulant tests, transfer UDS concentration for the slowest settling component, gibbsite, is constant with scale and jet velocity. For the fast settling and therefore more challenging stainless steel, $\mathrm{Bi}_{2} \mathrm{O}_{3}$ and $\mathrm{SiC}$, transfer concentration increases with jet velocity and has a scale exponent ranging from $\sim 0$ to 0.1 (SS). This is consistent with results for fast settling particles in the

Base simulant. Finally, $\mathrm{ZrO}_{2}$ demonstrates a negative dependence on jet velocity due to suspension of the solids upward in the tank over the tested range of jet velocity. The $\mathrm{ZrO}_{2}$ has an as-yet undetermined scale exponent as a component in the Complex 5 simulant tests; $\alpha=0.33$ was not a good fit. The influence of other components does appear significant in this case because single component $\mathrm{ZrO}_{2}$ simulant test results did provide good agreement with $\alpha=0.33$. It is postulated that the difference in transfer concentration scaling behavior for the same component, $\mathrm{ZrO}_{2}$, is due to homogeneity within the suspended cloud being affected by the other simulant components.

As stated in Section 2, related performance metrics (see Figure 2.1) are used to increase confidence in transfer concentration performance predictions for full scale. Cloud height and ECR scaling are discussed in Section 3.2, and it will be shown that the cloud height scaling for the single component $\mathrm{ZrO}_{2}$ simulant is also $\alpha=0.33$, confirming the behavior described in Figure 3.10. The homogenous distribution of likely slower settling and easier to suspend components has been observed in full-scale actual waste testing in AZ-101 (Wells and Ressler 2009), full-scale testing with simulant in AP-102 (Gauglitz et al. 2010), and in scaled testing (Gauglitz et al. 2010).

\subsection{Cloud Height and ECR Performance Metrics}

In this section, consideration is given to other performance metrics beyond transfer UDS concentration to increase confidence in the transfer UDS concentration test data scale-up. The performance metrics of interest here include cloud height and ECR. The cloud height is the level in the tank that the solid particulate reaches during the mixing cycle. Likewise, ECR is the radius from the mixing pump that settled solids are eroded off the tank floor. These additional performance metrics are of interest because they are available for small-scale and full-scale tests and predictions, whereas transfer 
UDS concentration is not. Therefore, these additional metrics provide a way to test scaling relationships and they present a means by which to relate expectations for other metrics to full scale.

ZrO2: $\mathrm{BS}=$ Complex 5, SV=water, $\mathrm{CV}=11.3, \mathrm{TL}=$ Riser 30, L

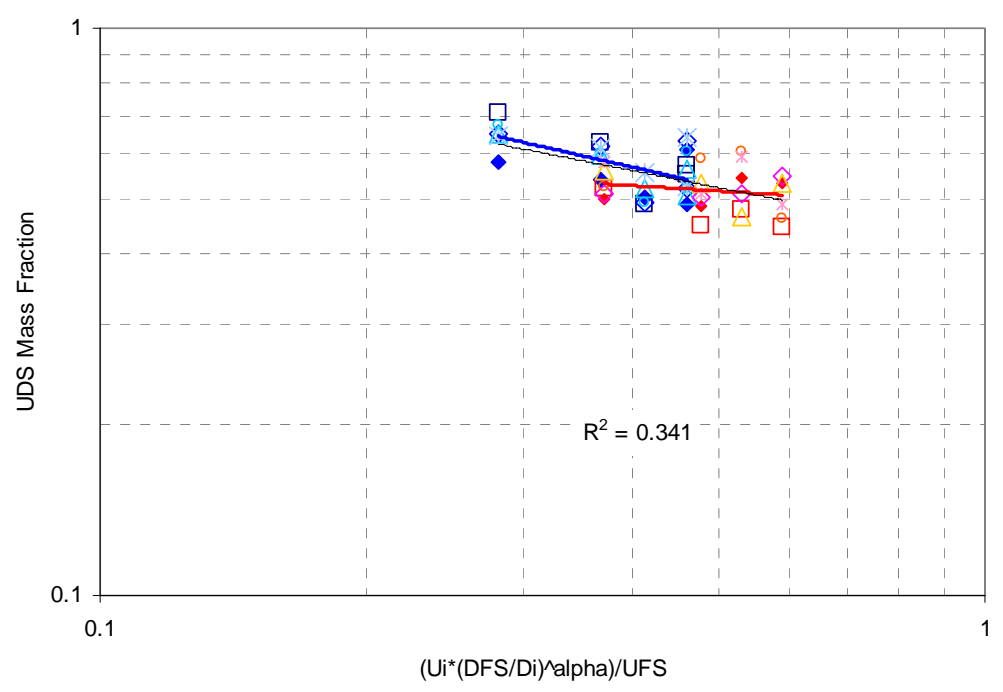

\begin{tabular}{|c|}
\hline alpha $=0$ \\
\hline Small \\
\hline Pre-Transfer \\
\hline$\square$ Batch 1 \\
\hline$\diamond$ Batch 2 \\
\hline$\triangle$ Batch 3 \\
\hline - Batch 4 \\
\hline * Batch 5 \\
\hline Large \\
\hline - Pre-Transfer \\
\hline$\square$ Batch 1 \\
\hline$\diamond$ Batch 2 \\
\hline$\triangle$ Batch 3 \\
\hline - Batch 4 \\
\hline * Batch 5 \\
\hline
\end{tabular}

$\left(U{ }^{\star}(\mathrm{DFS} / \mathrm{Di})^{\wedge}\right.$ alpha)/UFS

ZrO2: $\mathrm{BS}=$ Complex 5, SV=water, $\mathrm{CV}=11.3, \mathrm{TL}=$ Riser 30, L

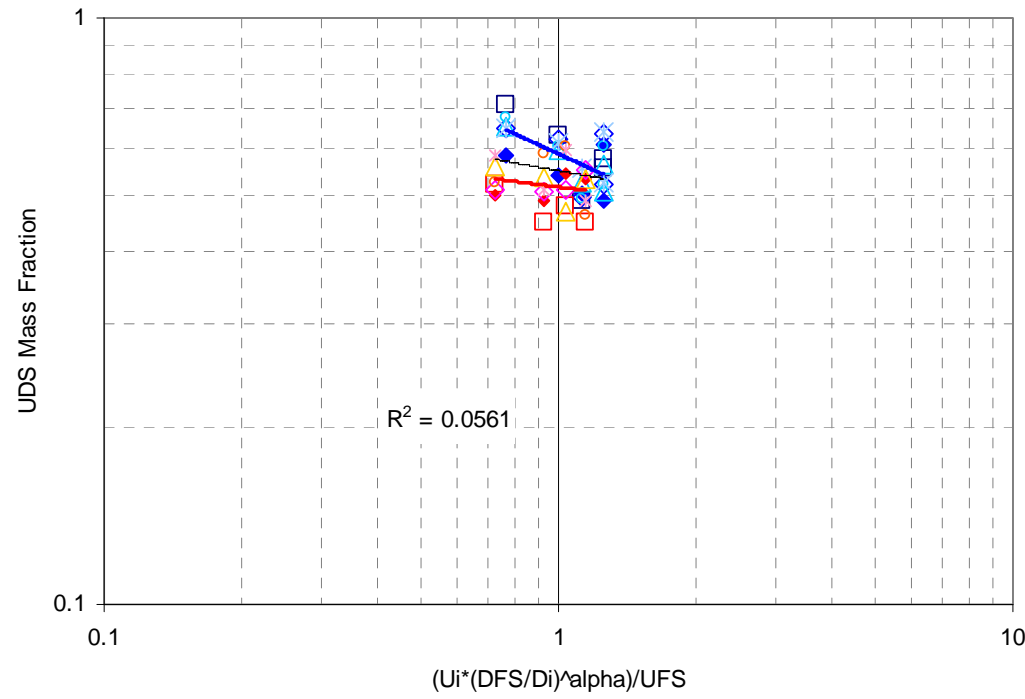

\begin{tabular}{|c|}
\hline alpha $=0.33$ \\
\hline Small \\
\hline Pre-Transfer \\
\hline$\square$ Batch 1 \\
\hline$\diamond$ Batch 2 \\
\hline$\triangle$ Batch 3 \\
\hline - Batch 4 \\
\hline * Batch 5 \\
\hline Large \\
\hline - Pre-Transfer \\
\hline$\square$ Batch 1 \\
\hline$\diamond$ Batch 2 \\
\hline$\triangle$ Batch 3 \\
\hline - Batch 4 \\
\hline * Batch 5 \\
\hline
\end{tabular}

(Ui*(DFS/Di)^alpha)/UFS

Figure 3.11. Transfer UDS Concentration for $\mathrm{ZrO}_{2}$ Component of Complex 5 Simulant 

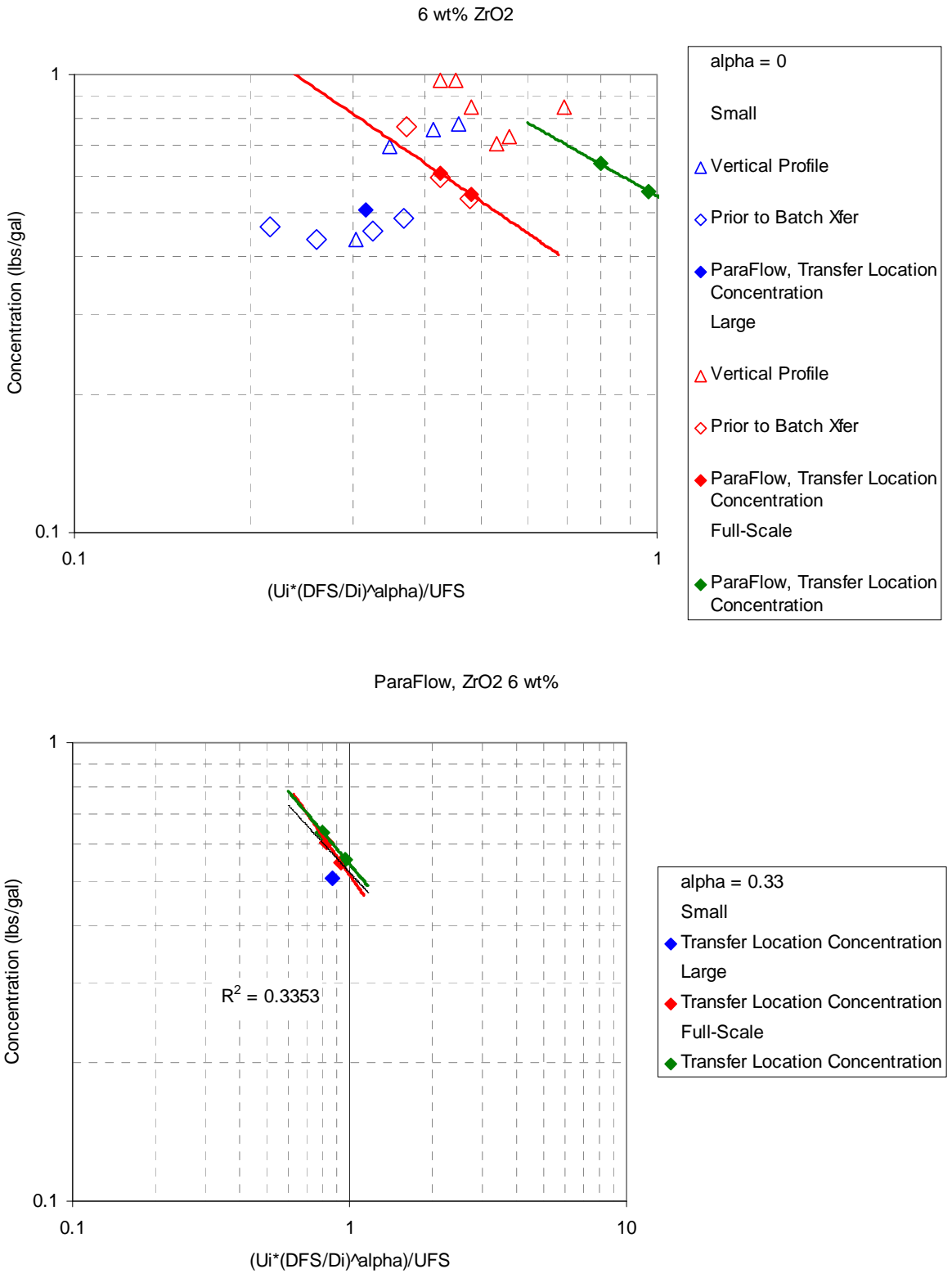

Figure 3.12. Transfer UDS Concentration for $\mathrm{ZrO}_{2}$ Single Component Simulant

\subsubsection{Cloud Height}

The cloud height can be determined visually in clear walled test vessels, but can also be determined by a measurement of concentration profile. Cloud height measurements are available for $\mathrm{ZrO}_{2}$ simulant and for Complex 5 simulant. Figure 3.13, upper plot, shows results for cloud height, $\mathrm{H}_{\mathrm{C}}$, normalized with the liquid depth, $\mathrm{H}_{\mathrm{L}}$, as a function of test jet velocity for $\mathrm{ZrO}_{2}$. This includes test data at the two small scales plus predictions from ParaFlow (see Section 3.1 and Appendix B) at those two scales and at fullscale. The ParaFlow predictions (solid symbols) are reasonably close to measurements for the 43 -inch tank, and they are very close for the 120-inch tank. There are of course no full-scale tests with this simulant, so those predictions stand alone. The lower plot of Figure 3.13 shows these same data and 
predictions plotted as a function of normalized velocity (see Equation (3.1)) using a scale exponent of $\alpha=0.33$; the coincidence of scaled-test data fits and predictions demonstrates very good agreement with this value of the scale exponent. The comparable performance of the measured and predicted cloud heights at test scales and the constant scaling to the full-scale prediction increases confidence in full-scale transfer UDS concentration performance predictions based on test scale data. The cloud height scaling for the single component $\mathrm{ZrO}_{2}$ simulant agrees with the transfer concentration data and prediction scaling for the same simulant; $\alpha=0.33$. This behavior is expected as described in Section 3.1, see Figure 3.10.

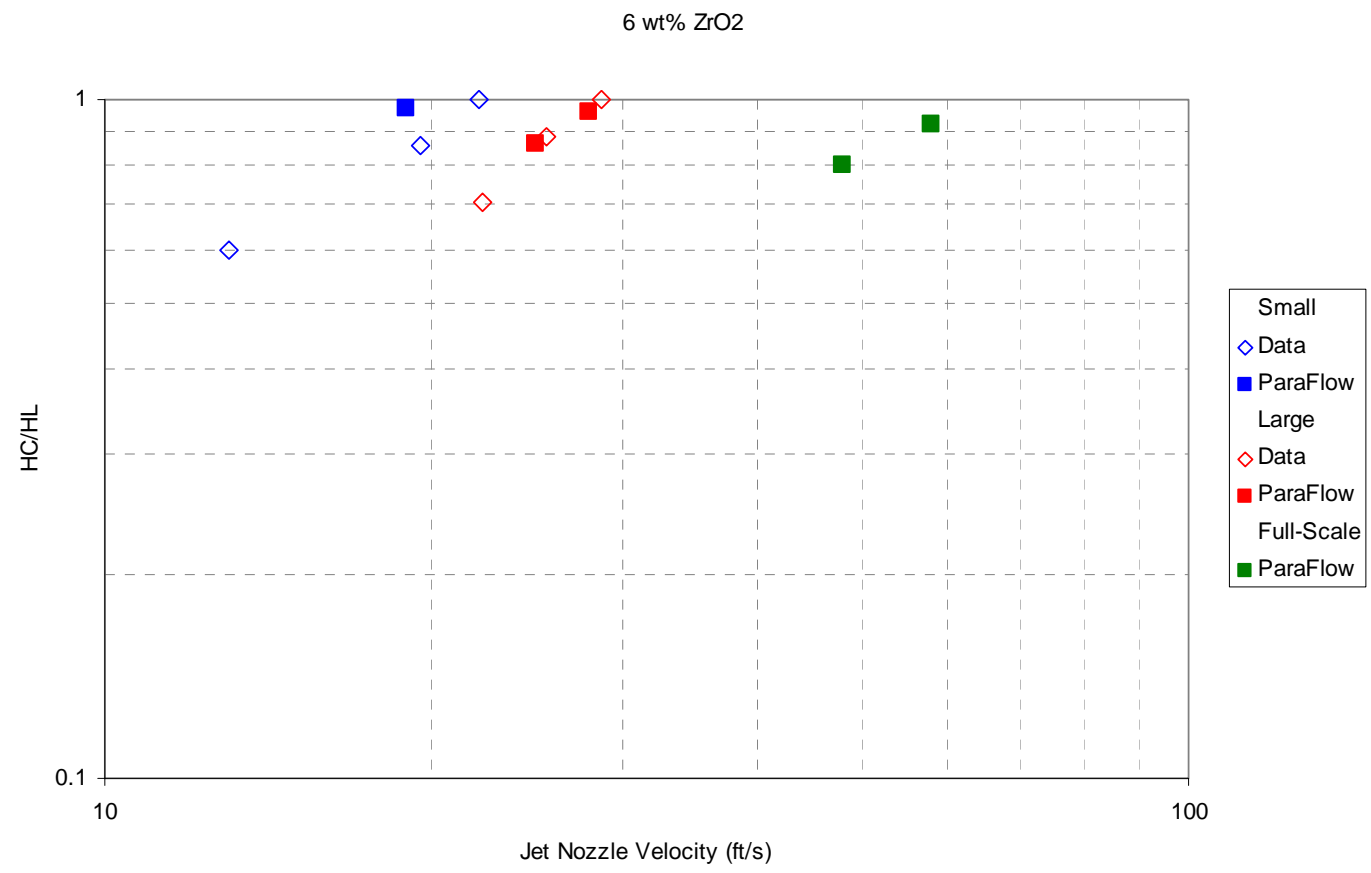

$6 \mathrm{wt} \% \mathrm{ZrO} 2$

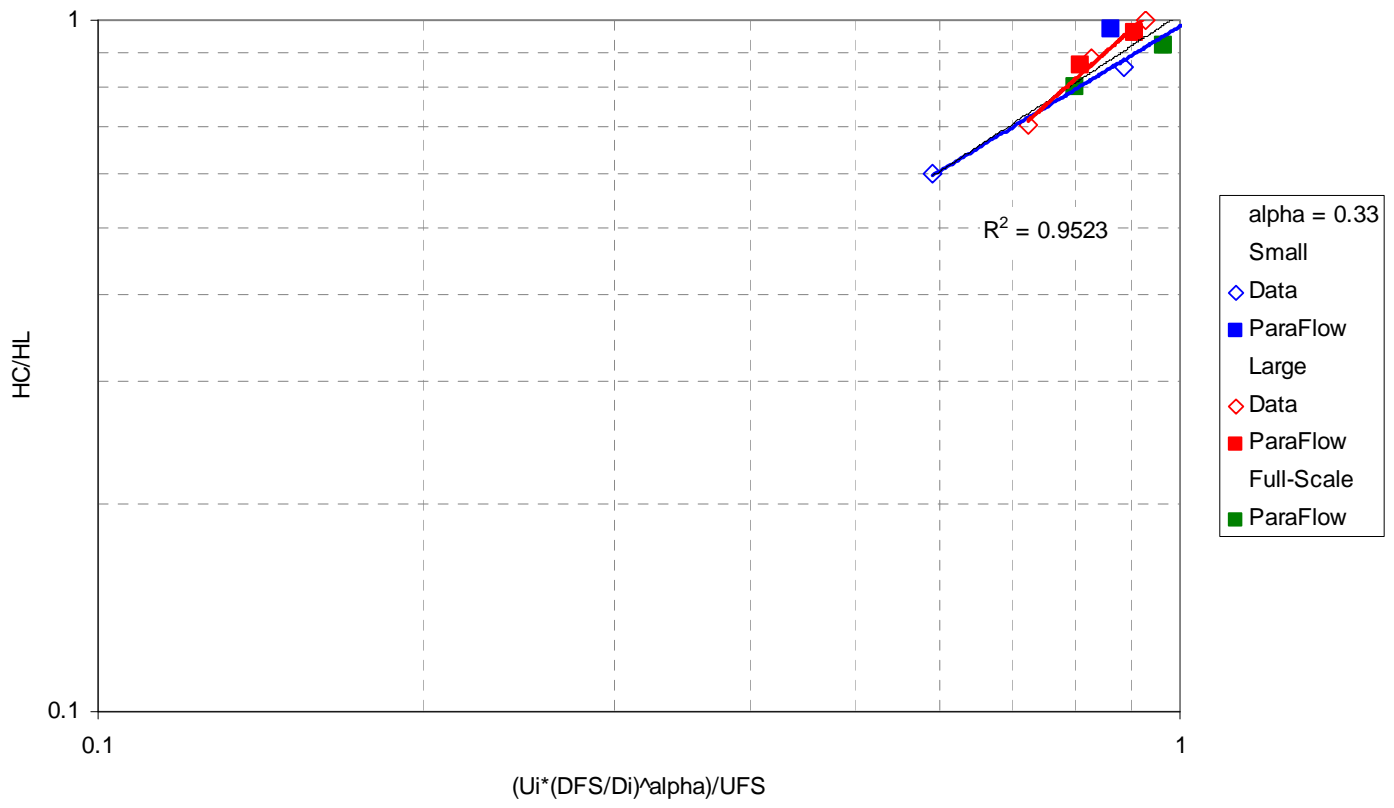

Figure 3.13. Cloud Height Measurements and Predictions for $\mathrm{ZrO}_{2}$ Simulant 
Cloud height measurements for Complex 5 simulant are shown in Figure 3.14 along with scaling of those data using $\alpha=0.33$. Again, this scale exponent appears to be a good fit. In summary for cloud height, the test results for single component $\mathrm{ZrO}_{2}$ and Complex 5 simulant show consistent scaling with $\alpha \sim 0.33$. For $\mathrm{ZrO}_{2}$, predictions with ParaFlow to full scale are in agreement with this.

BS=Complex 5, SV=water, $\mathrm{CV}=11.3, \mathrm{TL}=$ Riser $30, \mathrm{~L}$

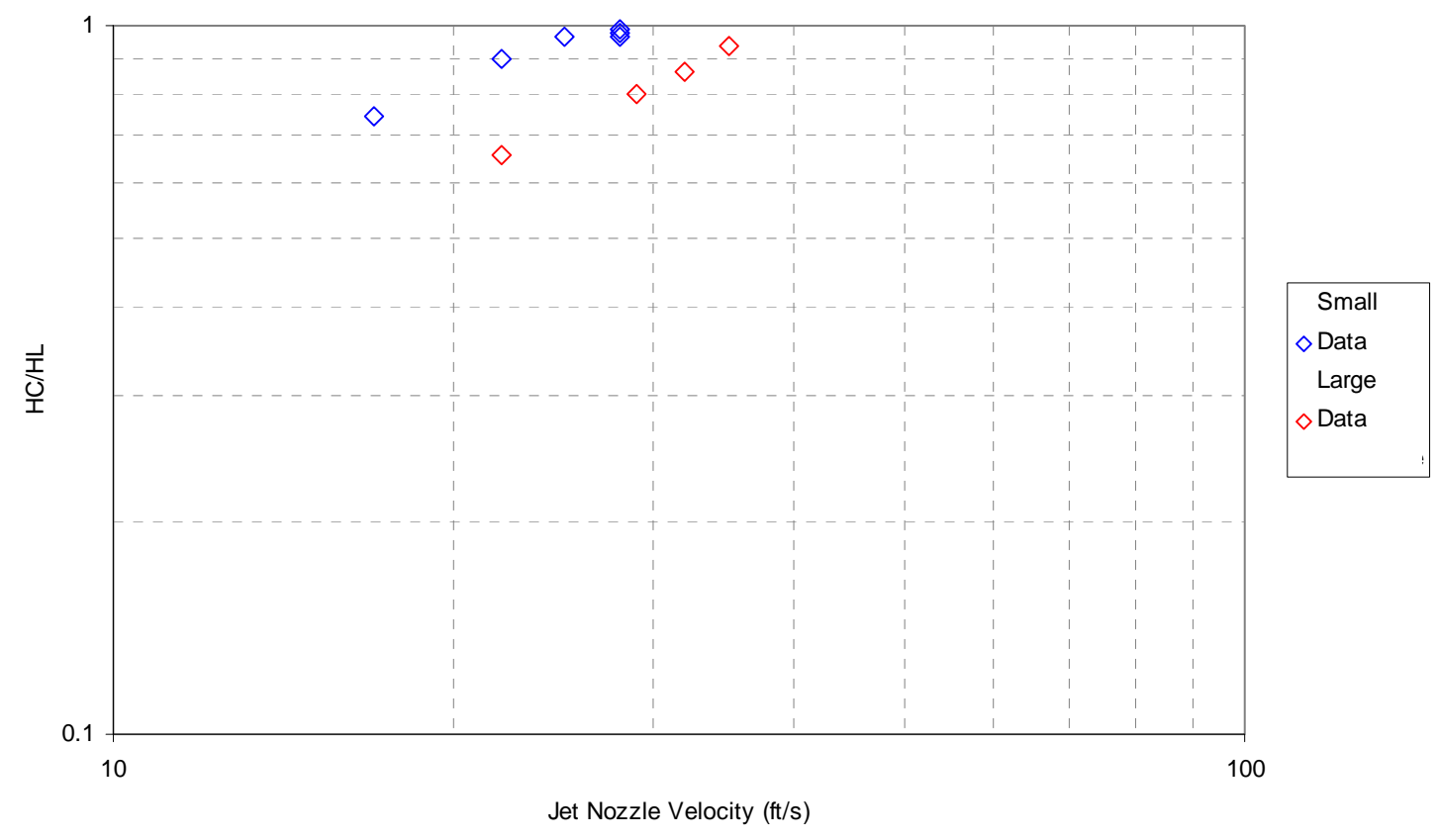

BS=Complex 5, SV=water, $\mathrm{CV}=11.3, \mathrm{TL}=$ Riser $30, \mathrm{~L}$

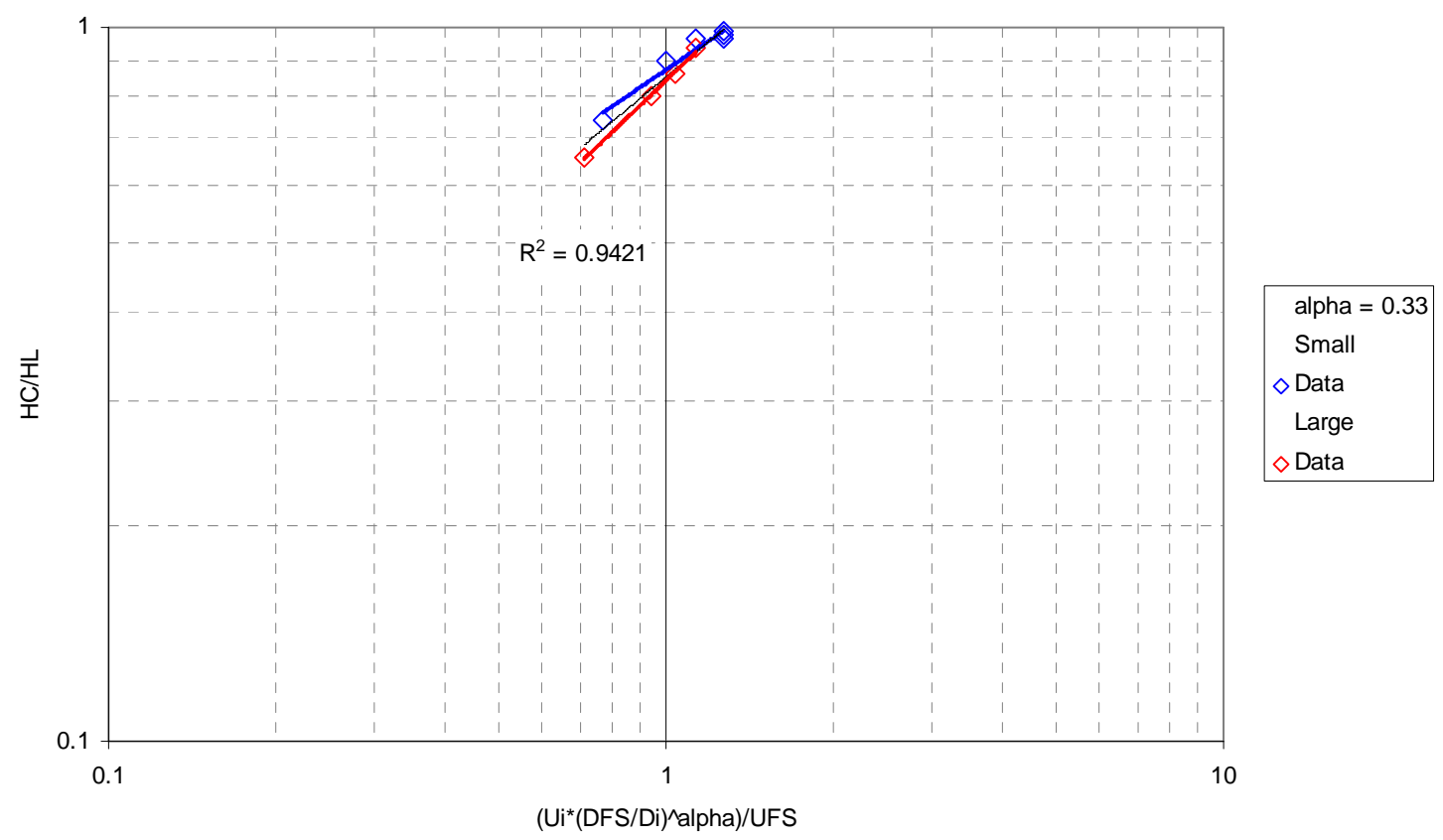

Figure 3.14. Cloud Height Measurements and Predictions for Complex 5 Simulant 


\subsubsection{ECR}

As described in Gauglitz et al. (2010), the ECR is the distance between the exit of the mixer pump nozzle and the base of the sediment eroded by the mixer pump via mass or surface erosion. In a similar fashion as the cloud height metric relates to what fraction of the UDS is suspended and is available for ingestion into the transfer pump, the ECR relates to the fraction of the UDS that is mobilized and thus potentially suspended and available for ingestion into the transfer pump.

Gauglitz et al. (2010) described that cohesive particle interaction will have multiple effects on UDS uniformity and mobilization during jet mixing through a number of different mechanisms. The ECR is expected to correlate linearly with jet velocity and scale based on an evaluation of numerous studies (Powell et al. 1997) and may also depend on the strength of the sediment. Powell et al. (1995) identified that changing slurry rheology in the jet from Newtonian to non-Newtonian caused a significant reduction in the mobilization (erosion) of a clay layer, with a non-Newtonian jet requiring a $40 \%$ higher flow rate to achieve the same ECR as a Newtonian slurry jet.

Scoping tests to determine the magnitude of the impact caused by cohesive particle interactions and hence, non-Newtonian yield stress fluid rheology, on mixing were subsequently performed under the SSMD program and are reported in Adamson and Gauglitz (2011). Adamson and Gauglitz (2011) concluded that increasing the slurry yield stress tended to decrease in the ECR but the total transfer of settling particles increased with increasing yield stress. For jet mixing of non-Newtonian yield stress slurries, it is apparently more difficult to suspend particles from the tank bottom with increasing yield stress, but the particles stay suspended to a greater degree once lifted from the tank bottom. The combined effect of increasing the yield stress for the conditions tested is then an increase in the transfer of the settling particles.

The preceding shows that ECR scaling may be expected to be different for cohesive and non-cohesive slurries when the particle concentration in the slurry is high enough to create a non-Newtonian yield stress material. More significantly with respect to the current investigation, the ECR and transfer UDS concentration are related phenomena. ECR measurements are thus compared for scaled tank tests with the Base simulant with prior scaled test data and for measurements during full-scale testing with actual waste in AZ-101. As with the cloud height comparison, Section 3.2.1, favorable comparison of available related performance metrics between test scales and full scale increases confidence in full-scale transfer UDS concentration performance predictions based on test scale data. The AZ-101 ECR data is especially significant as it represents the most comprehensive full-scale actual waste data available for a prototypic WFD mixing system.

Measurement data from SSMD testing with the Base simulant is shown in the upper plot of Figure 3.15. These data are for the same simulant and capture velocity [BS=H, SV=H, CV=11.3] discussed in Section 2.2.2. In this plot, ECR is shown normalized by tank diameter, D. Note that tank diameter is a convenient normalizing parameter in this uniformly scaled system, but the ECR is actually driven by the jet velocity and jet nozzle diameter. The small- and large-scale tank data fall almost on the same line, both showing ECR/D increasing with jet nozzle velocity. Test data from AZ-101 mixer pump tests (Carlson et al. 2001) are shown in the lower plot in Figure 3.15. These ECR measurements were made by tracking changes in thermocouple measurements in the tank floor and this process is described in Carlson et al. (2001). As a prototypic WFD mixing system test, there are two mixer pumps, identified 
$\mathrm{BS}=\mathrm{H}, \mathrm{SV}=\mathrm{H}, \mathrm{CV}=11.3$

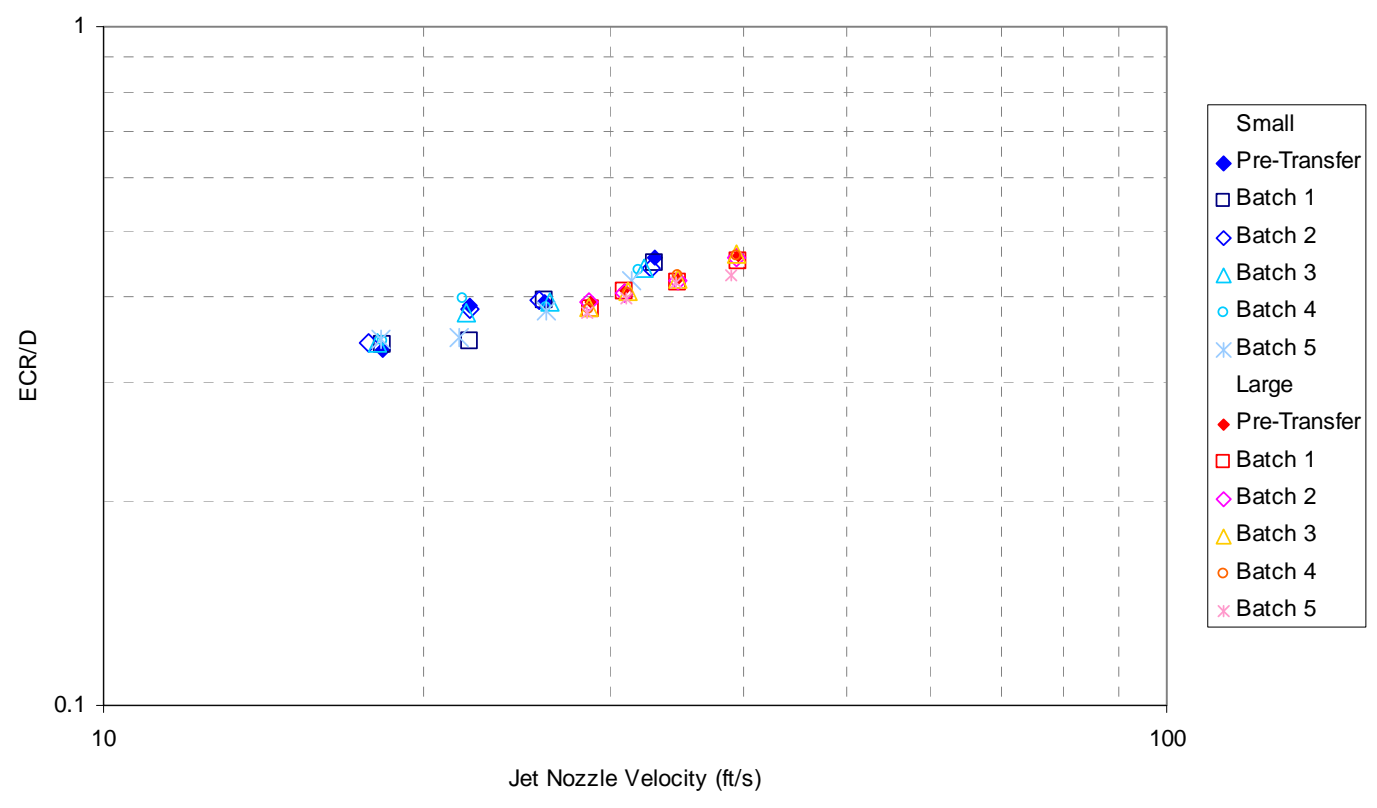

$\mathrm{BS}=\mathrm{H}, \mathrm{SV}=\mathrm{H}, \mathrm{CV}=11.3$

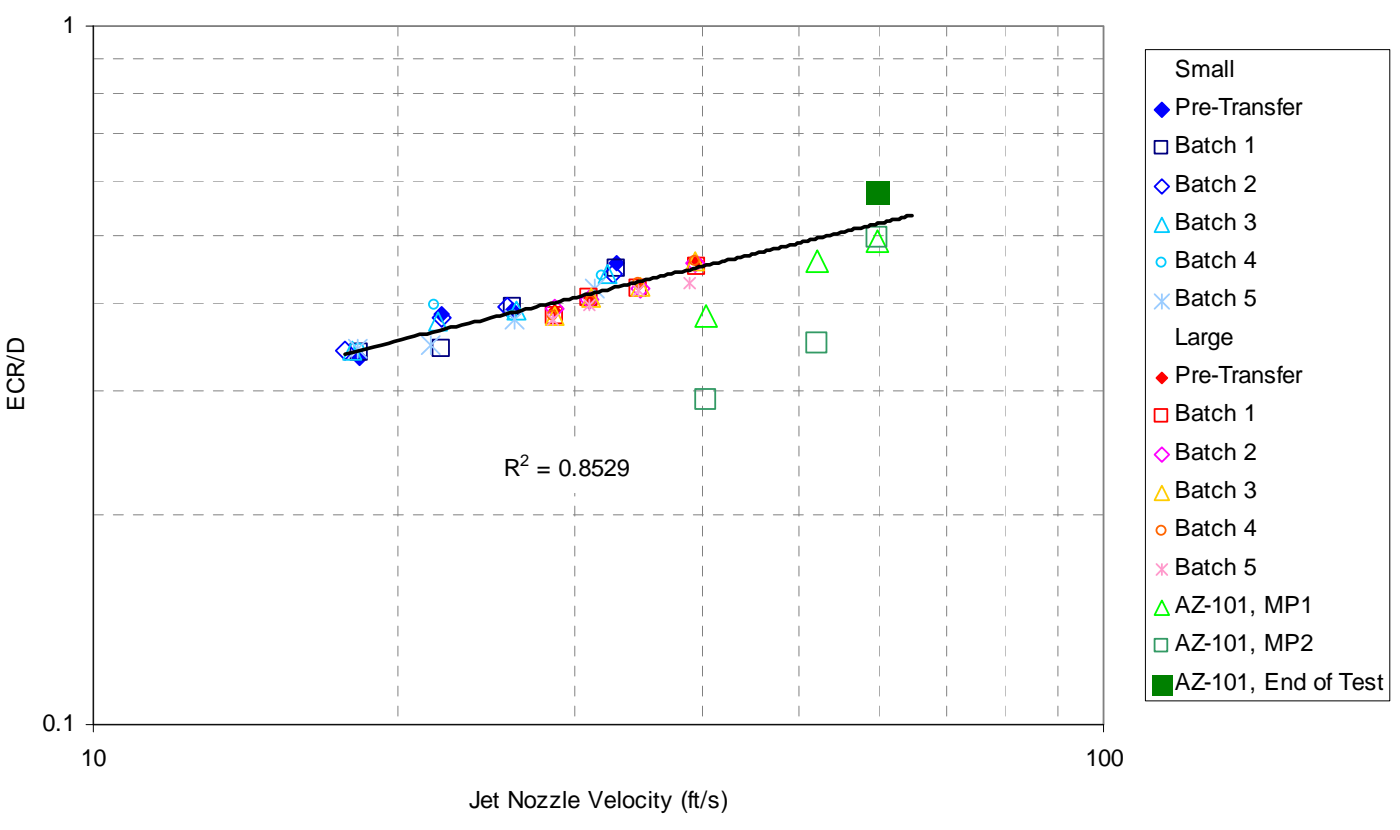

Figure 3.15. ECR; SSMD Testing with Base Simulant and Mixer Pump Tests in AZ-101

here as MP1 and MP2. At lower jet velocities, there is a notable difference in ECR achieved with each mixer pump. As described by Carlson et al. (2001), “... the ECR for mixer pump 1 is significantly larger than for mixer pump $2 \ldots$ because the material [sediment] closer to mixer pump 1 had been disturbed during [prior] testing, and subsequent remobilization of the material was easier...". The measurements from the two different mixer pumps at the highest velocity are in good agreement. The ECR at the end of 
the tests was larger likely due to the prior measurements not being at steady state. Aside from the lower velocity data points for MP1, the power law fit to the SSMD scaled-test data is in reasonable agreement with the full-scale test data, even with the differences for slurry properties and mixer pump rotation rate. To provide more basis to the favorable comparison of ECR between test scales and full scale, these differences are considered further, and scale exponents are evaluated.

With respect to slurry property differences, the ECR can be considered in terms of an estimated critical stress for erosion, $\tau_{\mathrm{c}}$. Two comparisons will be made for the critical stress for erosion:

1) estimates from test data, and 2) estimates based on particle properties. The model from Meacham et al. (2012), which incorporates expressions from the literature for the center-line velocity decay for a circular off-set jet that attaches to a vessel bottom and the resultant wall stress, will be used for test data estimates:

$$
E C R=\left[\frac{C_{f} \frac{1}{2} \rho\left(9.6 U_{0}\right)^{2} d_{0}{ }^{2.37}}{\tau_{c}}\right]^{1 / 2.37}
$$

The Base simulant test data from Figure 3.15 is fit individually for each tank scale. The results and the critical shear stress obtained in the fit are shown in the upper plot of Figure 3.16. These results can be compared to the critical stress for erosion of the AZ-101 waste estimated in Meacham et al. (2012) via the same approach as shown in the lower plot of Figure 3.16. The dashed, horizontal line in the lower plot of Figure 3.16 at $\mathrm{x} / \mathrm{D}_{0}=50$, which denotes the point at which the circular free jet from the mixer pump, can be described as a wall jet (Meacham et al. 2012). The critical stress for erosion of the Base simulant is estimated at up to approximately four times less than the AZ-101 waste. Given that the AZ-101 sediment has median yield stress in shear measurement of 1,769 $\mathrm{Pa}$ (Wells et al. 2011), higher critical stress for erosion estimates in AZ-101 are reasonable, potentially explaining the lower ECR measured for the AZ-101 individual mixer pumps at earlier stages of the test. The increased mixing time for the "end-oftest" AZ-101 results likely contributed to the increased ECR, countering the higher critical stress for erosion estimated from the earlier test results.

The slurry differences can also be considered based on the particle characteristics. If it is assumed that the simulant and waste particles are non-cohesive, the critical stress for erosion of the particles can be estimated from their respective PSDDs as summarized in Section 2. The results for the Base simulants "Typical" and "High" (see Table 2.2), the Complex 5 simulant (ECR data discussed below), and the AZ-101 waste (see Wells et al. 2012) are shown in Figure 3.17. This comparison shows that the High Base simulant used for the test cases that are the focus of this report is actually harder to mobilize than the AZ-101 waste. This result, counter to the estimated critical stress for erosion results of Figure 3.16, is likely due to the cohesive properties of the AZ-101 waste; median shear strength 1,769 Pa. Cohesive properties increasing the critical stress for erosion has been widely identified in the literature, e.g., see Wells et al. (2012).

In addition to potential cohesive effects in the AZ-101 waste, another effect that will cause differences between the Base simulant tests and AZ-101 tests is jet mixer rotation rate scaling. Adamson and Gauglitz (2011) found that the steady-state ECR could be increased by over $100 \%$ if the jet is 
operated at a fixed direction as opposed to rotating. For the SSMD Base simulant tests, Lee (2012) used Equation (3.3) to relate the mixer pump rotation rate, $\omega$, to jet velocity, $U$, and tank diameter, $D$,

$$
\omega_{\operatorname{tank} 2}=\frac{\omega_{\operatorname{tank} 1} U_{j e t 2}}{\left(\frac{d_{\operatorname{tank2}}}{\left.d_{\operatorname{tank} 1}\right)} U_{j e t 1}\right.}
$$

For the actual waste tests in AZ-101, fixed direction operations were conducted, and 180-degree pump rotation tests were conducted at varied jet velocities at 0.05 and $0.2 \mathrm{rpm}$. The rotational ECR data for AZ-101 shown in Figure 3.16 were at a fixed rotation rate of $0.05 \mathrm{rpm}$. Therefore, the relation of jet velocity and rotation rate was not equivalent from the full-scale tests to scaled testing.
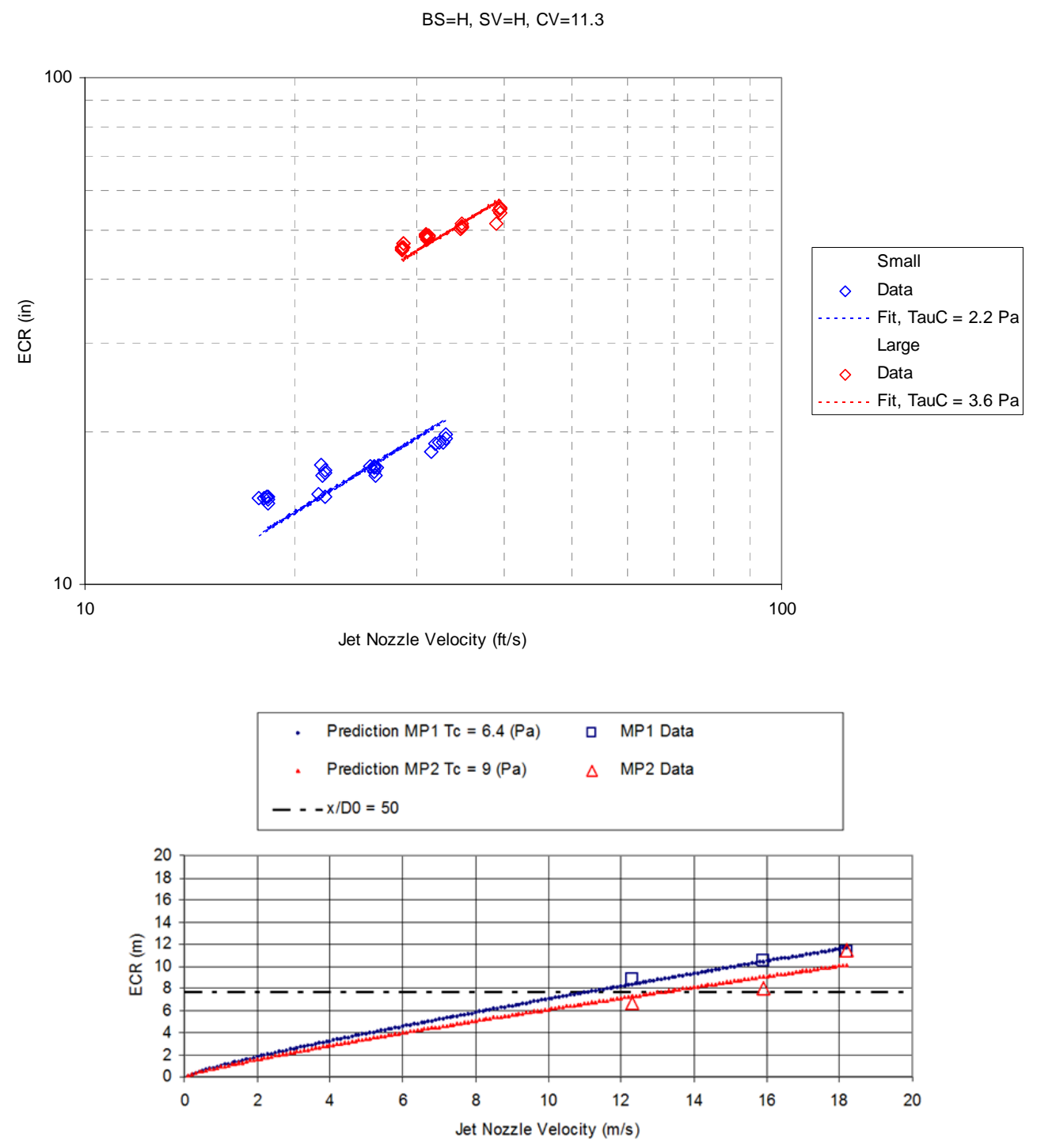

Figure 3.16. ECR, SSMD Testing with Base Simulant and Mixer Pump Tests in AZ-101 ${ }^{1}$

\footnotetext{
${ }^{1}$ Symbols TauC, in the legend for upper plot, and Tc, in the legend for lower plot, both represent critical shear stress.
} 

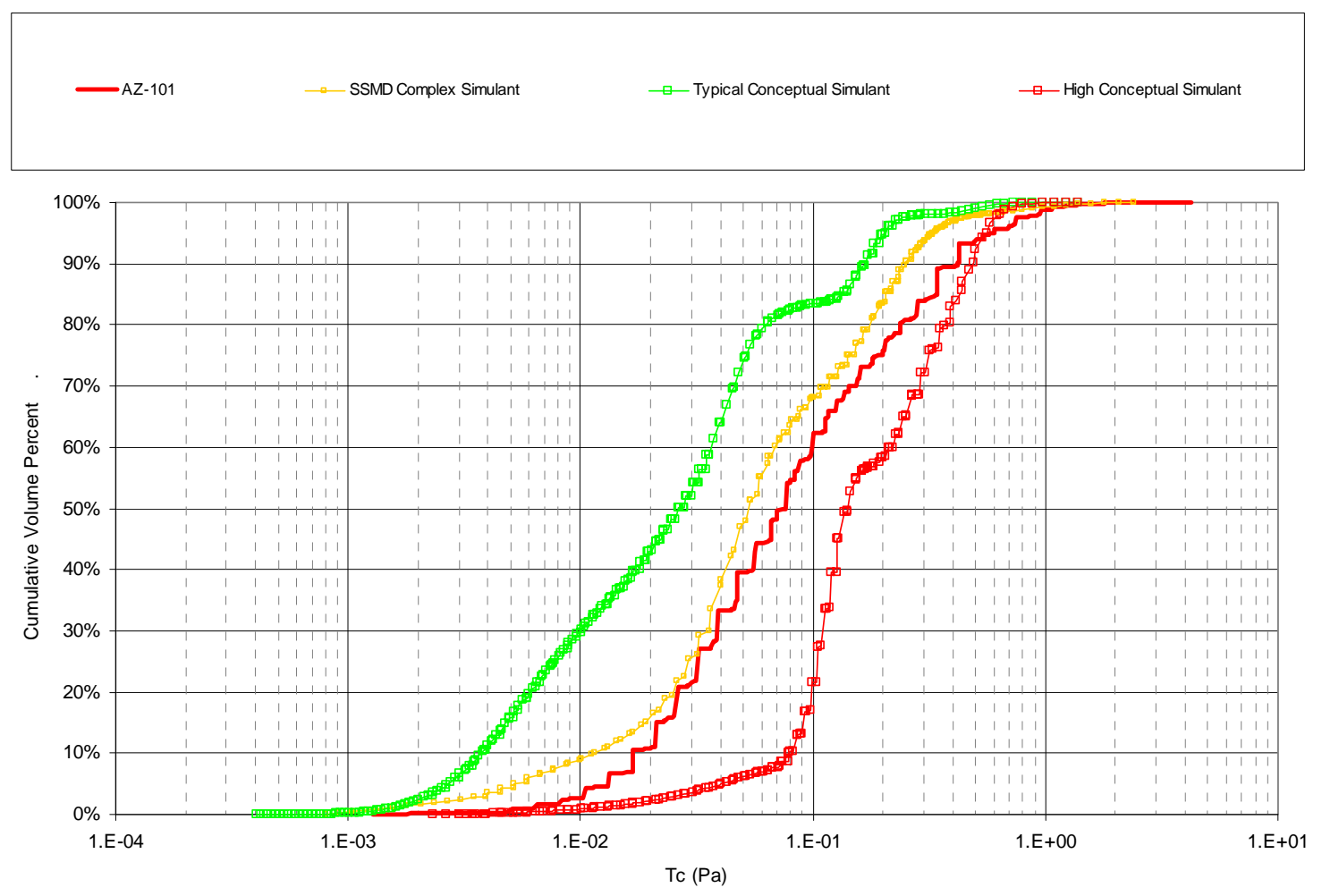

Figure 3.17. Critical Shear Stress Calculated from PSDDs

ECR scaling can be addressed using the same procedure used with transfer concentration. In Figure 3.18, the normalized data (ECR divided by tank diameter, $D$, and normalized velocity, Equation (3.1)) from the example SSMD test condition [BS=H, SV=H, CV=11.3] is shown for $\alpha=0$ in the top left plot, with remaining plots shown with scaling exponents of $0.1,0.2$ and 0.33 . The $\alpha=0$ data already fall very close to one another for the two scales, but closer coincidence is achieved at $\alpha=0.1$. The 'end of test' AZ-101 test data point is not as well fit, but this can likely be attributed to the differences in slurry properties and mixer pump rotation rate as previously discussed.

The same results and scaling process are shown next for the SSMD tests with Complex 5 simulant to evaluate further the effect of slurry properties and mixer pump rotation rate. Figure 3.19 shows the normalized ECR for the Complex 5 simulant tests, and similar conclusions can be made to the same AZ-101 data shown previously.

The Complex 5 simulant ECR data fit to Equation (3.2) are shown in Figure 3.20. The critical stress for erosion of the Complex 5 simulant is estimated at up to approximately eight times less than the AZ-101 waste, so the Complex 5 simulant is estimated form the ECR test data to be easier to erode than the High Base simulant. From Figure 3.17, the calculated critical stress for erosion of the Complex 5 simulant is less than that for AZ-101, and also less than that for the High Base simulant. As noted, this latter result is consistent with the ECR estimated critical stress for erosion results for these two simulants. 
$\mathrm{BS}=\mathrm{H}, \mathrm{SV}=\mathrm{H}, \mathrm{CV}=11.3$

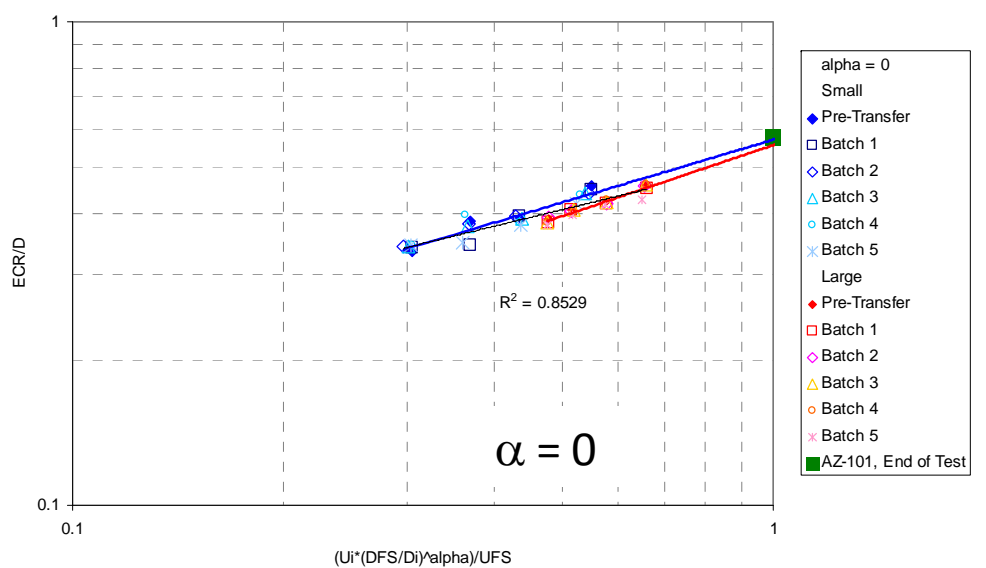

$B S=H, S V=H, C V=11.3$

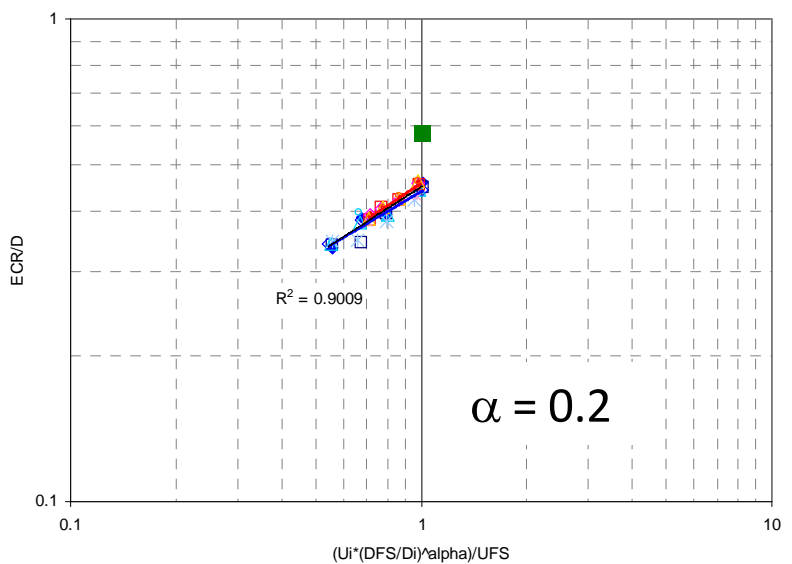

$\mathrm{BS}=\mathrm{H}, \mathrm{SV}=\mathrm{H}, \mathrm{CV}=113$

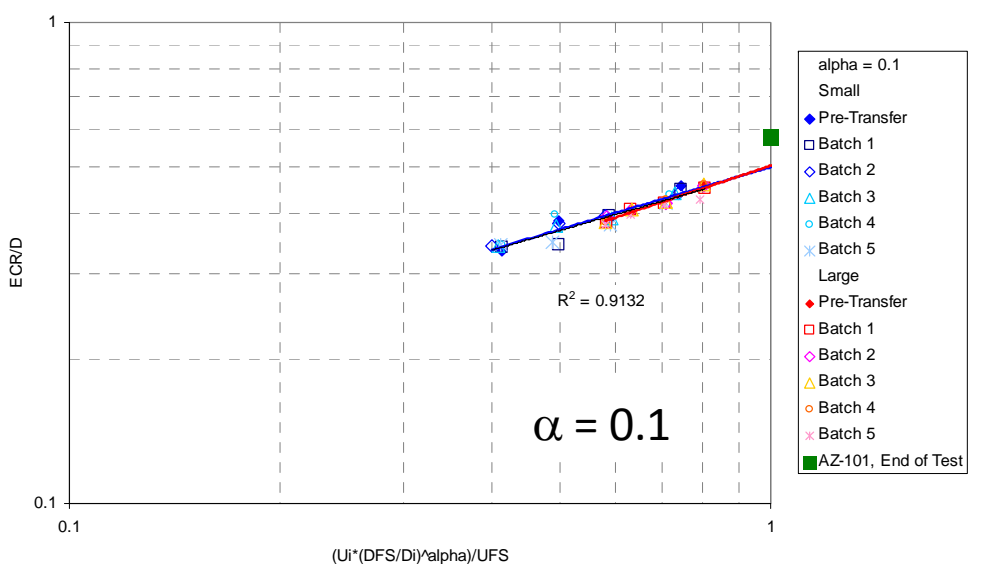

$B S=H, S V=H, C V=11.3$

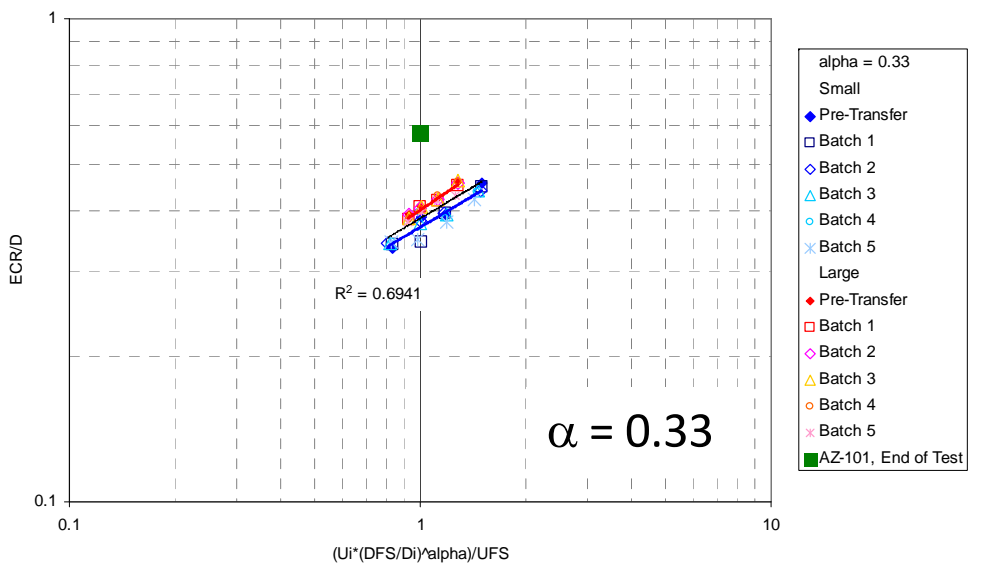

Figure 3.18. Comparison of Normalized ECR Data for Normalized Jet Velocity [BS=H, $S V=H, C V=11.3$ ] 


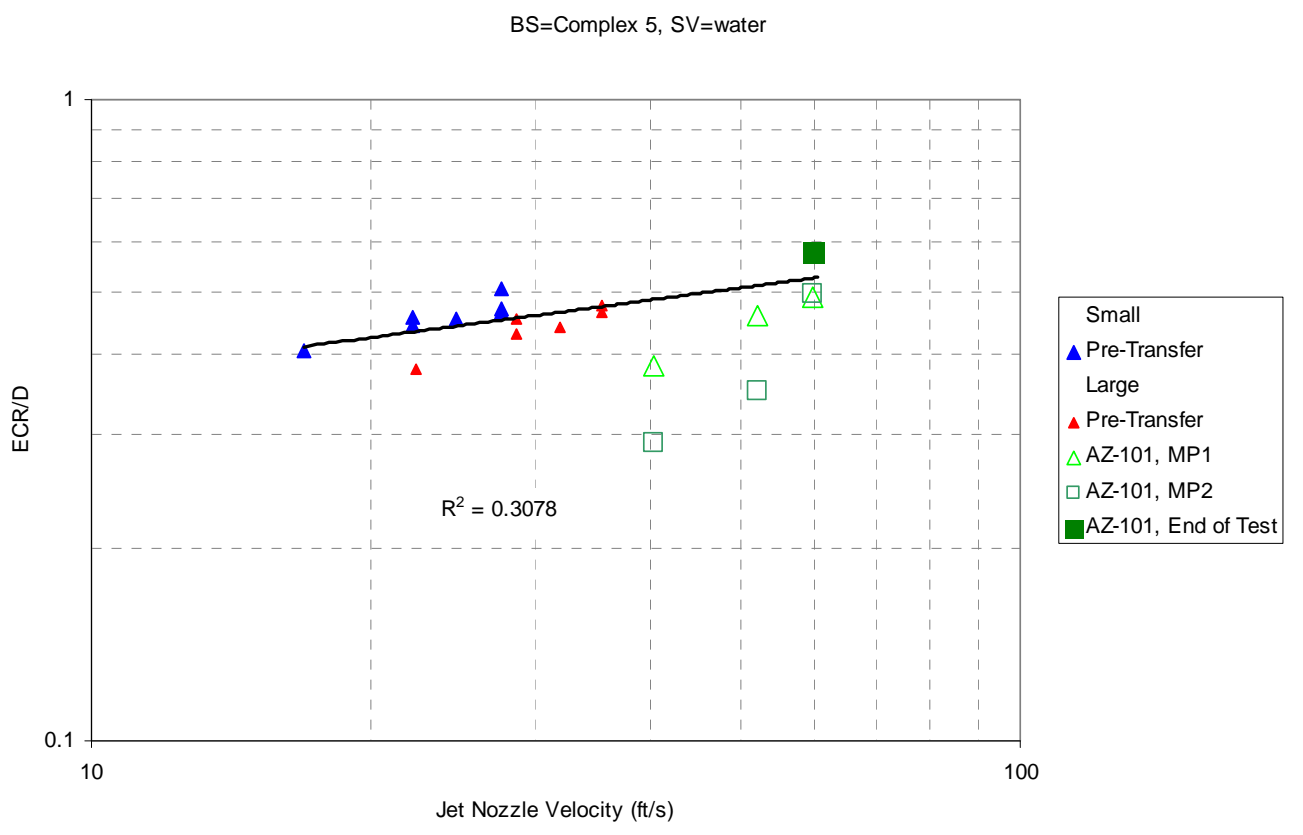

Figure 3.19. ECR; SSMD Testing with Complex 5 Simulant and Mixer Pump Tests in AZ-101

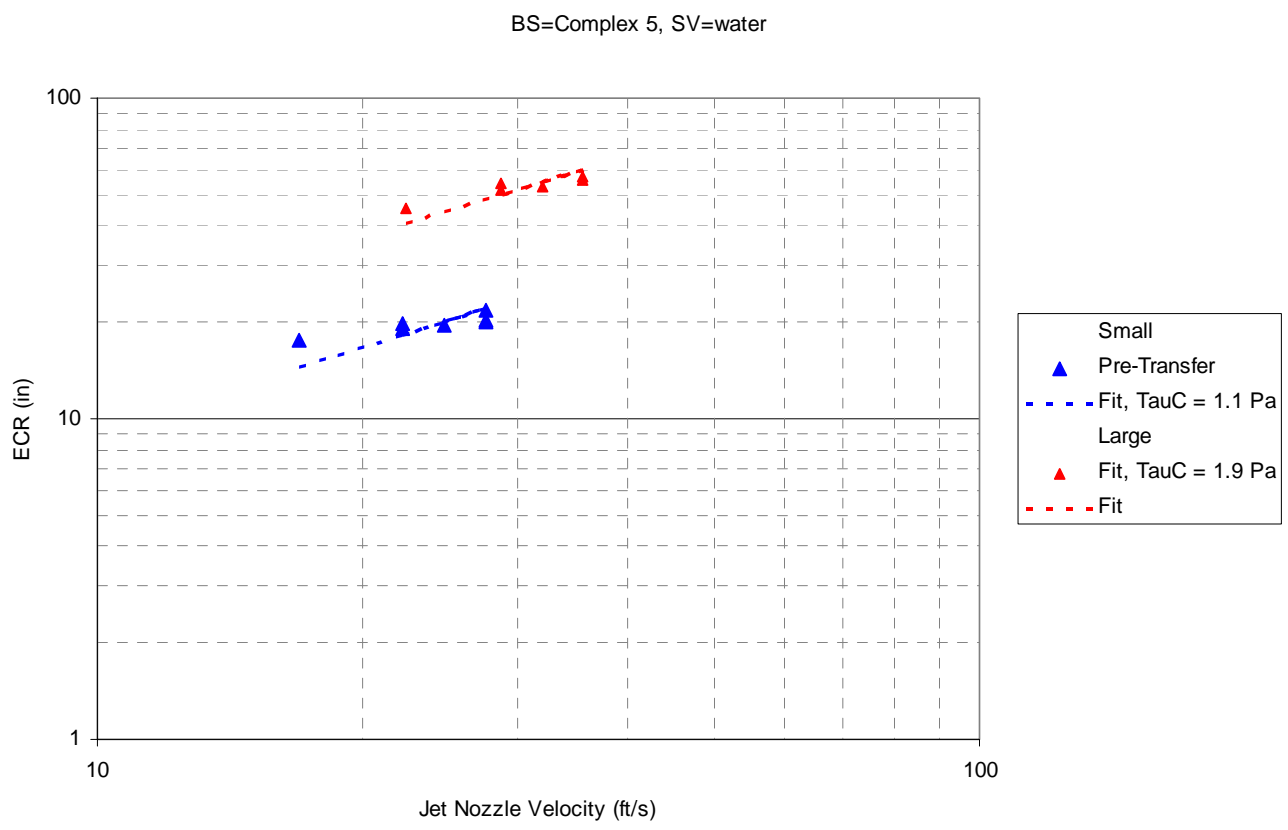

Figure 3.20. ECR, SSMD Testing with Complex 5 Simulant and Mixer Pump Tests in AZ-101

The mixer pump rotation rates were also different. For the Complex 5 simulant tests with 360 -degree mixer pump rotation, $1.53 \mathrm{rpm}$ was used in the 43.2 -inch vessel and $0.77 \mathrm{rpm}$ was used in the 120 -inch vessel. These rotation rates were fixed for each SSMD test scale regardless of the jet velocity. Although this case may be more similar to the AZ-101 test because the rotation rates were fixed regardless of jet velocity, the relation of jet velocity and rotation rate was not equivalent between Complex 5 simulant tests and the full-scale AZ-101 ECR tests (at $0.05 \mathrm{rpm}$ ) as specified by Equation (3.3). 
Scaling of the small-scale test data is shown in Figure 3.21. For the Complex 5 simulant, the best fit is not with $\alpha=0.1$, but with $\alpha=0.33$. Note that the AZ-101 falls well off the line of the ECR data for Complex 5 simulant, which may be attributed to the more extreme differences in slurry properties and mixer pump rotation rate.

For the SSMD test data evaluated, ECR appears to scale as $\alpha=0.1$ with velocity and geometry scaled pump rpm ( $\mathrm{BS}=\mathrm{H}, \mathrm{SV}=\mathrm{H}, \mathrm{CV}=11.3$, Base simulant tests), and $\alpha=0.33$ for geometric scaled pump rpm (Complex 5 simulant tests). For each SSMD simulant case, although the effects of different critical shear stress for erosion and mixer pump rotation are not clear, there is reasonable agreement with the AZ-101 full-scale test results with actual waste. The relatively comparable performance of the measured ECR at test scales and at full-scale, even with the influences of the different slurry properties and jet rotation rate as discussed, increases confidence in full-scale transfer UDS concentration performance predictions based on the test scale data.

\subsubsection{Summary of Scaling Behavior}

There is general consistency in scaling behavior between test campaigns, full-scale data, and predictions using ParaFlow. The scale coefficients are thus judged meaningful for different simulants and components as well as for full scale within the limited data and predictions considered.

The collective observations of test results with all SSMD simulants (Base, Complex 5, and $\mathrm{ZrO}_{2}$ ) is that for transfer UDS concentration, stratified components (those components with varied vertical suspended concentration) scale with $\alpha=0$ to 0.1 and homogeneous components (vertically within cloud less than fill height) scale with $\alpha=0.33$. A difference is observed between single component simulants $\left(\mathrm{ZrO}_{2}\right)$ and multi-component simulants (Complex 5) so it is apparent that this scaling is impacted by other UDS components.

Regarding the additional performance metrics, it was shown that for the data considered, cloud height scales with $\alpha=0.33$. Scaling for ECR varied from $\alpha \sim 0.1$ to 0.33 , but may have been impacted by jet rotation rate scaling. 
BS=Complex 5, SV=water

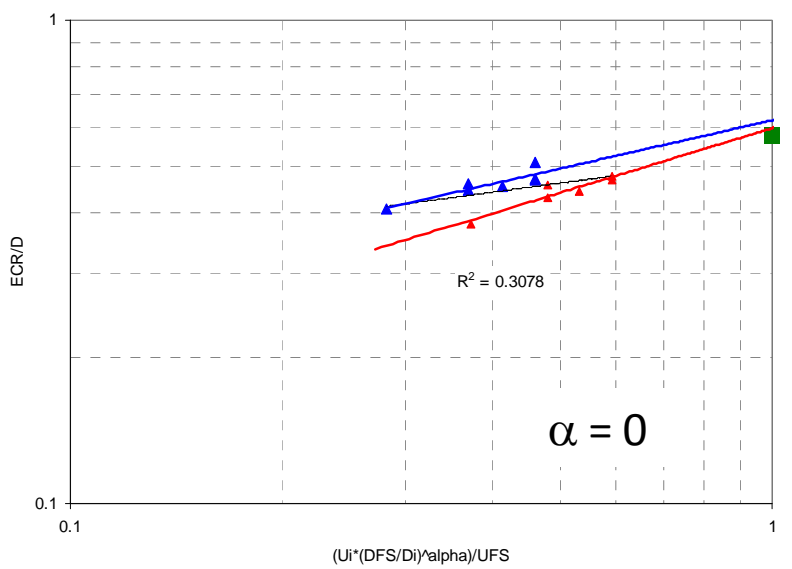

BS=Complex 5 , SV=water
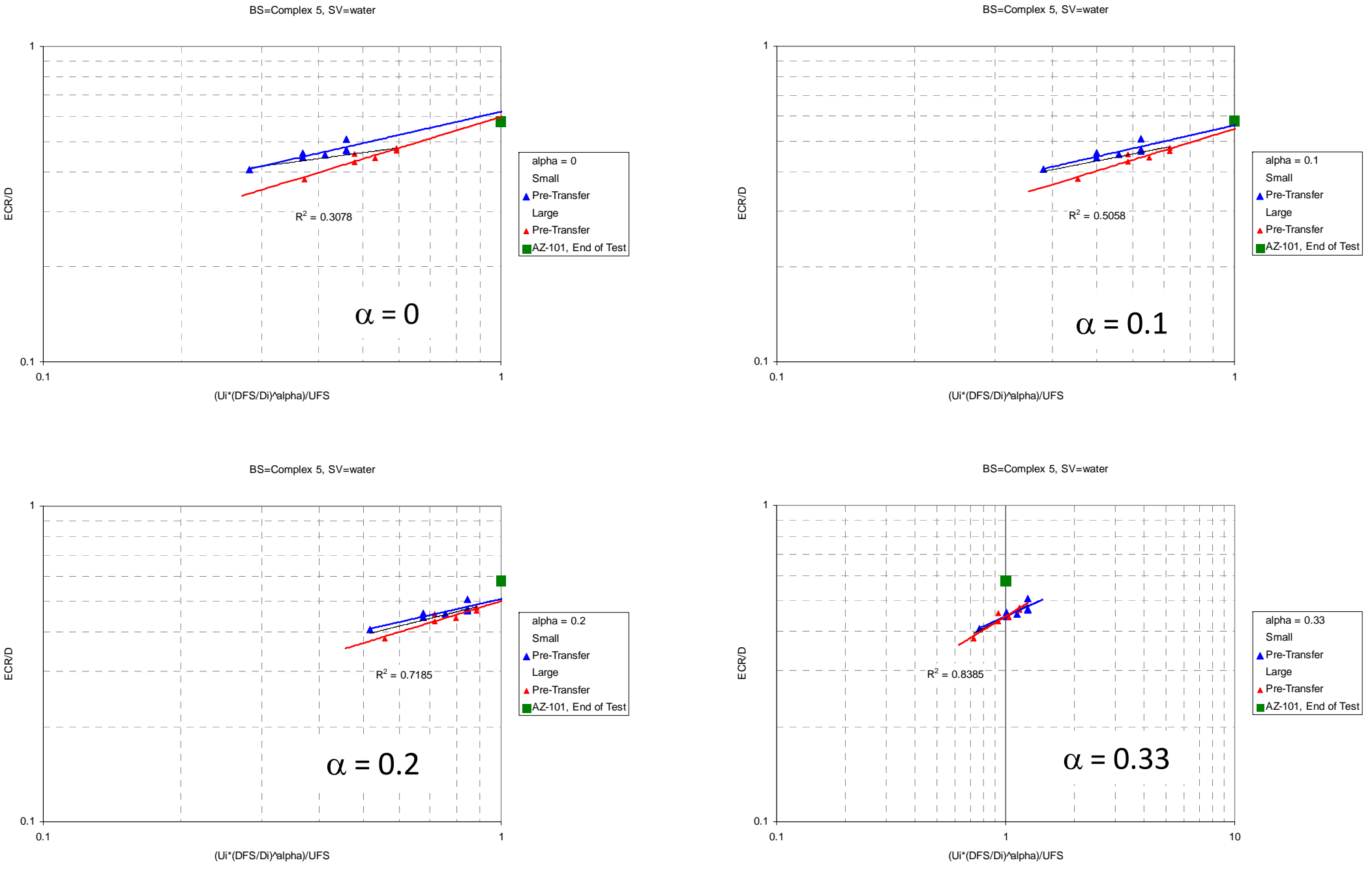

Figure 3.21. Comparison of Normalized ECR Data for Normalized Jet Velocity - Complex 5 Simulant 



\subsection{Estimate of Full-Scale Performance}

The SSMD test plan established a range of mixer jet pump jet velocities for each scaled tank. With a scaling exponent for the transfer UDS concentration indicated by the test data of $\alpha=0$ to 0.1 , Section 3, the jet velocities used in these tests are lower than the jet velocities required to relate performance to full scale. Again, in this study, the primary performance metric being examined is the transfer UDS concentration. When relating these results to full-scale performance, higher test jet velocities are thus more representative of full-scale performance. Performance should be estimated at higher scaled-tank jet velocities, and the transfer UDS concentration trends observed in testing (Section 3) suggest higher scaled-tank jet velocities would result in improved performance, i.e., transfer UDS concentration closer to the pre-transfer sample concentration.

\subsection{Total UDS Concentration}

First consider total UDS concentration and again look to data for the High Base simulant and $11.3 \mathrm{~m} / \mathrm{s}$ capture velocity [BS=H, $\mathrm{SV}=\mathrm{H}, \mathrm{CV}=11.3$ ]. Figure 4.1 shows that higher jet velocity gives higher total transfer UDS concentration with values approaching the initial homogeneous condition (calculated concentration assuming all solids are distributed homogenously in the liquid) at both test scales.

Total UDS: $B S=H, S V=H, C V=11.3$

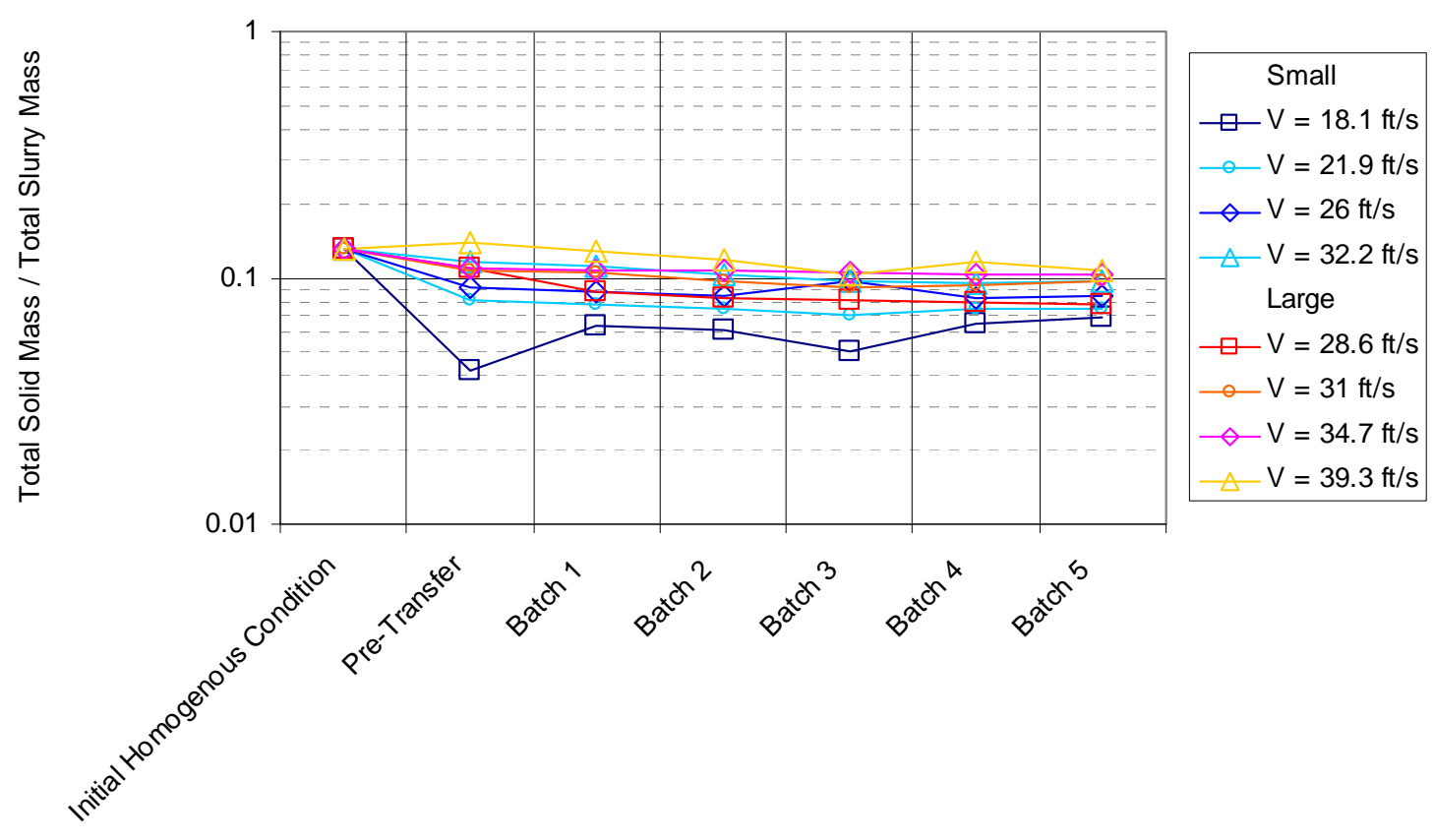

Figure 4.1. Transfer UDS Concentration, Total UDS, SSMD [BS=H, $\mathrm{SV}=\mathrm{H}, \mathrm{CV}=11.3$ ] 


\subsection{UDS Composition in Slurry}

Figure 4.2 shows transfer UDS concentration for each simulant component. Included are the pretransfer sample concentrations and values for each batch. As for the total UDS concentration, Section 4.1, the initial homogeneous condition is the calculated concentration assuming all solids are distributed homogenously in the liquid.

Gibbsite and $\mathrm{ZrO}_{2}$ batch concentrations are shown in the upper two plots in Figure 4.2. The values are roughly constant for all batches for each test jet velocity and there is little change in concentration with changes in test jet velocities. Batches are similar in concentration to the pre-transfer measurement and the pre-transfer sample and batch concentrations are near the homogeneous condition.

Stainless steel batch concentrations are shown in the bottom left plot in Figure 4.2. They increase in batches with increasing test jet velocities. For a given jet velocity, they almost all decrease with batch count and become more uniform with batch count at higher test jet velocities. The one exception is at the lowest jet velocity in the small tank, but, at these very low concentrations for this test case, there may be larger measurement uncertainty. The pre-transfer sample concentration is larger than the batch values at lower test jet velocities and the batch concentrations approach the pre-transfer sample value at higher test jet velocities. Batches and pre-transfer samples are lower than the homogeneous condition, but they approach it at the highest test jet velocities.

Finally, sand batch concentration is shown in the bottom right side of Figure 4.2. It is shown to increase in batches with increasing test jet velocities. Again, sand batch concentrations at the jet lowest velocity in the small tank (low concentration) have increased scatter. Batch concentrations are approximately uniform at higher test jet velocities. Pre-transfer sample concentrations exceed those of batches at most conditions. Pre-transfer and batch concentrations are seen to nominally exceed the homogeneous condition at higher jet velocities.

\subsection{UDS Composition in Solids}

For the example SSMD High Base simulant test case, Figure 4.3 shows transfer UDS for each simulant component, but this time as a mass fraction of total solids. Normalized this way, the data give insight into bulk characteristics of the transferred slurry such as rheology. For example, changes that indicate higher concentrations of slower settling, easier to suspend particles may suggest that batch is easier to suspend and mobilize, but higher concentrations of small particulate may increase the rheology of the slurry (e.g., Wells et al. 2011). As described in Section 3, rheology changes can alter mixing and transfer performance.

Gibbsite and $\mathrm{ZrO}_{2}$ batch mass fractions are shown in the upper two plots in Figure 4.3. Decreases in batch mass fractions are seen to result from increasing test jet velocities; see discussion of Figure 3.10. Batch mass fractions at a given test jet velocity are roughly uniform. Batch values are similar to pretransfer values, except at low jet velocities where batches are higher than the homogeneous condition. At the highest jet velocity, batches approach the homogeneous condition; again, see discussion of Figure 3.10.

Stainless steel batch mass fractions are shown in the bottom left plot in Figure 4.3. The description of their behavior follows almost identically with that of the mass fraction in the slurry. Concentrations 
increase in batches with increasing test jet velocities. For a given jet velocity, they decrease with batch count and become more uniform at higher test jet velocities. Again, the exception is the batch trend for the lowest jet velocity in the small tank. The pre-transfer sample mass fraction is larger than the batch values at lower test jet velocities and the batch concentrations approach the pre-transfer sample values at higher test jet velocities. Batches approach the homogeneous condition at the highest test jet velocities.

Finally, sand mass fractions are shown in the bottom right side of Figure 4.3. Batch mass fractions are not consistently impacted by increasing test jet velocities; they are roughly uniform. Batch mass fractions are approximately uniform and similar to pre-transfer samples values. Batches are uniformly higher than the homogeneous condition, which suggests that the sand particles are concentrated near the tank bottom. 
Gibbsite: $B S=H, S V=H, C V=11.3$

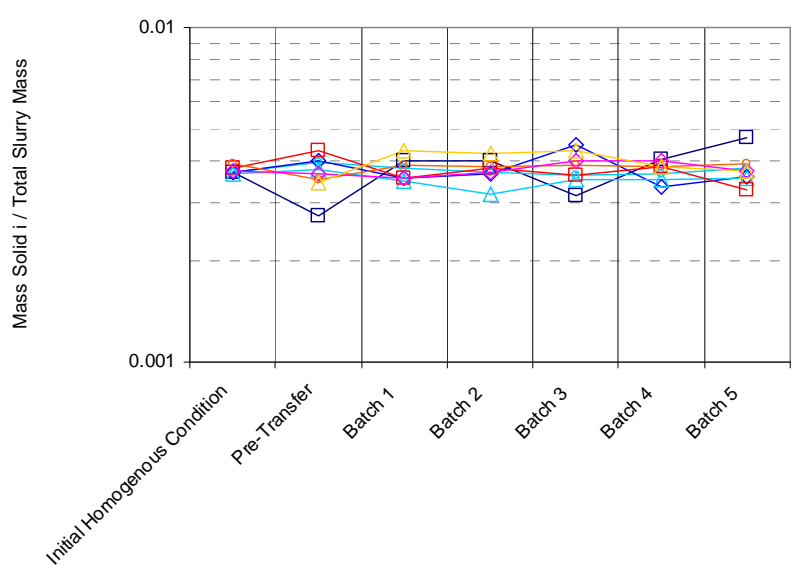

SS: $B S=H, S V=H, C V=11.3$

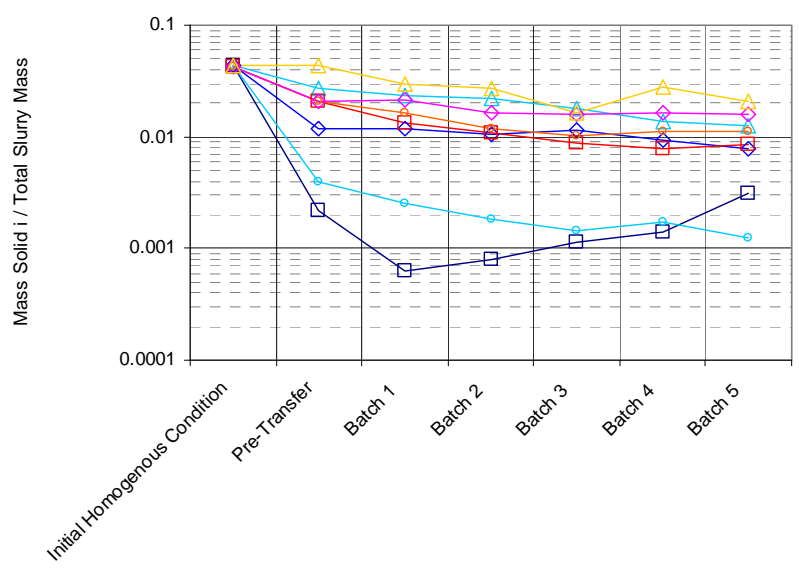

ZrO2: $\mathrm{BS}=\mathrm{H}, \mathrm{SV}=\mathrm{H}, \mathrm{CV}=11.3$

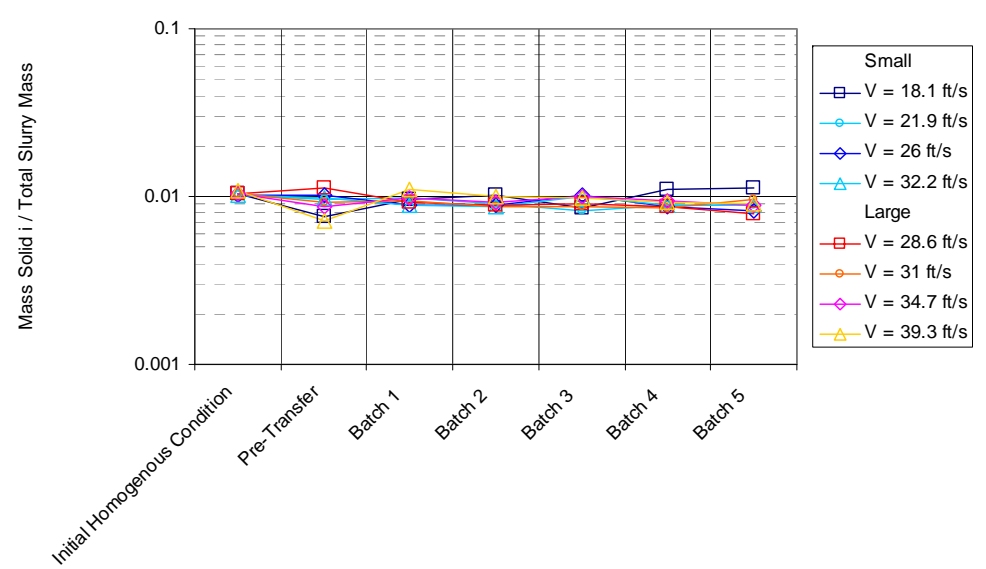

Sand: $B S=H, S V=H, C V=11.3$

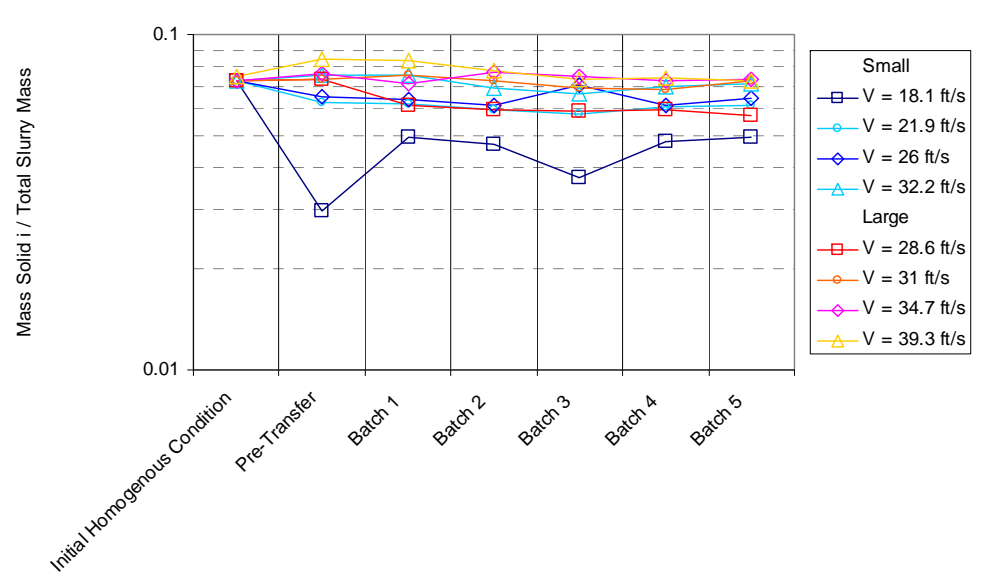

Figure 4.2. Transfer UDS Concentration - Composition in Slurry - SSMD [BS=H, SV=H, CV=11.3] 
Gibbsite: $\mathrm{BS}=\mathrm{H}, \mathrm{SV}=\mathrm{H}, \mathrm{CV}=11.3$

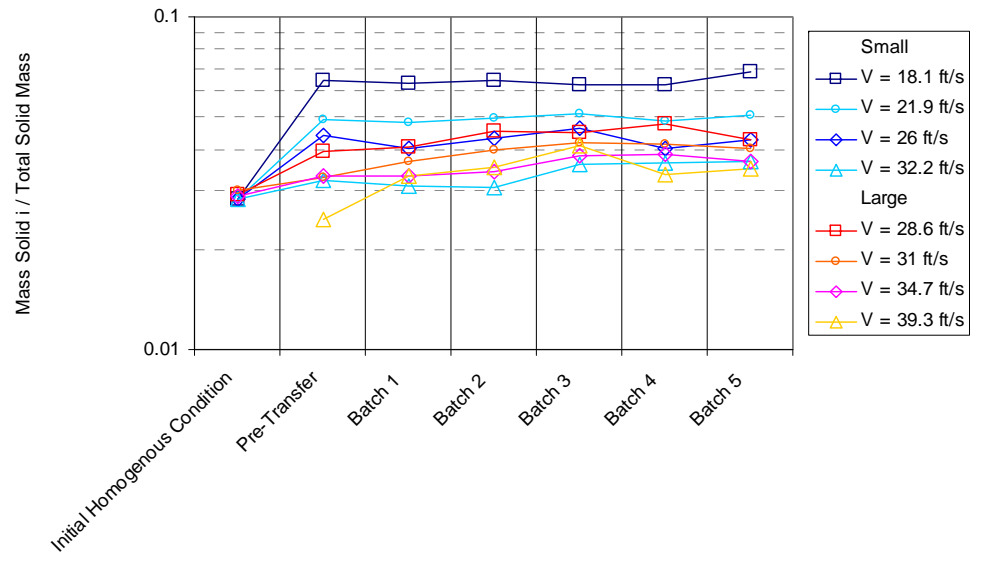

SS: $B S=H, S V=H, C V=11.3$

$\stackrel{\oplus}{\text { in }}$

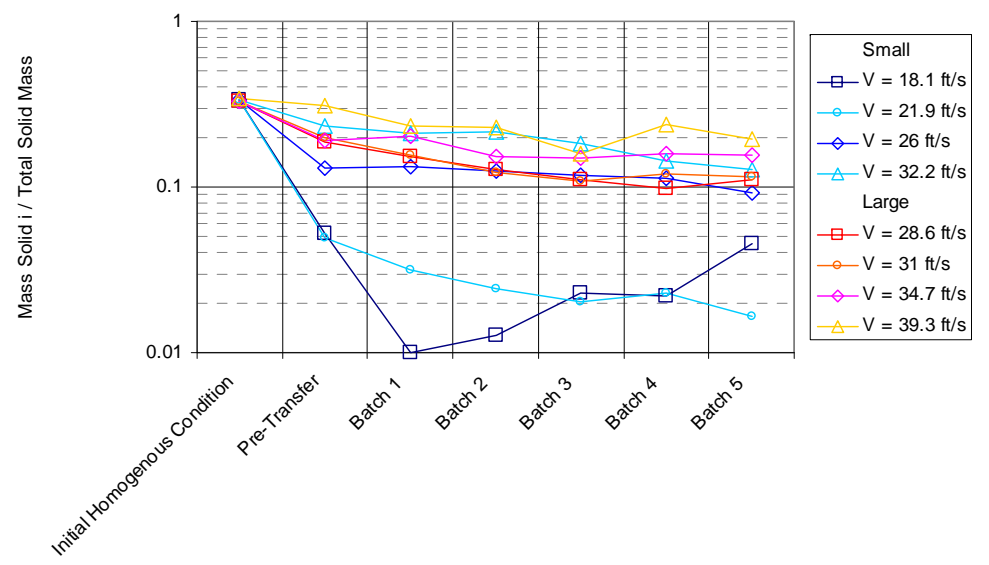

ZrO2: $\mathrm{BS}=\mathrm{H}, \mathrm{SV}=\mathrm{H}, \mathrm{CV}=11.3$

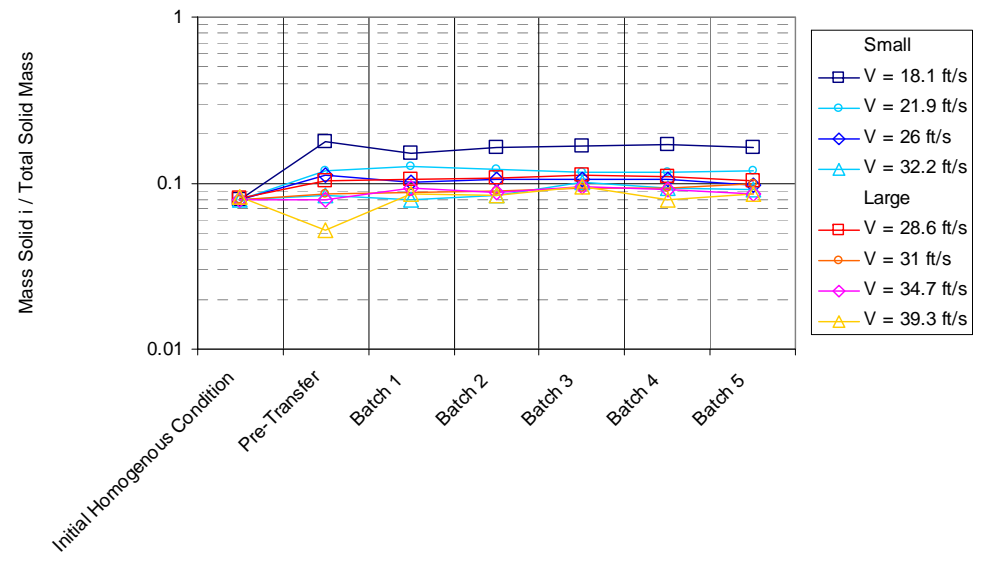

Sand: $B S=H, S V=H, C V=11.3$

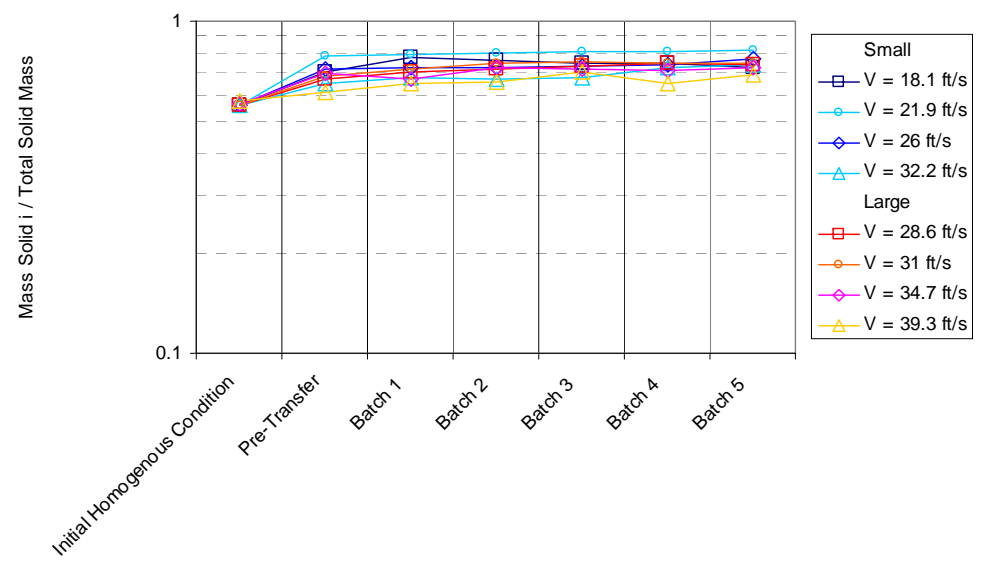

Figure 4.3. Transfer UDS Concentration - Composition in Solids $-\mathrm{SSMD}[\mathrm{BS}=\mathrm{H}, \mathrm{SV}=\mathrm{H}, \mathrm{CV}=11.3]$ 



\subsection{Conclusions and Recommendations}

The Hanford DST system provides the staging location for waste feed delivery to the WTP. The objectives of Washington River Protection Solutions' SSMD project are to understand and demonstrate the DST sampling and batch transfer performance, and to do so the project utilizes geometrically scaled DST feed tanks and waste simulants to generate mixing, sampling, and transfer test data.

The purpose of this study was to take an independent look at the measurement data with an emphasis on estimating scaling exponents for performance metrics as a function of jet velocity for a subset of the 2013 SSMD test data. The principal performance metric of interest in this study was transfer UDS concentration, a specific requirement for WFD. The selected data set had the largest number of jet velocities for otherwise constant conditions. In addition to transfer UDS concentration, consideration was given to scaling with jet velocity for additional metrics, including cloud height and effective cleaning radius to increase confidence in the transfer concentration test data scale-up. These additional performance metrics were evaluated because they are available for small-scale and full-scale tests and predictions, whereas transfer UDS concentration data is not available from the limited full-scale testing. Therefore, these additional metrics provide a way to test scaling relationships and they present a means by which to relate expectations for other metrics to full scale.

The collective observations of test results with all SSMD simulants (Base, Complex 5 and $\mathrm{ZrO}_{2}$ ) is that for transfer UDS concentration, stratified components scale with $\alpha=0$ to 0.1 . From experience and physical reasoning, homogeneous components (uniform concentration vertically within cloud less than fill height) scale with $\alpha=0.33$. For example, this behavior is observed in the test results for single component $\mathrm{ZrO}_{2}$ simulant. However, a difference is observed between scale exponent for single component $\mathrm{ZrO}_{2}$ simulants and the scaling exponent for $\mathrm{ZrO} 2$ as part of the multi-component Complex 5 simulant, so it is apparent that this scaling is impacted by the other UDS components. For the additional performance metrics, it was shown that for the data considered, cloud height scales with $\alpha=0.33$. Scaling for ECR varied from $\alpha \sim 0.1$ to 0.33 , but may have been impacted by jet rotation rate scaling.

There is general consistency in scaling behavior between test campaigns, full-scale data, and predictions using ParaFlow. The scale exponents are thus judged meaningful for different simulants and components as well as for full scale within the limited data and predictions considered.

With transfer UDS concentration scale exponents of $\alpha=0$ to 0.1 indicated by the test data, the jet velocities used in these tests are lower than the jet velocities required to relate performance to full scale. Improved performance is therefore estimated at full scale, as batch UDS concentrations are closer to the pre-transfer sample UDS concentrations at higher jet velocity.

As described, this study was primarily limited to four of the 22 available test cases for the Base simulant test cases. Within the remaining 18 test cases, there are additional data sets with repeat conditions except jet velocity to evaluate for transfer UDS concentration. Additional data, beyond what was evaluated in this report, is also available from prior SSMD testing with alternate simulants, Complex 5 and $\mathrm{ZrO}_{2}$. Evaluation of these data, together with available data for the other metrics, would be a step to further increasing confidence in the scale-up performance of the SSMD waste feed delivery testing performance. One approach to using the different metrics in scaled testing would be to attempt to relate the scaling of ECR and cloud height to the scaling of the UDS concentration at the transfer line. 



\subsection{References}

10 CFR 830, Subpart A. 2010. "Nuclear Safety Management.” Subpart A, "Quality Assurance Requirements." Code of Federal Regulations, U.S. Department of Energy.

Arakali AV, DL Banning, PA Benson, and DA Greer. 2011. Initial Data Quality Objectives for WTP Feed Acceptance Criteria. WTP Project Doc. No. 24590-WTP-RPT-MGT-11-014, Rev. 0, Bechtel National, Inc., Richland, Washington.

Carlson AB, PJ Certa, TM Hohl, JR Bellomy III, TW Crawford, DC Hedengren, AM Templeton, HS Fisher, SJ Greenwood, DG Douglas, and WJ Ulbright Jr. 2001. Test Report, 241-AZ-101 Mixer Pump Test. RPP-6548, Rev. 1, Numatec Hanford Corporation, Richland, Washington.

DOE Order 414.1D. 2011. “Quality Assurance.” U.S. Department of Energy, Washington, D.C.

Gauglitz PA, BE Wells, JA Bamberger, JA Fort, J Chun, and JWJ Jenks. 2010. The Role of Cohesive Particle Interactions on Solids Uniformity and Mobilization During Jet Mixing: Testing Recommendations. PNNL-19245, Pacific Northwest National Laboratory, Richland, Washington.

Jackson V. 2011. Small Scale Mixing Demonstration Sampling and Batch Transfers Initial Results Report. RPP-49740 (RPT-SSMD-EG-0005, Rev. A), EnergySolutions, Richland, Washington.

Kelly SE, RX Milleret, and TA Wooley. 2013. One System Waste Feed Delivery Mixing Performance and Solids Accumulation Test Report. RPP-53931, Rev. A, Washington River Protection Solutions, Richland, Washington.

Lee KP. 2012. One System Waste Feed Delivery Mixing and Sampling Program System Performance Test Plan. RPP-PLAN-52623, Rev. 0, Washington River Protection Solutions, Richland, Washington.

Lee KP, BE Wells, PA Gauglitz, and RA Sexton. 2012a. Waste Feed Delivery Mixing and Sampling Program Simulant Definition for Tank Farm Performance Testing. RPP-PLAN-51625, Rev. 0, Washington River Protection Solutions, Richland, Washington.

Lee KP, GF Piepel, AE Holmes, and A Heredia-Langner. 2012b. Tank Farm Approach to Develop Scaling Relationships Based on Scaled Tank Mixing and Transfer Results. RPP-PLAN-53454, Rev. 1, Washington River Protection Solutions, Richland, Washington.

Meacham JE, SJ Harrington, JS Rodriguez, VC Nguyen, JG Reynolds, BE Wells, GF Piepel, SK Cooley, CW Enderlin, DR Rector, J Chun, A Heredia-Langner, and RF Gimpel. 2012. One System Evaluation of Waste Transferred to the Waste Treatment Plant. RPP-RPT-51652, Rev. 0, Washington River Protection Solutions, Richland, Washington.

Olson JW. 2011. ICD 19 - Interface Control Document for Waste Feed. 24590-WTP-ICD-MG-01-019, Rev. 5, River Protection Project, Waste Treatment Plant, Bechtel National, Inc., Richland, Washington. 
Pfeifer KW. 2012. One System Waste Feed Delivery Small-Scale Mixing Demonstration Effective Cleaning Radius Evaluation. RPP-RPT-53101, Washington River Protection Solutions, Richland, Washington.

Piepel GF, AE Holmes, and A Heredia-Langner. 2013. Scaling Relationships Based on Scaled Tank Mixing and Transfer Test Results. PNNL-22644, Pacific Northwest National Laboratory, Richland, Washington.

Powell MR, GR Golcar, CR Hymas, and RL McKay. 1995. Fiscal Year 1993 1/25th-Scale Sludge Mobilization Testing. PNL-10464, Pacific Northwest Laboratory, Richland, Washington.

Powell MR, Y Onishi, and R Shekarriz. 1997. Research on Jet Mixing of Settled Sludges in Nuclear Waste Tanks at Hanford and Other DOE Sites: A Historical Perspective. PNNL-11686, Pacific Northwest National Laboratory, Richland, Washington.

Rector DR, ML Stewart, and J Bao. 2012. "Modeling of HLW Tank Solids Resuspension and Mixing Processes." Presented at the 2012 Waste Management Conference, February 27-March 1, 2012, Phoenix, Arizona.

Schwuger MJ. 1996. Detergents in the Environment. ISBN 0-8247-9396-X, Marcel Dekker, Inc., New York.

Townson P. 2009. Tank Farm Mixing Demonstration Planning Workshop. RPT-1741-0001, Rev. 0, EnergySolutions, Richland, Washington.

Wells BE and JJ Ressler. 2009. Estimate of the Distribution of Solids Within Mixed Hanford DoubleShell Tank AZ-101: Implications for AY-102. PNNL-18327, Pacific Northwest National Laboratory, Richland, Washington.

Wells BE, DE Kurath, LA Mahoney, Y Onishi, JL Huckaby, SK Cooley, CA Burns, EC Buck, JM Tingey, RC Daniel, and KK Anderson. 2011. Hanford Waste Physical and Rheological Properties: Data and Gaps. PNNL-20646, Pacific Northwest National Laboratory, Richland Washington.

Wells BE, PA Gauglitz and DR Rector. 2012. Comparison of Waste Feed Delivery Small Scale Mixing Demonstration Simulant to Hanford Waste. PNNL-20637, Rev. 2, Pacific Northwest National Laboratory, Richland, Washington.

Woodworth R and PA Townson. 2010. Small Scale Mixing Demonstration Initial Results Report. RPP-47557 (RPT-SSMD-EG-0003, Rev. 0), EnergySolutions, Richland, Washington. 
Appendix A

Data Observations 



\section{Appendix A}

\section{Data Observations}

This report deals primarily with Small Scale Mixing Demonstration (SSMD) test results for transfer undissolved solids (UDS) concentration. However, additional test data were recorded during each test and some of these are important to show consistency with planned test conditions or are helpful in interpreting individual test rests. Test data plots are included in this appendix for four test parameters: jet mixer pump flow rate, transfer stream slurry density, temperature, and tank surface level. ${ }^{1}$ Specific measurement locations and instruments for each of these are described in Kelly et al. (2013). Each of these parameters were recorded for the duration of each test, beginning with tank slurry mixing prior to pre-transfer sample measurements through completion of the five batch transfers. Figure A.1 to Figure A.40 show this plotted data along with annotations at the time of pre-transfer sample measurements and over the time of each batch transfer. These data are referenced to specific test conditions by Run Sheet number listed in Table A.1 for the small tank tests and Table A.2 for the large tank tests. Specific observations about these data are provided in Section 2.3 of the report.

Table A.1. SSMD Test Identification - Small Tank

\begin{tabular}{|c|c|c|c|c|c|c|c|}
\hline Run Sheet Number & $\begin{array}{l}\text { Tank } \\
\text { Size }\end{array}$ & $\begin{array}{l}\text { Test } \\
\text { Seq. }\end{array}$ & Velocity & Base & Supernatant & $\begin{array}{l}\text { Capture } \\
\text { Velocity }\end{array}$ & Label \\
\hline RS-SSMD-OP-0058 & Small & 8 & $\mathrm{~V}-1$ & High & Typical & 7.3 & $\mathrm{~V}=1, \mathrm{BS}=\mathrm{H}, \mathrm{SV}=\mathrm{T}, \mathrm{CV}=7.3$ \\
\hline RS-SSMD-OP-0059 & Small & 1 & $\mathrm{~V}-3$ & High & Typical & 7.3 & $\mathrm{~V}=3, \mathrm{BS}=\mathrm{H}, \mathrm{SV}=\mathrm{T}, \mathrm{CV}=7.3$ \\
\hline RS-SSMD-OP-0060 & Small & 14 & $\mathrm{~V}-2$ & Typical & Typical & 7.3 & $\mathrm{~V}=2, \mathrm{BS}=\mathrm{T}, \mathrm{SV}=\mathrm{T}, \mathrm{CV}=7.3$ \\
\hline RS-SSMD-OP-0061 & Small & 11 & $\mathrm{~V}-5$ & Typical & Typical & 7.3 & $\mathrm{~V}=5, \mathrm{BS}=\mathrm{T}, \mathrm{SV}=\mathrm{T}, \mathrm{CV}=7.3$ \\
\hline RS-SSMD-OP-0062 & Small & 20 & V-5 & Typical & Typical & 7.3 & $\mathrm{~V}=5, \mathrm{BS}=\mathrm{T}, \mathrm{SV}=\mathrm{T}, \mathrm{CV}=7.3$ \\
\hline RS-SSMD-OP-0063 & Small & 21 & $\mathrm{~V}-2$ & High & Mod. High & 3.8 & $\mathrm{~V}=2, \mathrm{BS}=\mathrm{H}, \mathrm{SV}=\mathrm{M}, \mathrm{CV}=3.8$ \\
\hline RS-SSMD-OP-0064 & Small & 3 & $\mathrm{~V}-2$ & High & Mod. High & 3.8 & $\mathrm{~V}=2, \mathrm{BS}=\mathrm{H}, \mathrm{SV}=\mathrm{M}, \mathrm{CV}=3.8$ \\
\hline RS-SSMD-OP-0065 & Small & 2 & $\mathrm{~V}-4$ & High & Mod. High & 3.8 & $\mathrm{~V}=4, \mathrm{BS}=\mathrm{H}, \mathrm{SV}=\mathrm{M}, \mathrm{CV}=3.8$ \\
\hline RS-SSMD-OP-0066 & Small & 13 & V-1 & High & Mod. High & 7.3 & $\mathrm{~V}=1, \mathrm{BS}=\mathrm{H}, \mathrm{SV}=\mathrm{M}, \mathrm{CV}=7.3$ \\
\hline RS-SSMD-OP-0067 & Small & 9 & $\mathrm{~V}-5$ & High & Mod. High & 7.3 & $\mathrm{~V}=5, \mathrm{BS}=\mathrm{H}, \mathrm{SV}=\mathrm{M}, \mathrm{CV}=7.3$ \\
\hline RS-SSMD-OP-0068 & Small & 12 & V-3 & High & Mod. High & 11.3 & $\mathrm{~V}=3, \mathrm{BS}=\mathrm{H}, \mathrm{SV}=\mathrm{M}, \mathrm{CV}=11.3$ \\
\hline RS-SSMD-OP-0069 & Small & 5 & $\mathrm{~V}-3$ & High & Mod. High & 11.3 & $\mathrm{~V}=3, \mathrm{BS}=\mathrm{H}, \mathrm{SV}=\mathrm{M}, \mathrm{CV}=11.3$ \\
\hline RS-SSMD-OP-0070 & Small & 22 & V-3 & Typical & Mod. High & 3.8 & $\mathrm{~V}=3, \mathrm{BS}=\mathrm{T}, \mathrm{SV}=\mathrm{M}, \mathrm{CV}=3.8$ \\
\hline RS-SSMD-OP-0071 & Small & 19 & V-1 & Typical & Mod. High & 7.3 & $\mathrm{~V}=1, \mathrm{BS}=\mathrm{T}, \mathrm{SV}=\mathrm{M}, \mathrm{CV}=7.3$ \\
\hline RS-SSMD-OP-0072 & Small & 7 & $\mathrm{~V}-5$ & Typical & Mod. High & 7.3 & $\mathrm{~V}=5, \mathrm{BS}=\mathrm{T}, \mathrm{SV}=\mathrm{M}, \mathrm{CV}=7.3$ \\
\hline RS-SSMD-OP-0073 & Small & 16 & $\mathrm{~V}-3$ & Typical & Mod. High & 11.3 & $\mathrm{~V}=3, \mathrm{BS}=\mathrm{T}, \mathrm{SV}=\mathrm{M}, \mathrm{CV}=11.3$ \\
\hline RS-SSMD-OP-0074 & Small & 4 & V-3 & Typical & Mod. High & 11.3 & $\mathrm{~V}=3, \mathrm{BS}=\mathrm{T}, \mathrm{SV}=\mathrm{M}, \mathrm{CV}=11.3$ \\
\hline RS-SSMD-OP-0075 & Small & 10 & $\mathrm{~V}-1$ & High & High & 11.3 & $\mathrm{~V}=1, \mathrm{BS}=\mathrm{H}, \mathrm{SV}=\mathrm{H}, \mathrm{CV}=11.3$ \\
\hline RS-SSMD-OP-0076 & Small & 15 & $\mathrm{~V}-3$ & High & High & 11.3 & $\mathrm{~V}=3, \mathrm{BS}=\mathrm{H}, \mathrm{SV}=\mathrm{H}, \mathrm{CV}=11.3$ \\
\hline RS-SSMD-OP-0077 & Small & 17 & V-5 & High & High & 11.3 & $\mathrm{~V}=5, \mathrm{BS}=\mathrm{H}, \mathrm{SV}=\mathrm{H}, \mathrm{CV}=11.3$ \\
\hline RS-SSMD-OP-0078 & Small & 18 & $\mathrm{~V}-2$ & High & High & 11.3 & $\mathrm{~V}=2, \mathrm{BS}=\mathrm{H}, \mathrm{SV}=\mathrm{H}, \mathrm{CV}=11.3$ \\
\hline RS-SSMD-OP-0079 & Small & 6 & $\mathrm{~V}-4$ & Typical & High & 11.3 & $\mathrm{~V}=4, \mathrm{BS}=\mathrm{T}, \mathrm{SV}=\mathrm{H}, \mathrm{CV}=11.3$ \\
\hline
\end{tabular}

\footnotetext{
${ }^{1}$ Email communication from RX Milleret, Washington River Protection Solutions, to BE Wells and PP Schonewill, Pacific Northwest National Laboratory, May 2013.
} 
Table A.2. SSMD Test Identification - Large Tank

\begin{tabular}{|c|c|c|c|c|c|c|c|}
\hline Run Sheet Number & $\begin{array}{l}\text { Tank } \\
\text { Size }\end{array}$ & $\begin{array}{l}\text { Test } \\
\text { Seq. }\end{array}$ & Velocity & Base & Supernatant & $\begin{array}{l}\text { Capture } \\
\text { Velocity }\end{array}$ & Label \\
\hline RS-SSMD-OP-0084 & Large & 8 & $\mathrm{~V}-1$ & High & Typical & 7.3 & $\mathrm{~V}=1, \mathrm{BS}=\mathrm{H}, \mathrm{SV}=\mathrm{T}, \mathrm{CV}=7.3$ \\
\hline RS-SSMD-OP-0085 & Large & 1 & V-3 & High & Typical & 7.3 & $\mathrm{~V}=3, \mathrm{BS}=\mathrm{H}, \mathrm{SV}=\mathrm{T}, \mathrm{CV}=7.3$ \\
\hline RS-SSMD-OP-0086 & Large & 14 & $\mathrm{~V}-2$ & Typical & Typical & 7.3 & $\mathrm{~V}=2, \mathrm{BS}=\mathrm{T}, \mathrm{SV}=\mathrm{T}, \mathrm{CV}=7.3$ \\
\hline RS-SSMD-OP-0087 & Large & 11 & V-5 & Typical & Typical & 7.3 & $\mathrm{~V}=5, \mathrm{BS}=\mathrm{T}, \mathrm{SV}=\mathrm{T}, \mathrm{CV}=7.3$ \\
\hline RS-SSMD-OP-0088 & Large & 20 & $\mathrm{~V}-5$ & Typical & Typical & 7.3 & $\mathrm{~V}=5, \mathrm{BS}=\mathrm{T}, \mathrm{SV}=\mathrm{T}, \mathrm{CV}=7.3$ \\
\hline RS-SSMD-OP-0089 & Large & 21 & $\mathrm{~V}-2$ & High & Mod. High & 3.8 & $\mathrm{~V}=2, \mathrm{BS}=\mathrm{H}, \mathrm{SV}=\mathrm{M}, \mathrm{CV}=3.8$ \\
\hline RS-SSMD-OP-0090 & Large & 3 & $\mathrm{~V}-2$ & High & Mod. High & 3.8 & $\mathrm{~V}=2, \mathrm{BS}=\mathrm{H}, \mathrm{SV}=\mathrm{M}, \mathrm{CV}=3.8$ \\
\hline RS-SSMD-OP-0091 & Large & 2 & V-4 & High & Mod. High & 3.8 & $\mathrm{~V}=4, \mathrm{BS}=\mathrm{H}, \mathrm{SV}=\mathrm{M}, \mathrm{CV}=3.8$ \\
\hline RS-SSMD-OP-0092 & Large & 13 & $\mathrm{~V}-1$ & High & Mod. High & 7.3 & $\mathrm{~V}=1, \mathrm{BS}=\mathrm{H}, \mathrm{SV}=\mathrm{M}, \mathrm{CV}=7.3$ \\
\hline RS-SSMD-OP-0093 & Large & 9 & $\mathrm{~V}-5$ & High & Mod. High & 7.3 & $\mathrm{~V}=5, \mathrm{BS}=\mathrm{H}, \mathrm{SV}=\mathrm{M}, \mathrm{CV}=7.3$ \\
\hline RS-SSMD-OP-0094 & Large & 12 & V-3 & High & Mod. High & 11.3 & $\mathrm{~V}=3, \mathrm{BS}=\mathrm{H}, \mathrm{SV}=\mathrm{M}, \mathrm{CV}=11.3$ \\
\hline RS-SSMD-OP-0095 & Large & 5 & $\mathrm{~V}-3$ & High & Mod. High & 11.3 & $\mathrm{~V}=3, \mathrm{BS}=\mathrm{H}, \mathrm{SV}=\mathrm{M}, \mathrm{CV}=11.3$ \\
\hline RS-SSMD-OP-0096 & Large & 22 & $\mathrm{~V}-3$ & Typical & Mod. High & 3.8 & $\mathrm{~V}=3, \mathrm{BS}=\mathrm{T}, \mathrm{SV}=\mathrm{M}, \mathrm{CV}=3.8$ \\
\hline RS-SSMD-OP-0097 & Large & 19 & $\mathrm{~V}-1$ & Typical & Mod. High & 7.3 & $\mathrm{~V}=1, \mathrm{BS}=\mathrm{T}, \mathrm{SV}=\mathrm{M}, \mathrm{CV}=7.3$ \\
\hline RS-SSMD-OP-0098 & Large & 7 & $\mathrm{~V}-5$ & Typical & Mod. High & 7.3 & $\mathrm{~V}=5, \mathrm{BS}=\mathrm{T}, \mathrm{SV}=\mathrm{M}, \mathrm{CV}=7.3$ \\
\hline RS-SSMD-OP-0099 & Large & 16 & V-3 & Typical & Mod. High & 11.3 & $\mathrm{~V}=3, \mathrm{BS}=\mathrm{T}, \mathrm{SV}=\mathrm{M}, \mathrm{CV}=11.3$ \\
\hline RS-SSMD-OP-0100 & Large & 4 & V-3 & Typical & Mod. High & 11.3 & $\mathrm{~V}=3, \mathrm{BS}=\mathrm{T}, \mathrm{SV}=\mathrm{M}, \mathrm{CV}=11.3$ \\
\hline RS-SSMD-OP-0101 & Large & 10 & $\mathrm{~V}-1$ & High & High & 11.3 & $\mathrm{~V}=1, \mathrm{BS}=\mathrm{H}, \mathrm{SV}=\mathrm{H}, \mathrm{CV}=11.3$ \\
\hline RS-SSMD-OP-0102 & Large & 15 & V-3 & High & High & 11.3 & $\mathrm{~V}=3, \mathrm{BS}=\mathrm{H}, \mathrm{SV}=\mathrm{H}, \mathrm{CV}=11.3$ \\
\hline RS-SSMD-OP-0103 & Large & 17 & $\mathrm{~V}-5$ & High & High & 11.3 & $\mathrm{~V}=5, \mathrm{BS}=\mathrm{H}, \mathrm{SV}=\mathrm{H}, \mathrm{CV}=11.3$ \\
\hline RS-SSMD-OP-0104 & Large & 18 & $\mathrm{~V}-2$ & High & High & 11.3 & $\mathrm{~V}=2, \mathrm{BS}=\mathrm{H}, \mathrm{SV}=\mathrm{H}, \mathrm{CV}=11.3$ \\
\hline RS-SSMD-OP-0105 & Large & 6 & V-4 & Typical & High & 11.3 & $\mathrm{~V}=4, \mathrm{BS}=\mathrm{T}, \mathrm{SV}=\mathrm{H}, \mathrm{CV}=11.3$ \\
\hline
\end{tabular}




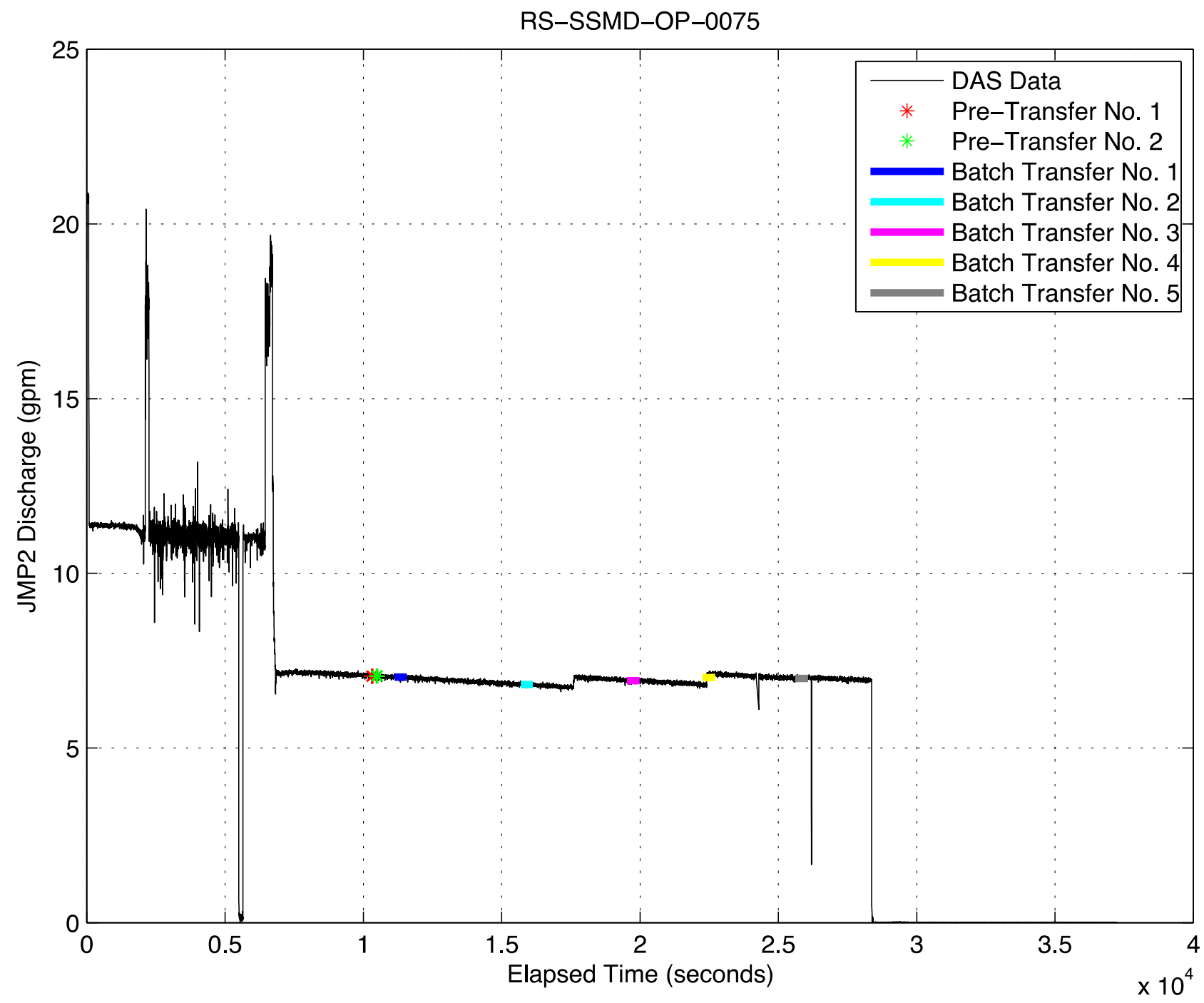

Figure A.1. RS-SSMD-OP-0075 [43-in., V=1, BS=H, $\mathrm{SV}=\mathrm{H}, \mathrm{CV}=11.3$ ] 


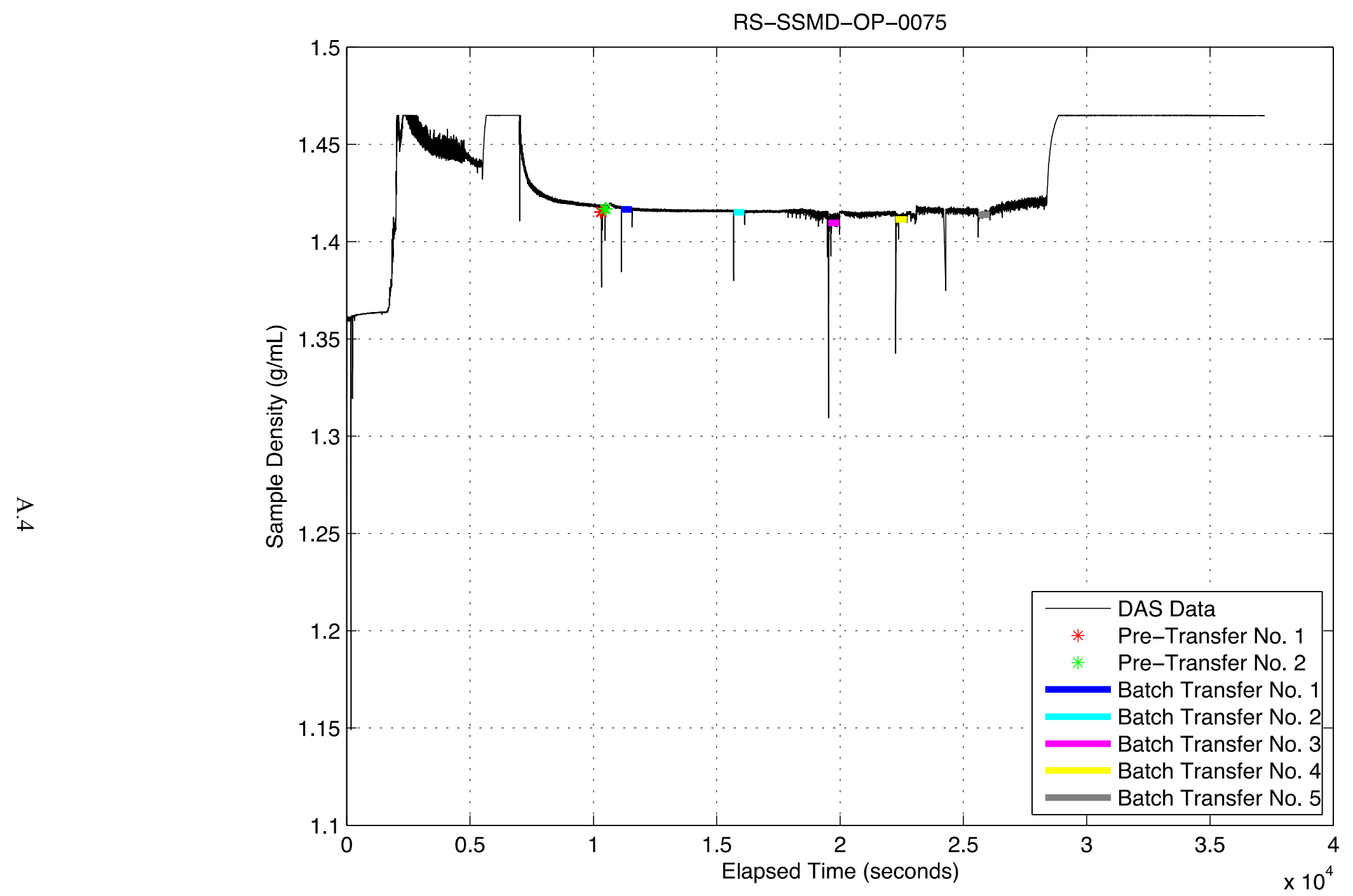

Figure A.2. RS-SSMD-OP-0075 [43-in., V=1, BS=H, SV=H, CV=11.3] 


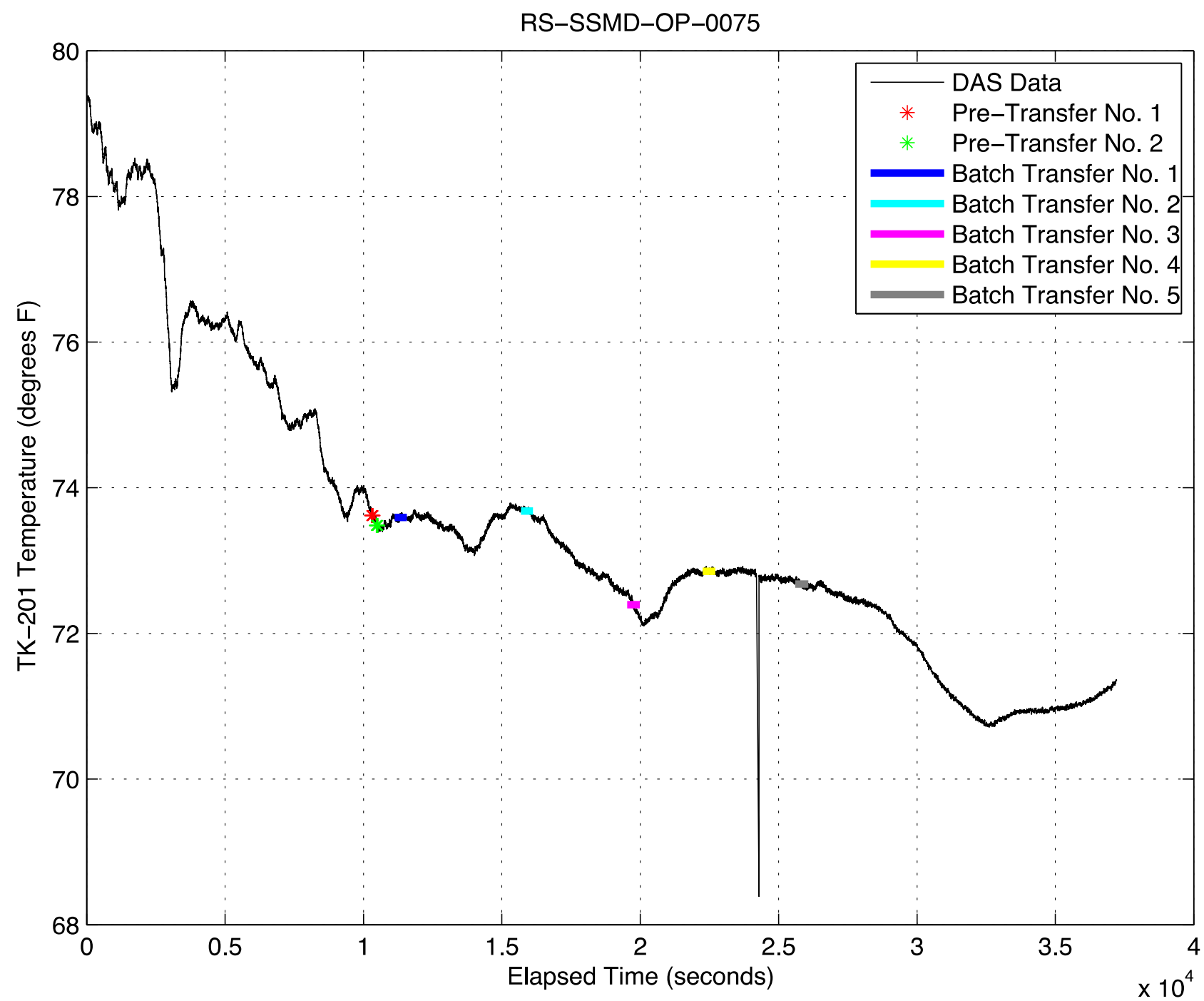

Figure A.3. RS-SSMD-OP-0075 [43-in., V=1, BS=H, SV=H, CV=11.3] 


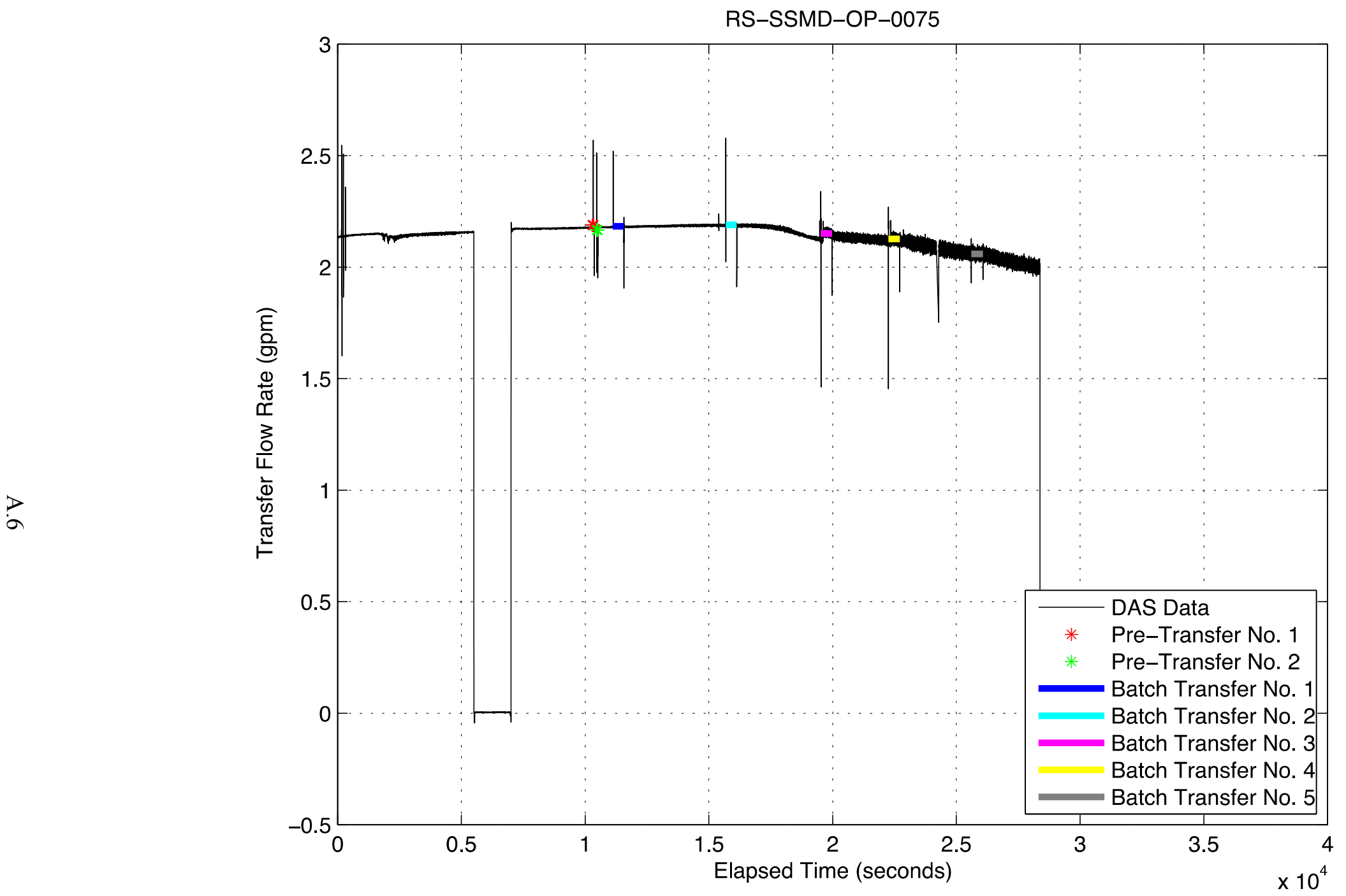

Figure A.4. RS-SSMD-OP-0075 [43-in., V=1, BS=H, SV=H, CV=11.3] 
RS-SSMD-OP-0075

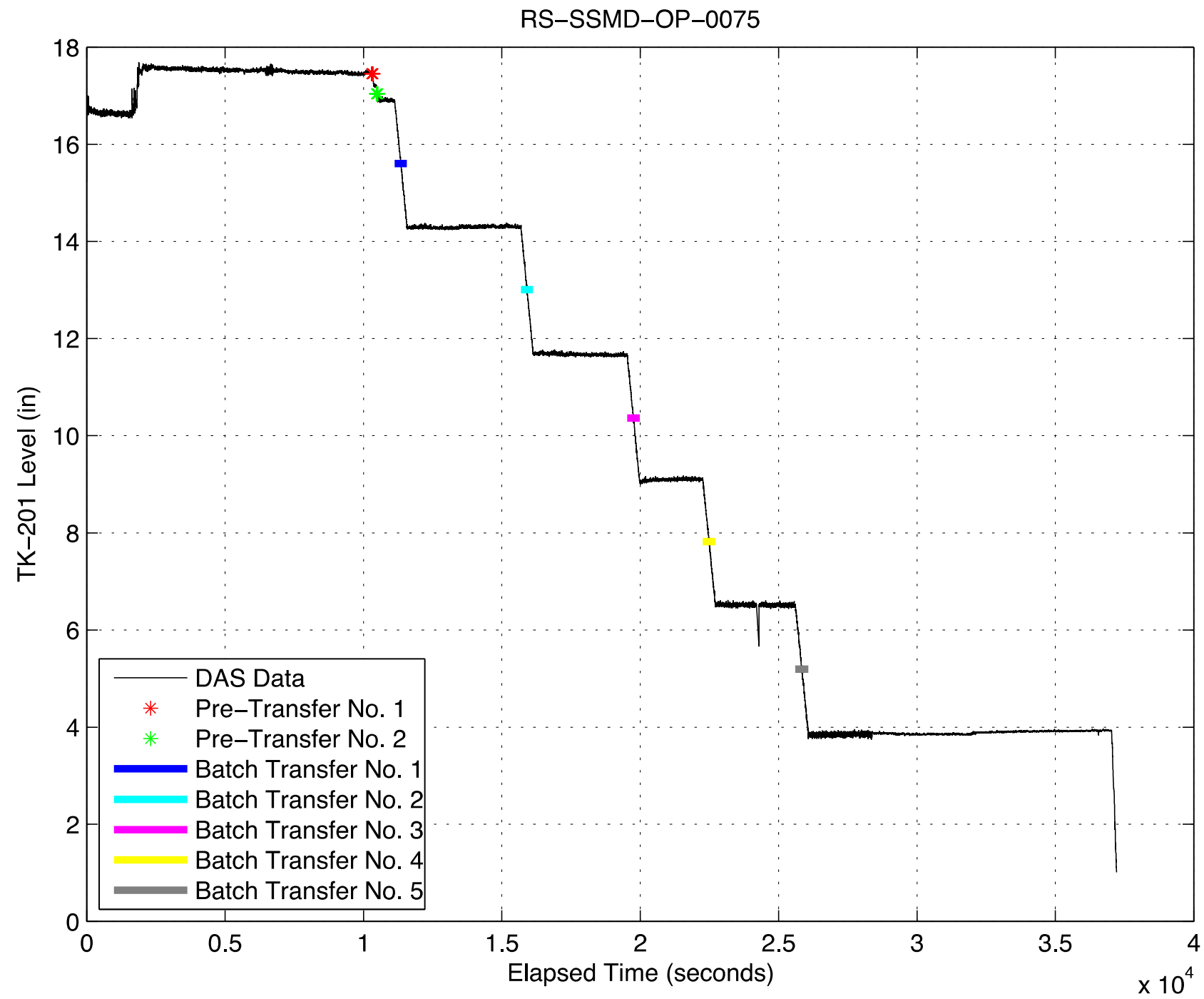

Figure A.5. RS-SSMD-OP-0075 [43-in., $\mathrm{V}=1, \mathrm{BS}=\mathrm{H}, \mathrm{SV}=\mathrm{H}, \mathrm{CV}=11.3$ ] 
RS-SSMD-OP-0076

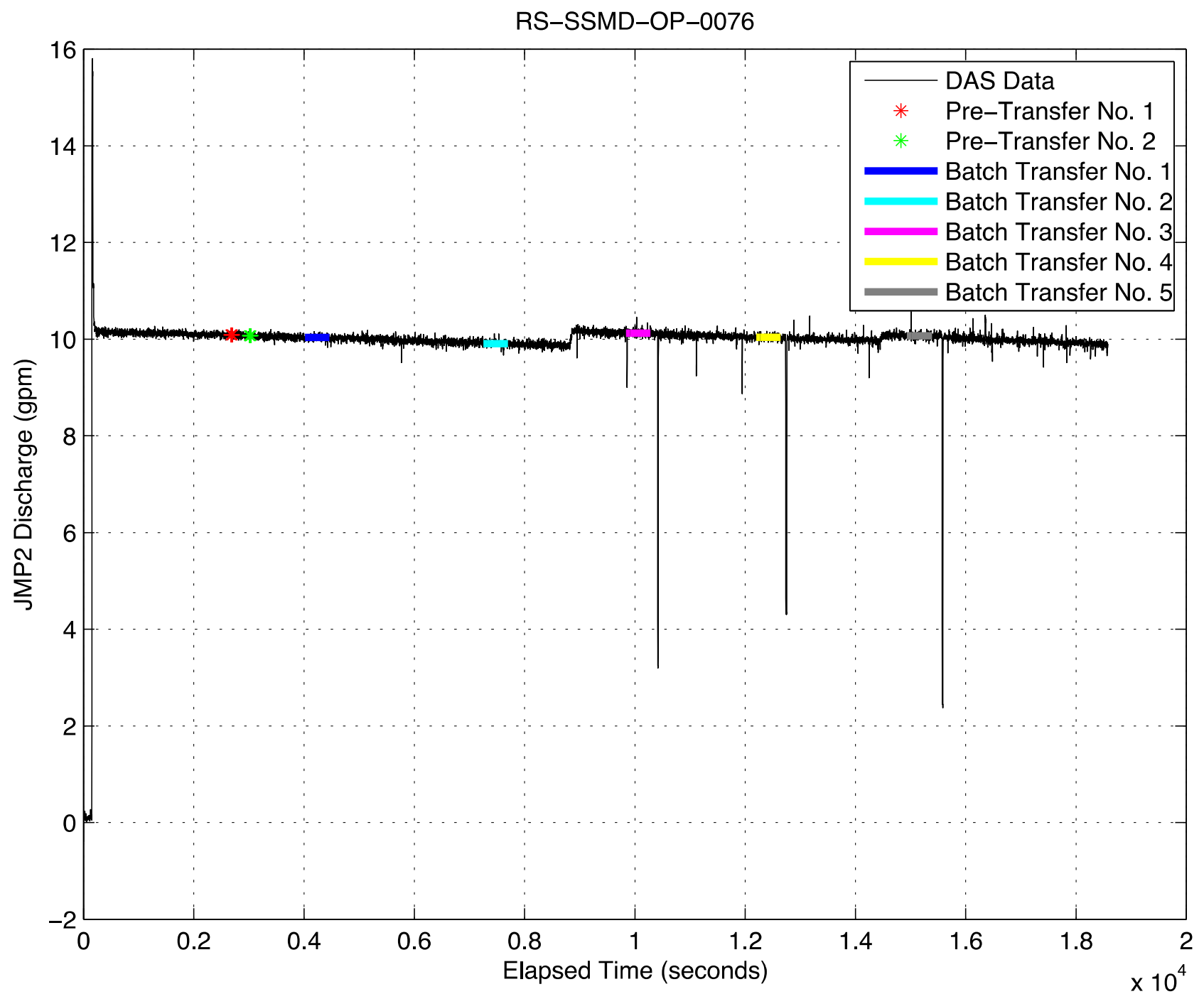

Figure A.6. RS-SSMD-OP-0076 [43-in., V=3, $B S=H, S V=H, C V=11.3]$ 


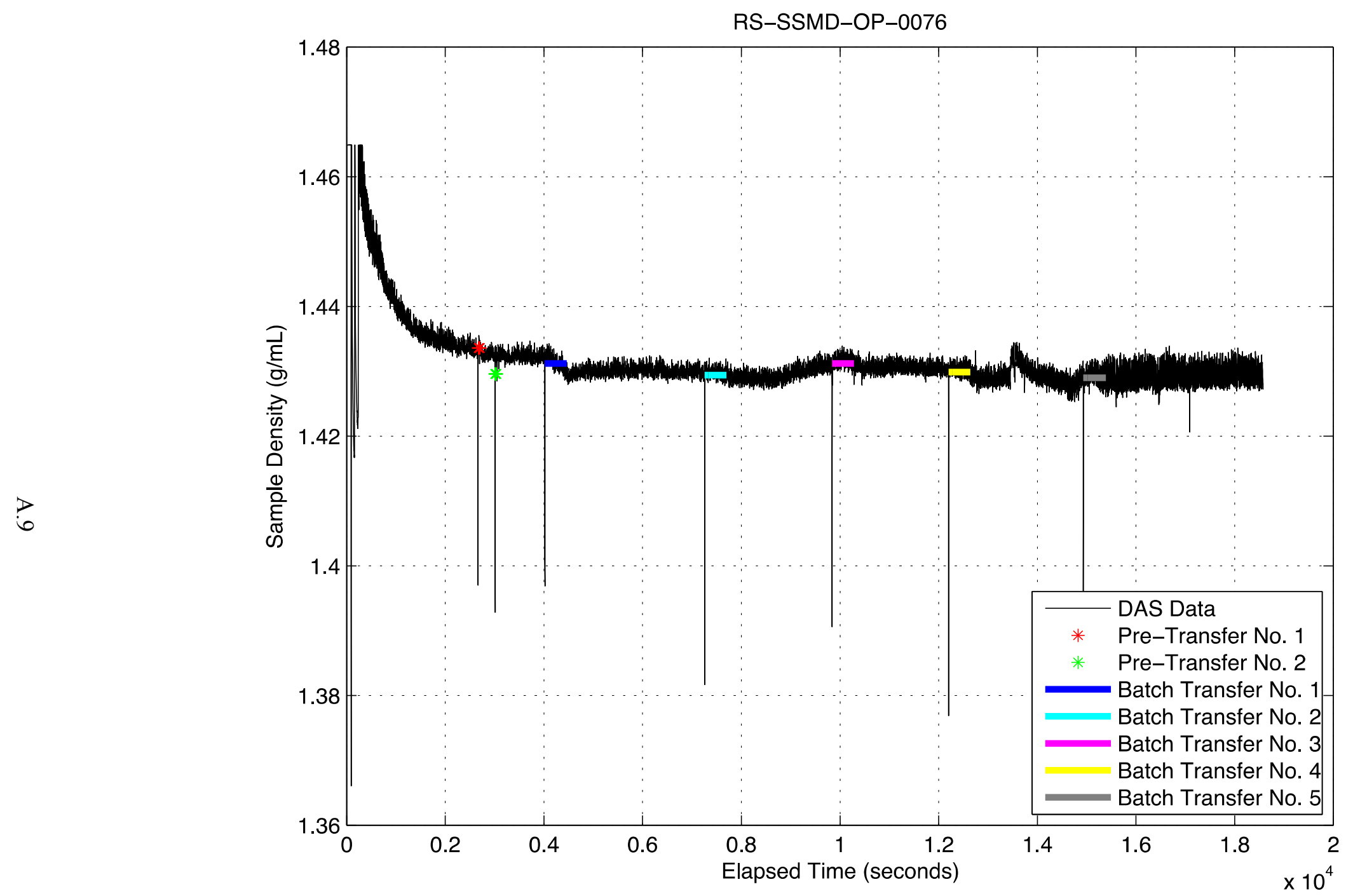

Figure A.7. RS-SSMD-OP-0076 [43-in., V=3, BS=H, SV=H, CV=11.3] 


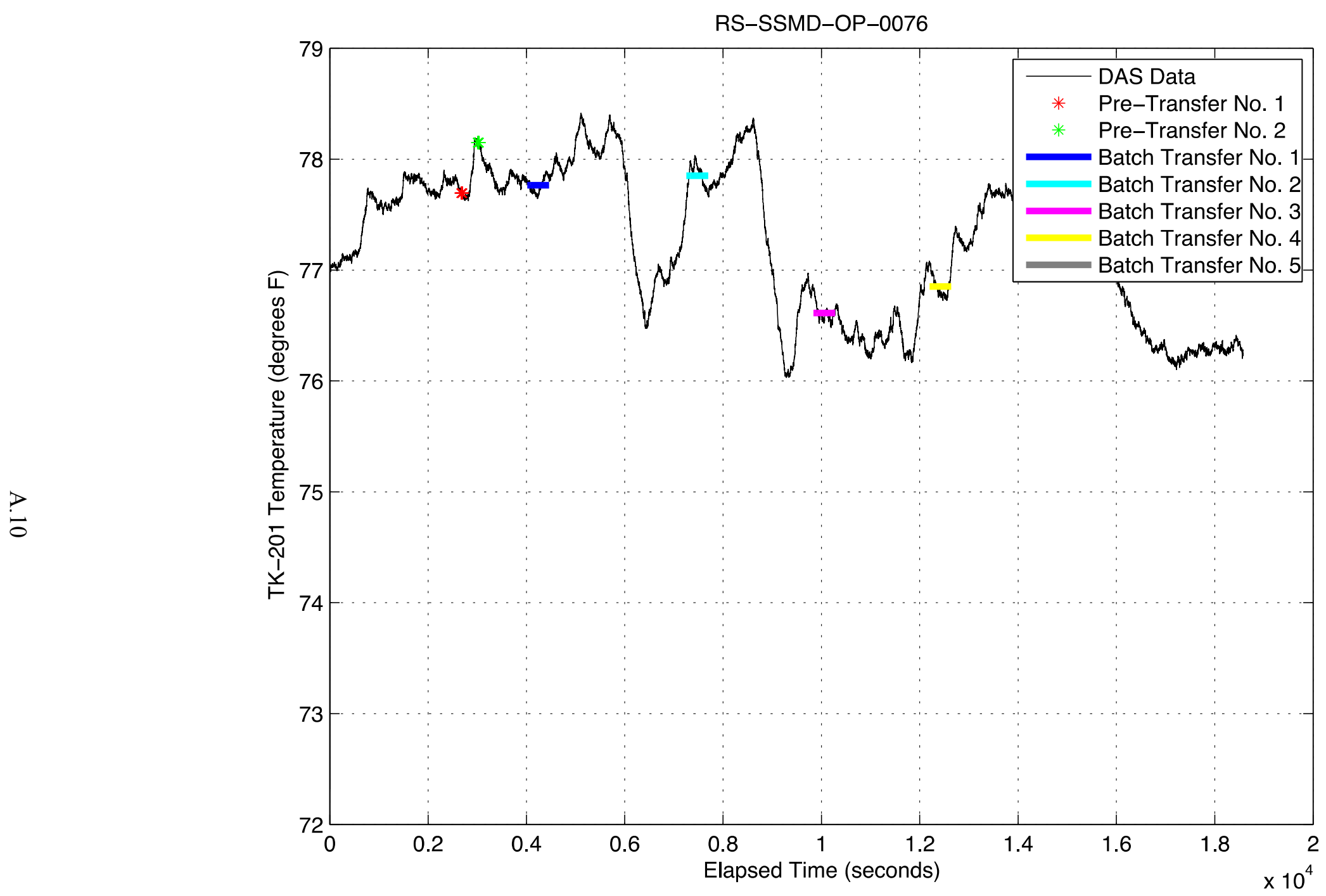

Figure A.8. RS-SSMD-OP-0076 [43-in., V=3, $B S=H, S V=H, C V=11.3]$ 


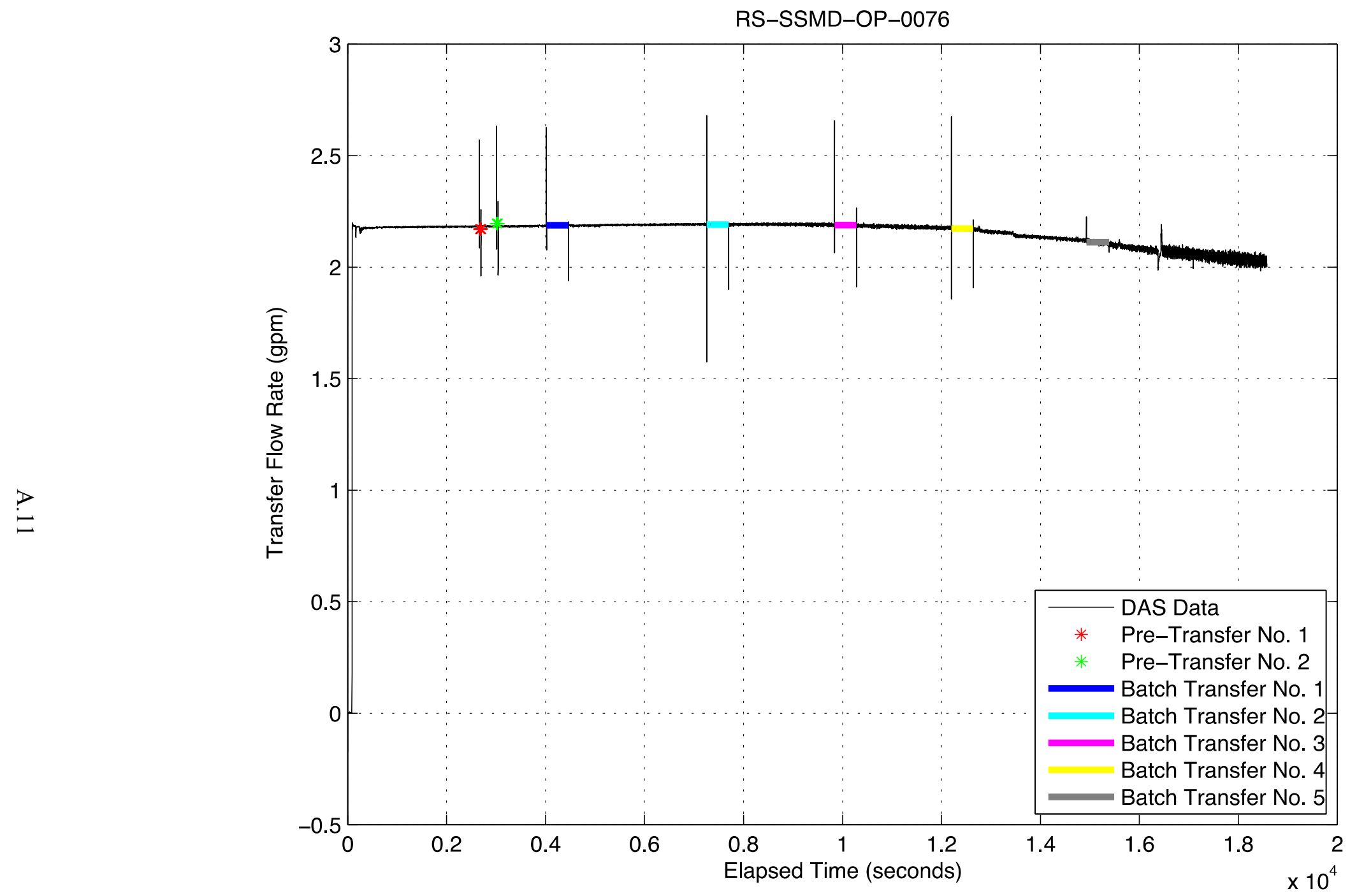

Figure A.9. RS-SSMD-OP-0076 [43-in., V=3, BS=H, SV=H, CV=11.3] 


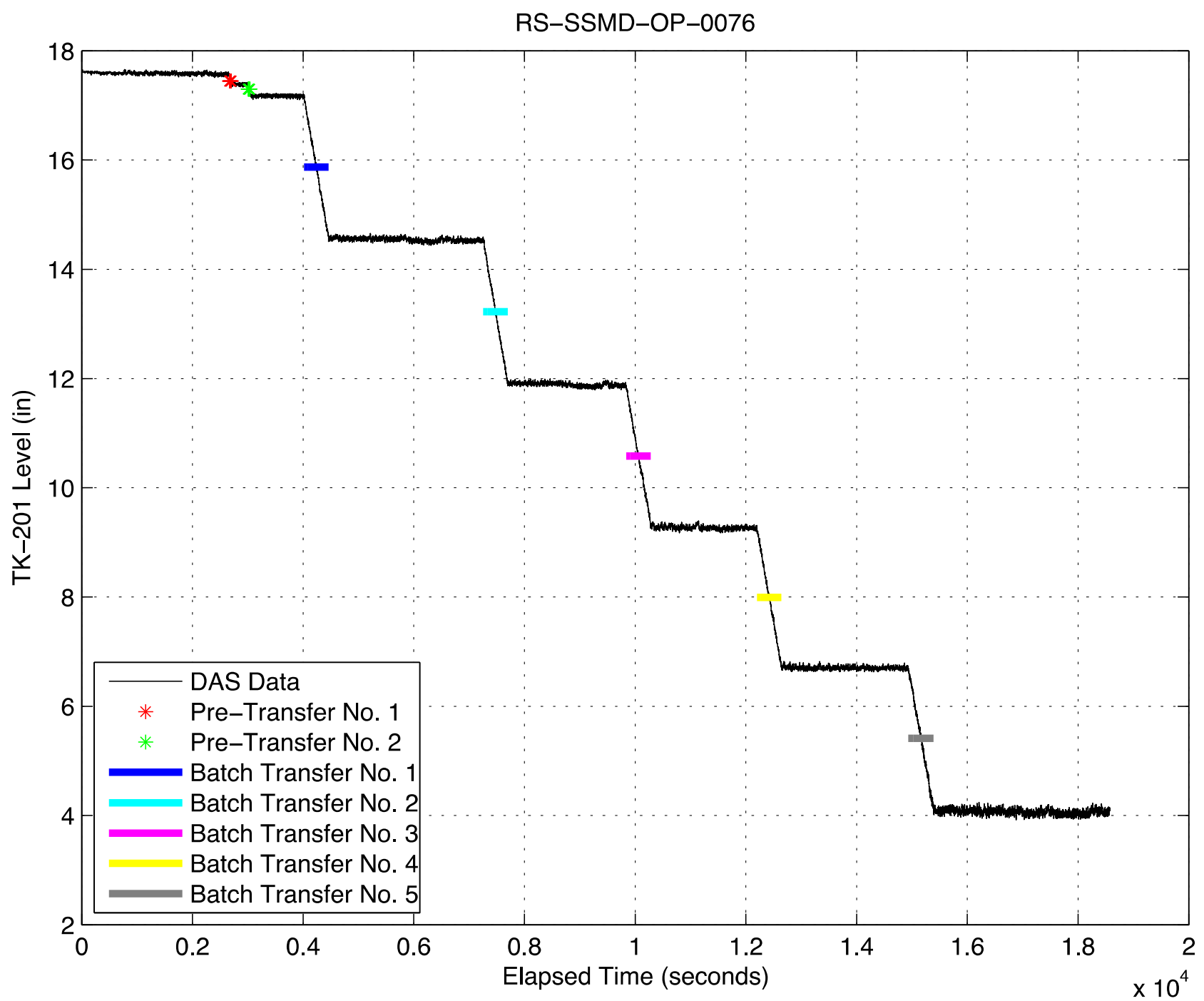

Figure A.10. RS-SSMD-OP-0076 [43-in., $\mathrm{V}=3, \mathrm{BS}=\mathrm{H}, \mathrm{SV}=\mathrm{H}, \mathrm{CV}=11.3$ ] 


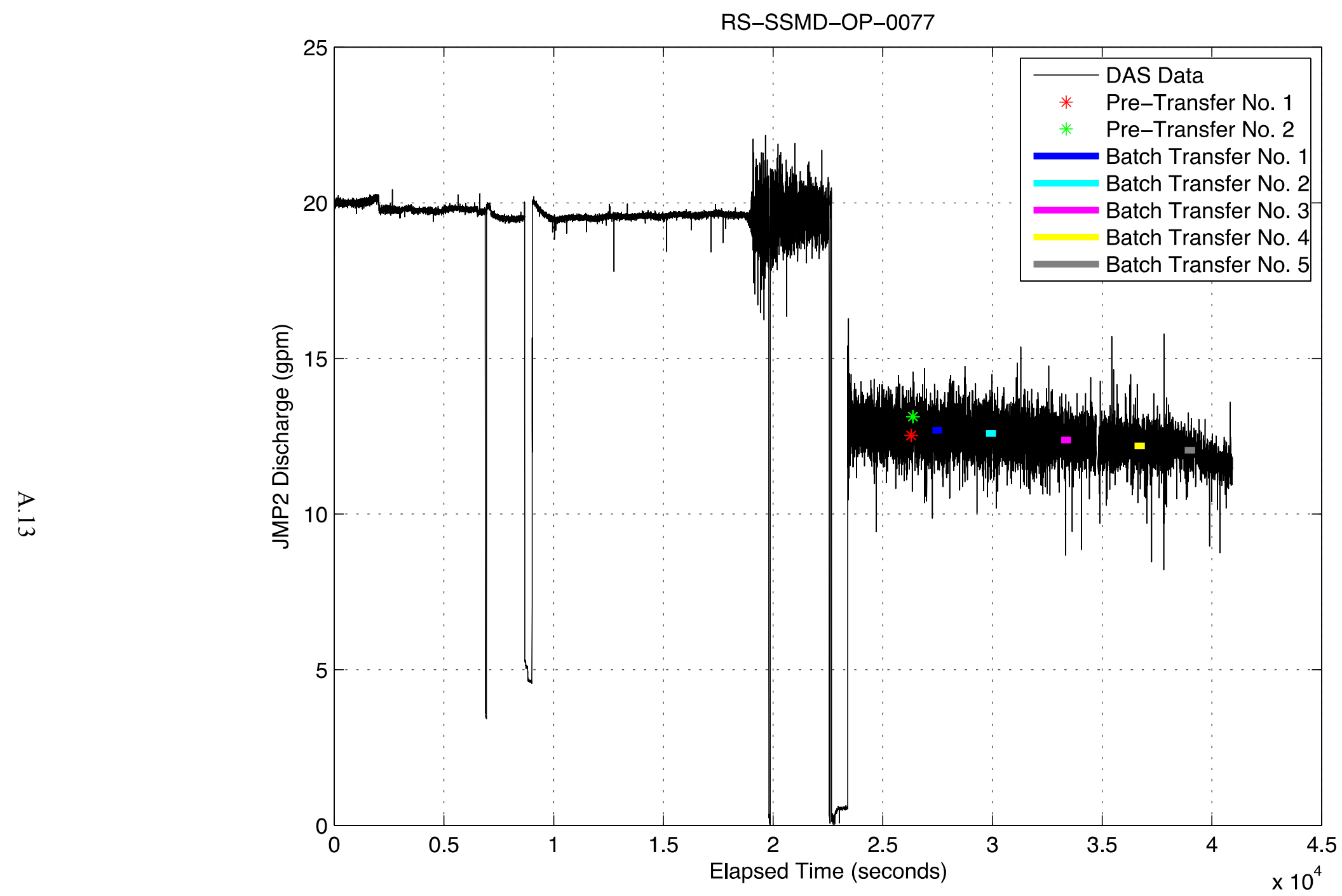

Figure A.11. RS-SSMD-OP-0077 [43-in., V=5, BS=H, SV=H, CV=11.3] 


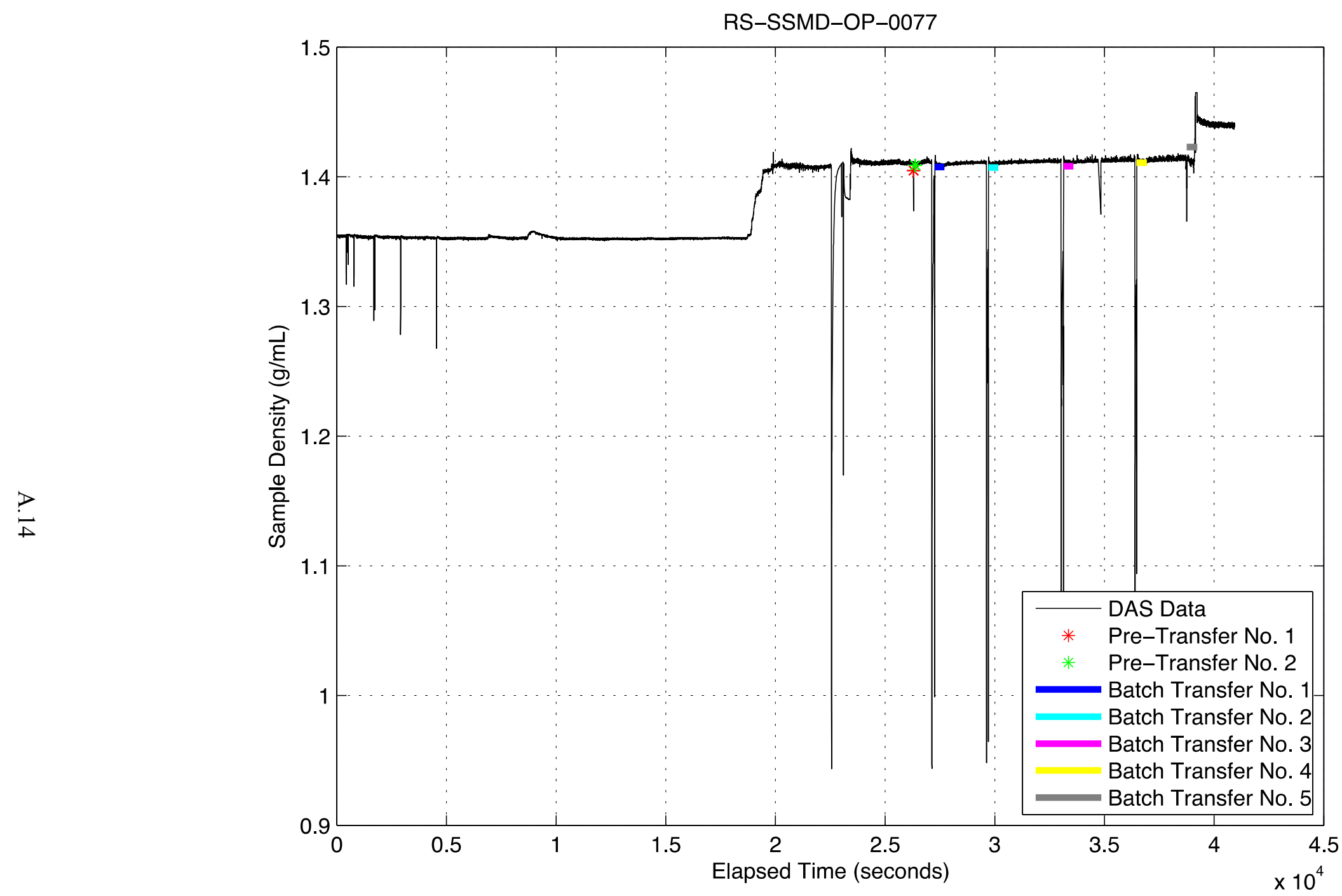

Figure A.12. RS-SSMD-OP-0077 [43-in., V=5, BS=H, SV=H, CV=11.3] 


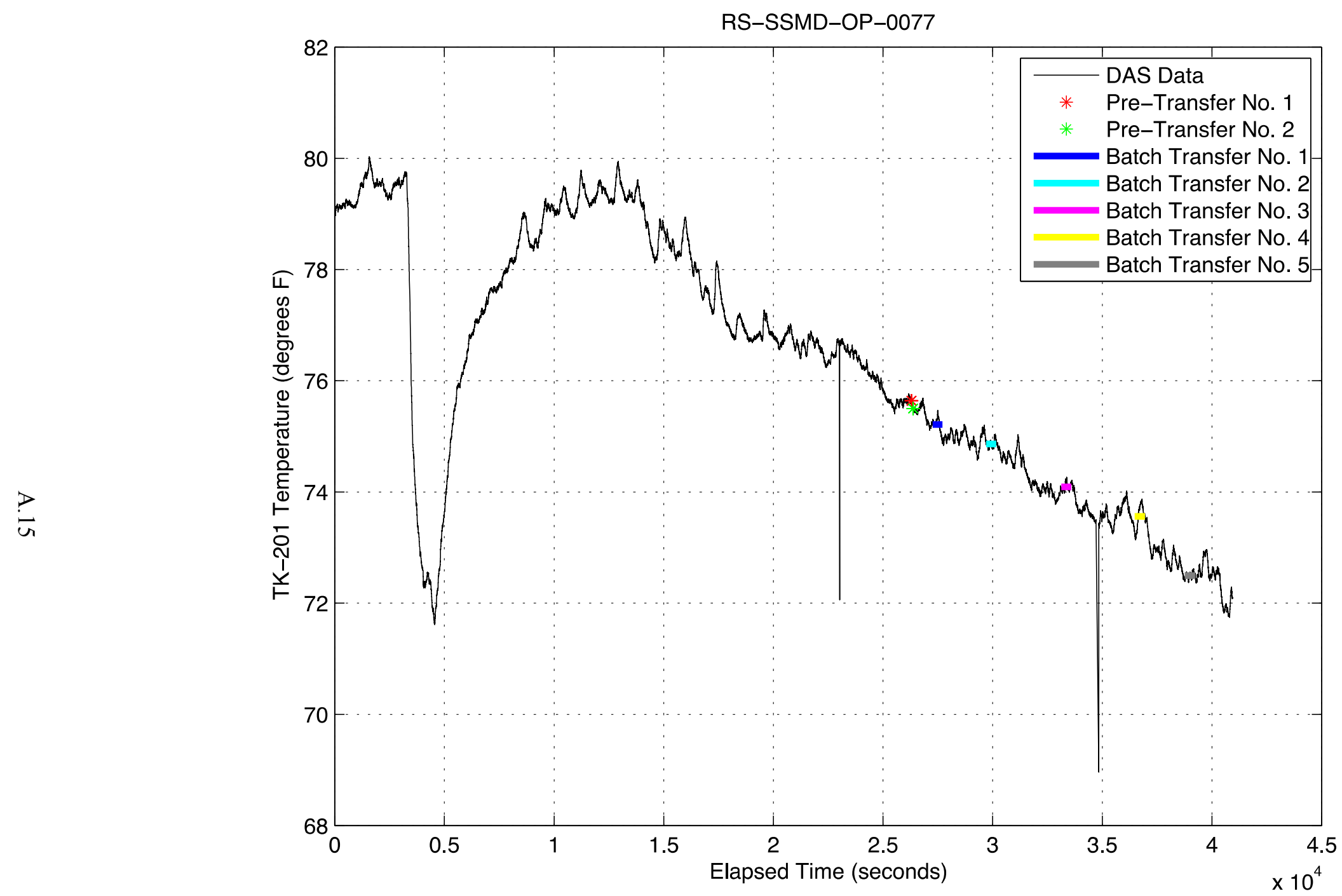

Figure A.13. RS-SSMD-OP-0077 [43-in., V=5, BS=H, SV=H, CV=11.3] 


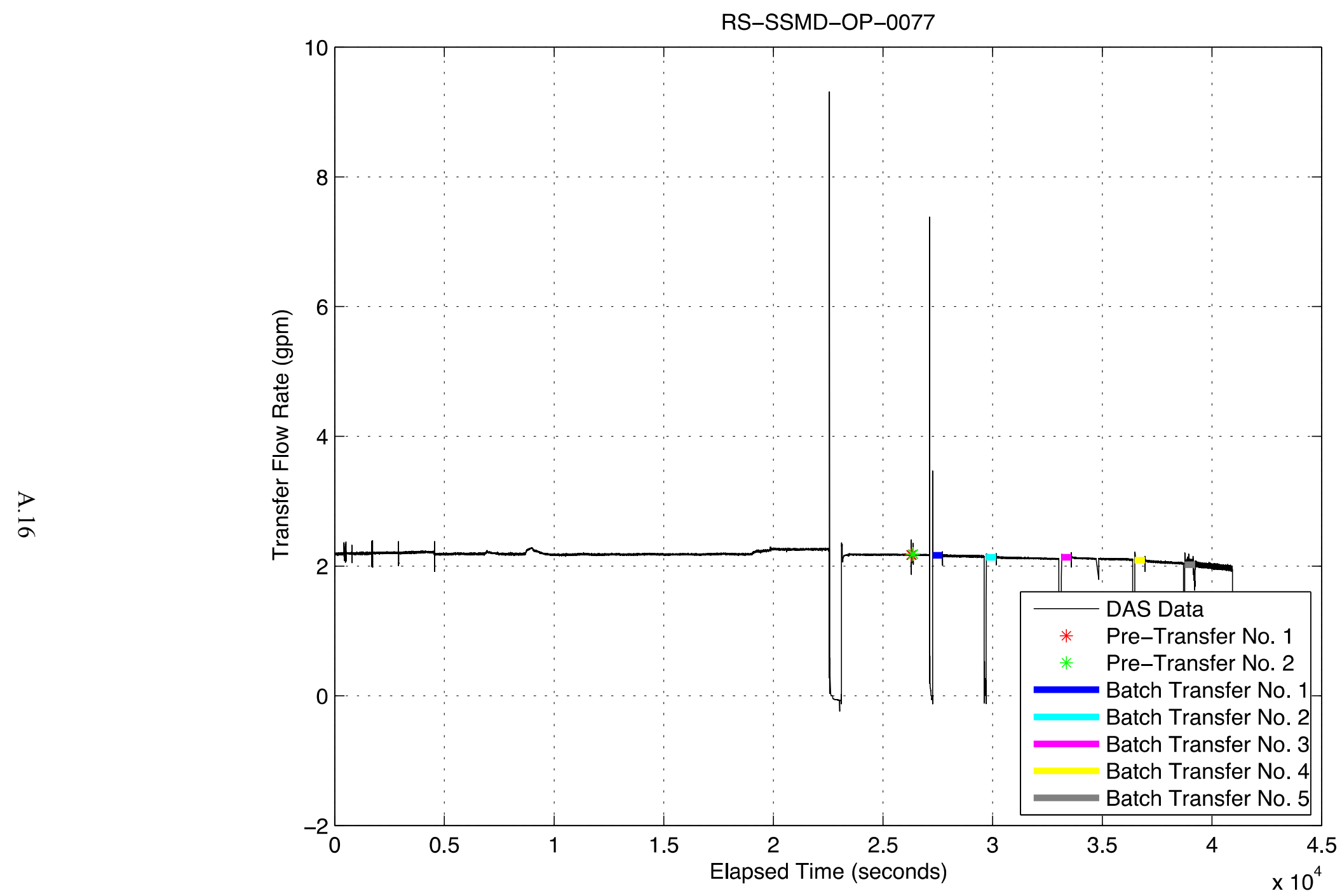

Figure A.14. RS-SSMD-OP-0077 [43-in., V=5, BS=H, SV=H, CV=11.3] 


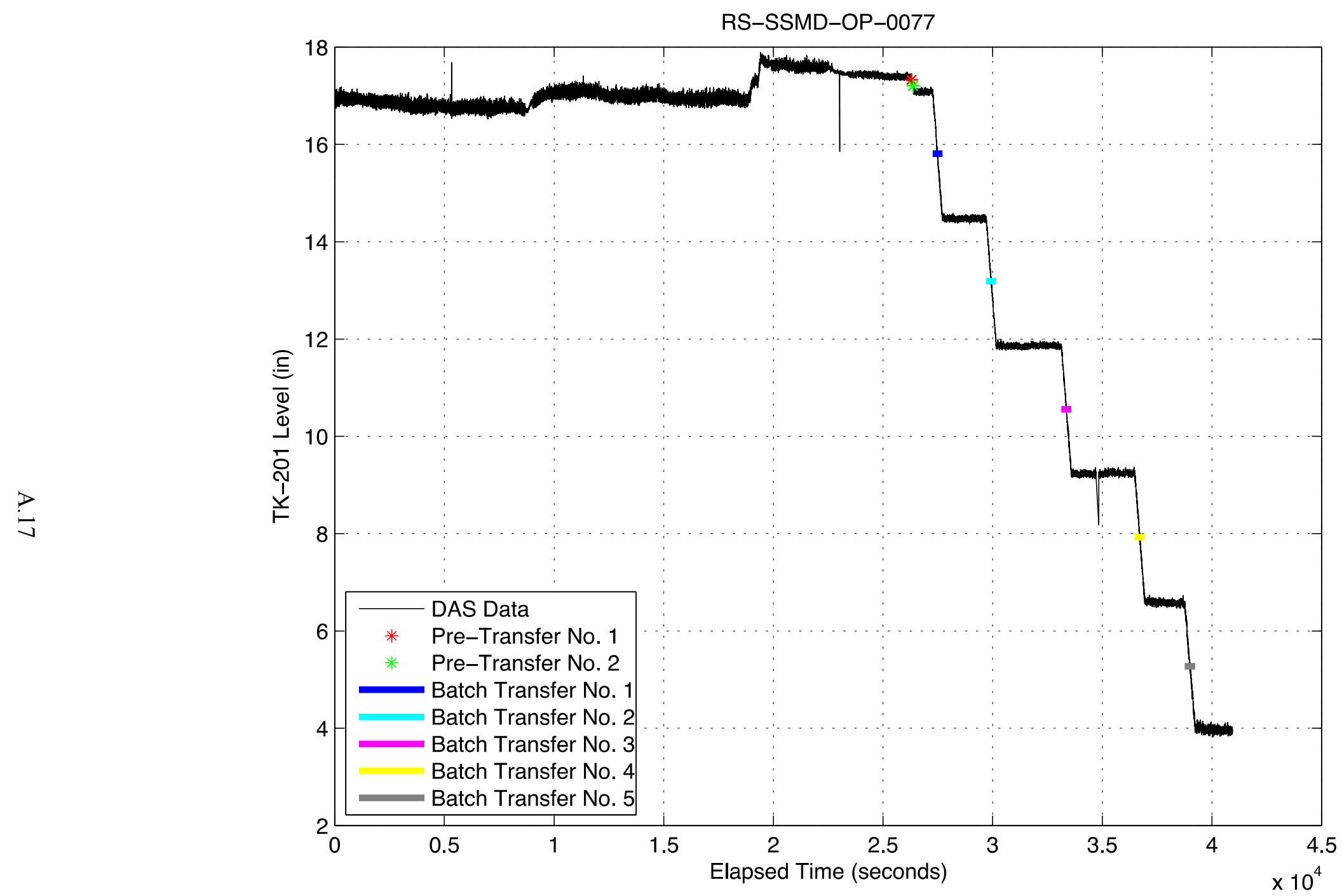

Figure A.15. RS-SSMD-OP-0077 [43-in., V=5, BS=H, SV=H, CV=11.3] 
RS-SSMD-OP-0078

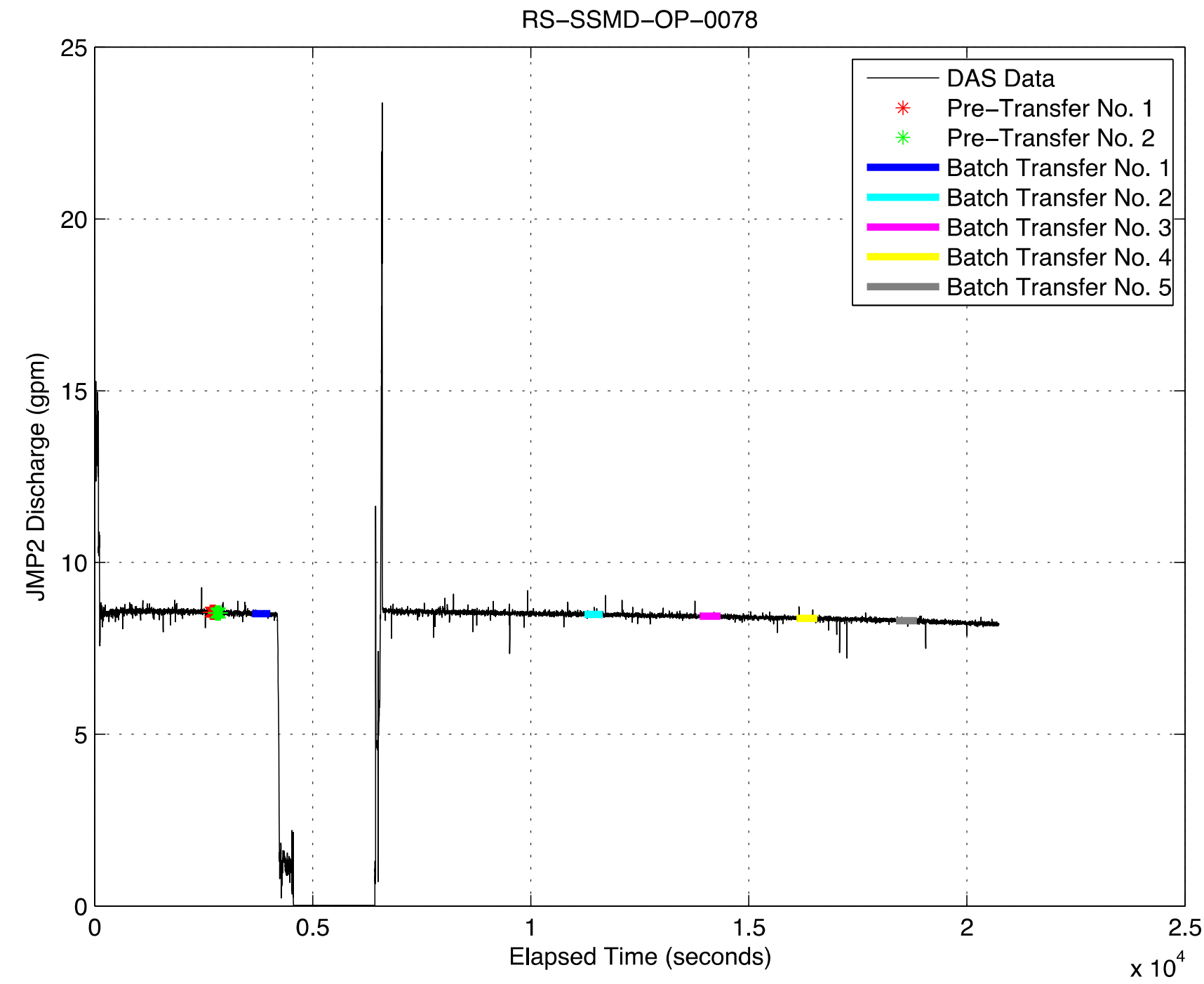

Figure A.16. RS-SSMD-OP-0078 [43-in., $\mathrm{V}=2$, $\mathrm{BS}=\mathrm{H}, \mathrm{SV}=\mathrm{H}, \mathrm{CV}=11.3]$ 


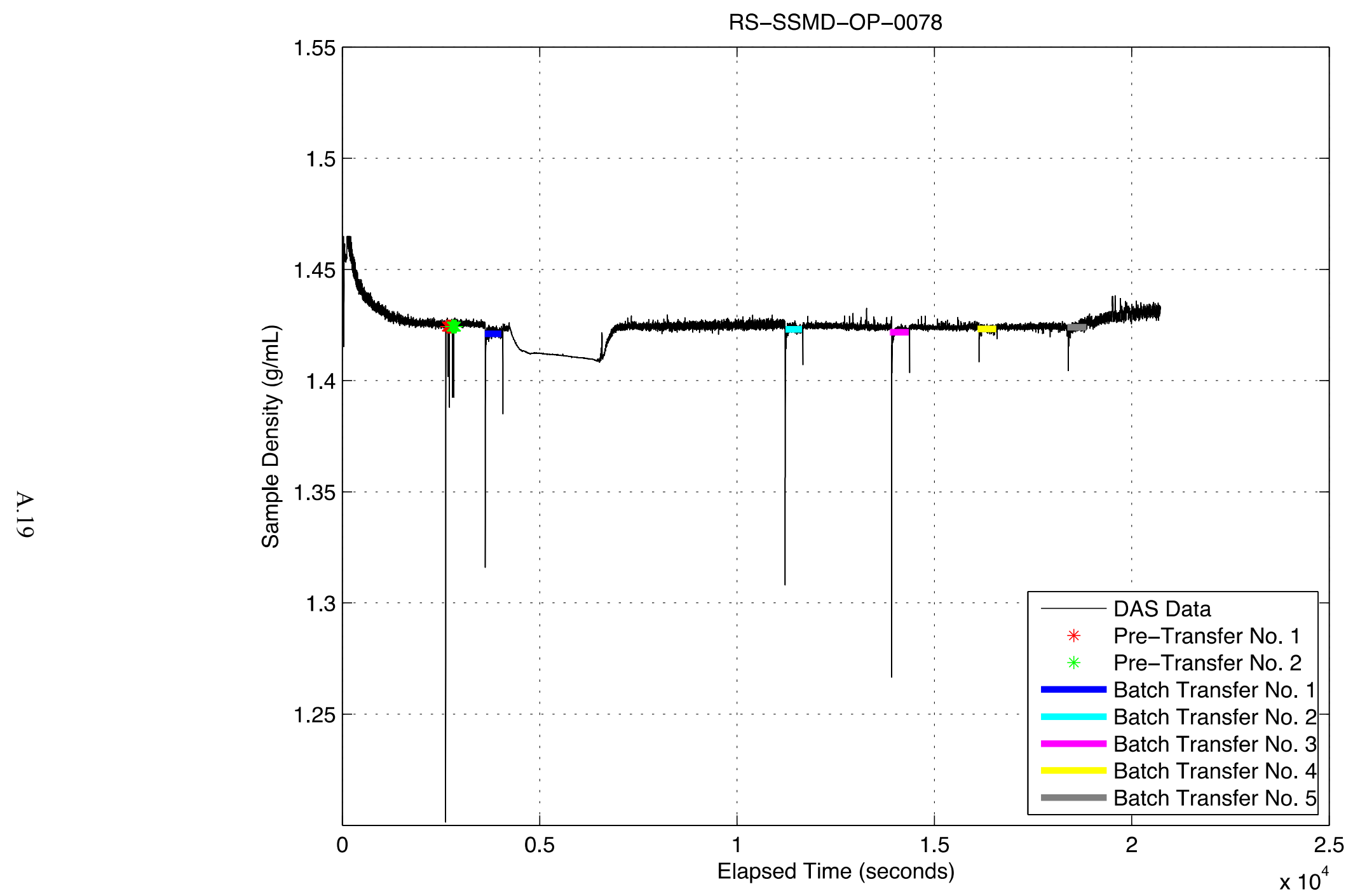

Figure A.17. RS-SSMD-OP-0078 [43-in., V=2, BS=H, SV=H, CV=11.3] 


\section{RS-SSMD-OP-0078}

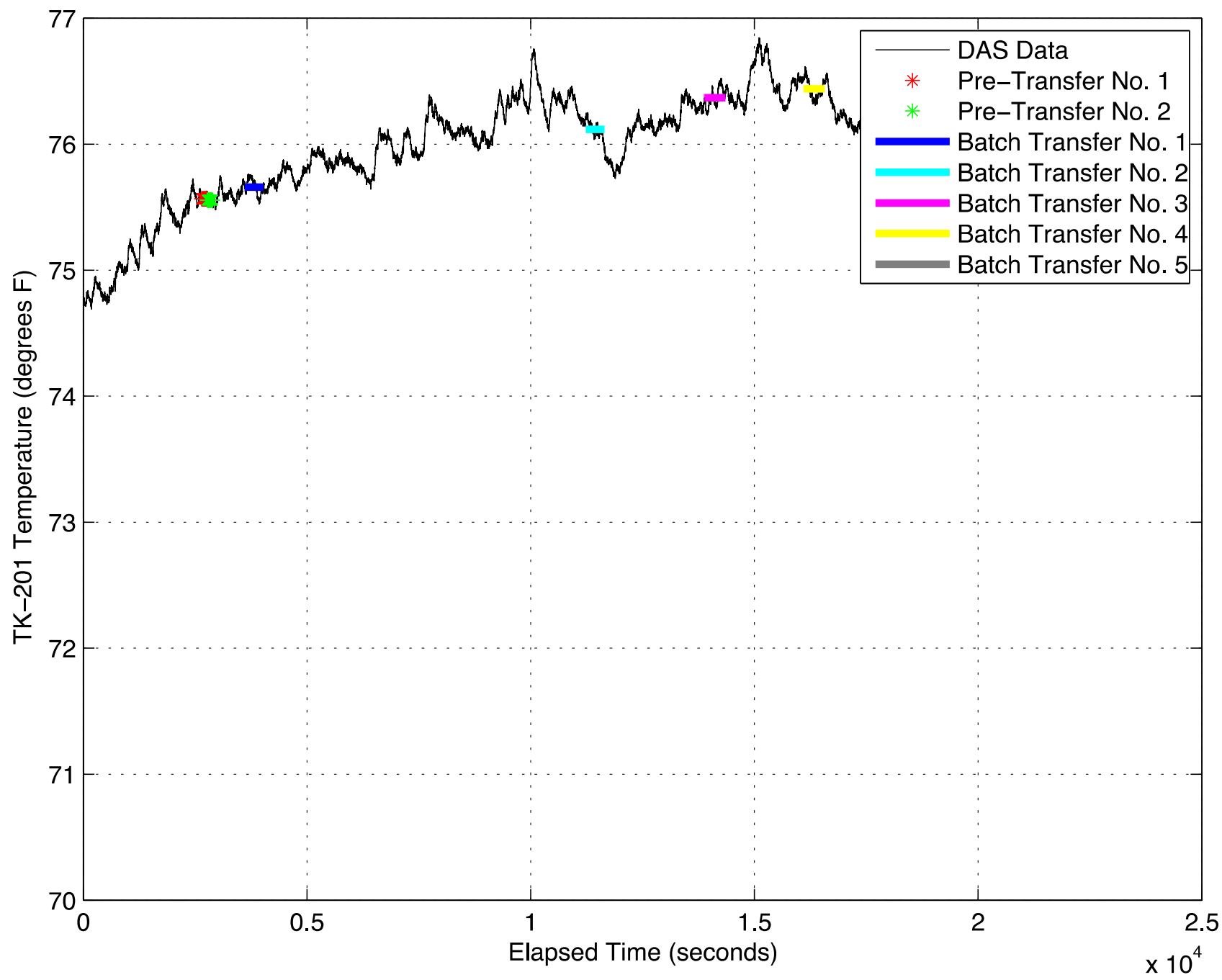

Figure A.18. RS-SSMD-OP-0078 [43-in., $\mathrm{V}=2$, $\mathrm{BS}=\mathrm{H}, \mathrm{SV}=\mathrm{H}, \mathrm{CV}=11.3]$ 


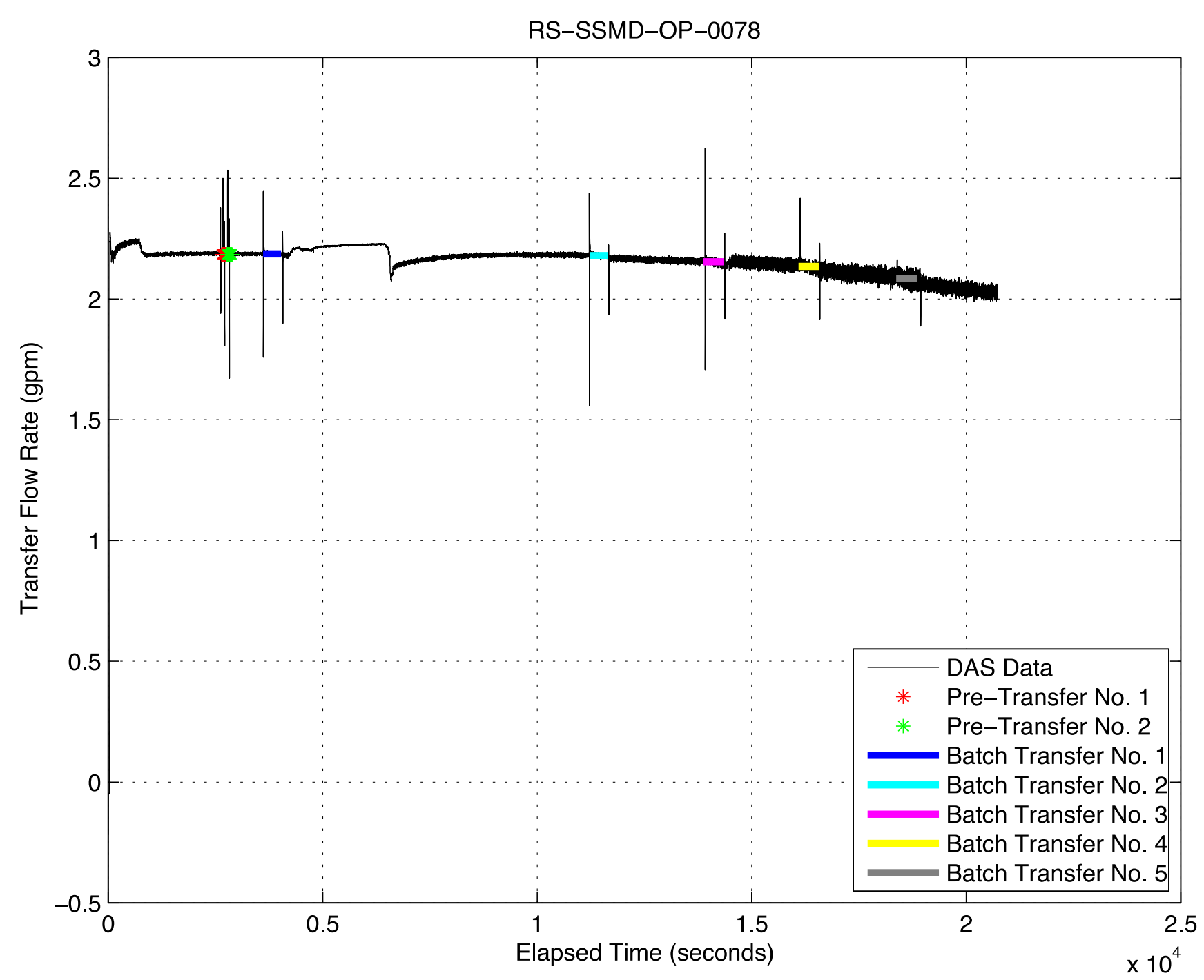

Figure A.19. RS-SSMD-OP-0078 [43-in., V=2, BS=H, SV=H, CV=11.3] 


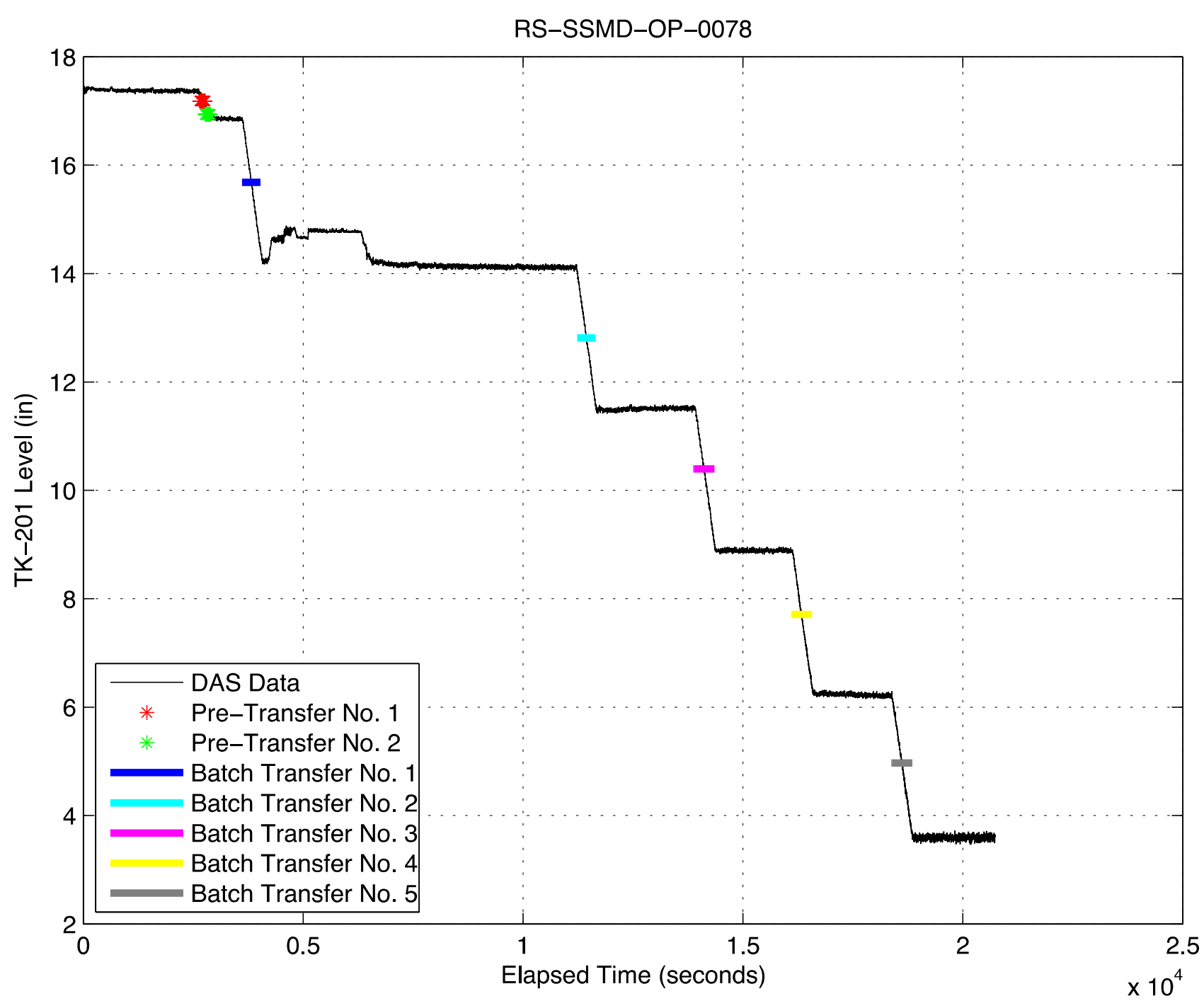

Figure A.20. RS-SSMD-OP-0078 [43-in., V=2, BS=H, SV=H, CV=11.3] 


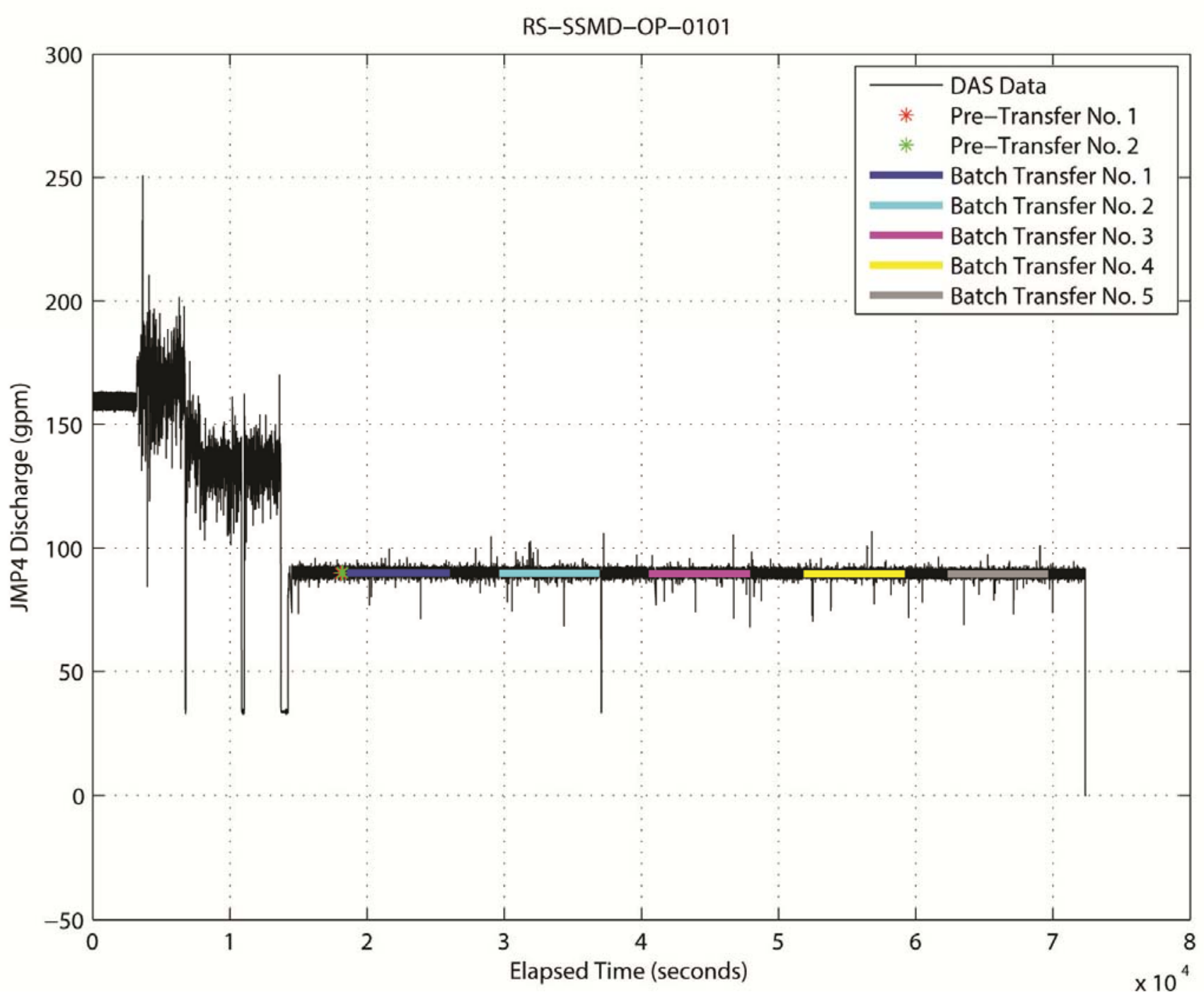

Figure A.21. RS-SSMD-OP-0101 [120-in., V=1, BS=H, SV=H, CV=11.3] 


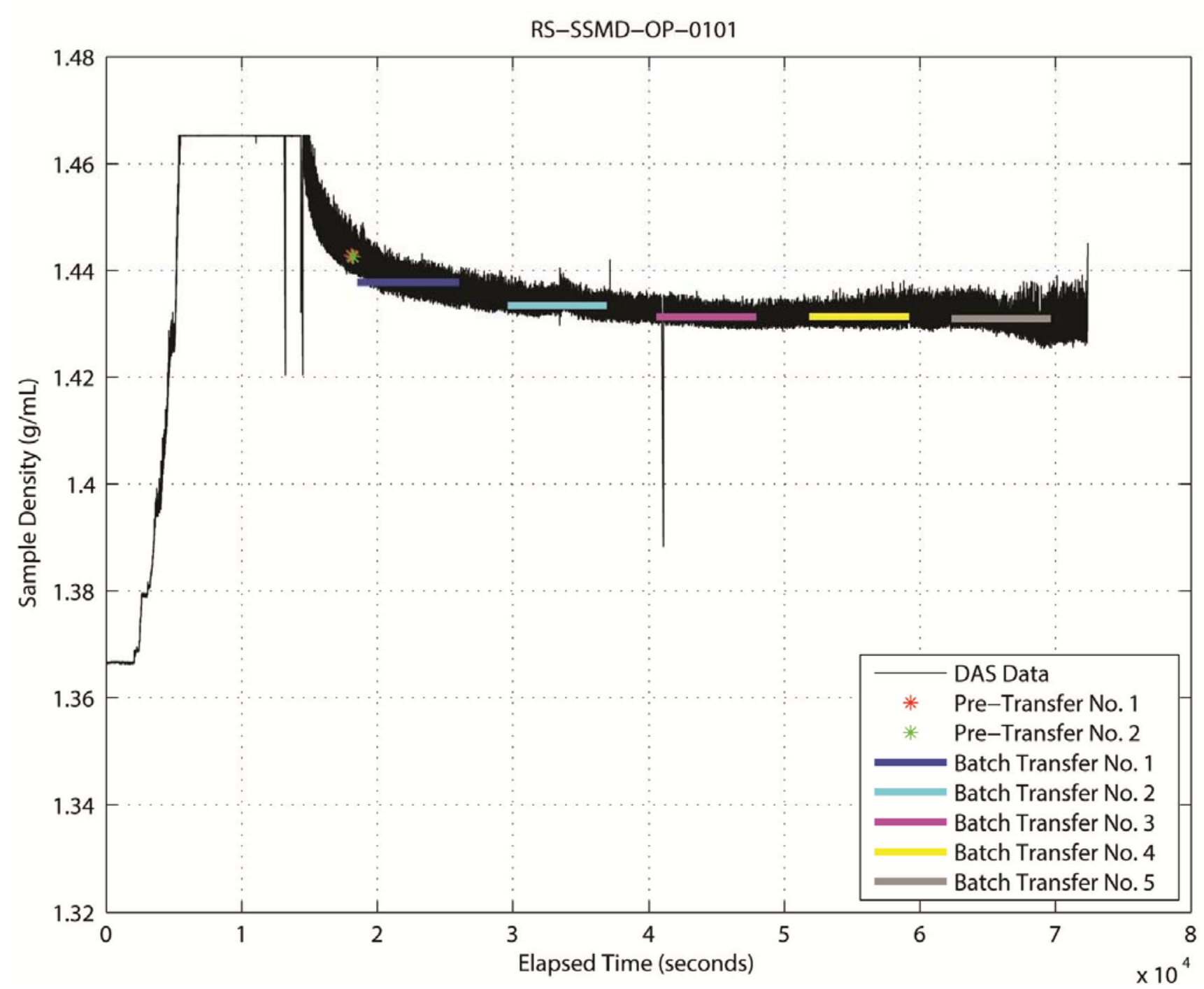

Figure A.22. RS-SSMD-OP-0101 [120-in., $\mathrm{V}=1, \mathrm{BS}=\mathrm{H}, \mathrm{SV}=\mathrm{H}, \mathrm{CV}=11.3$ ] 


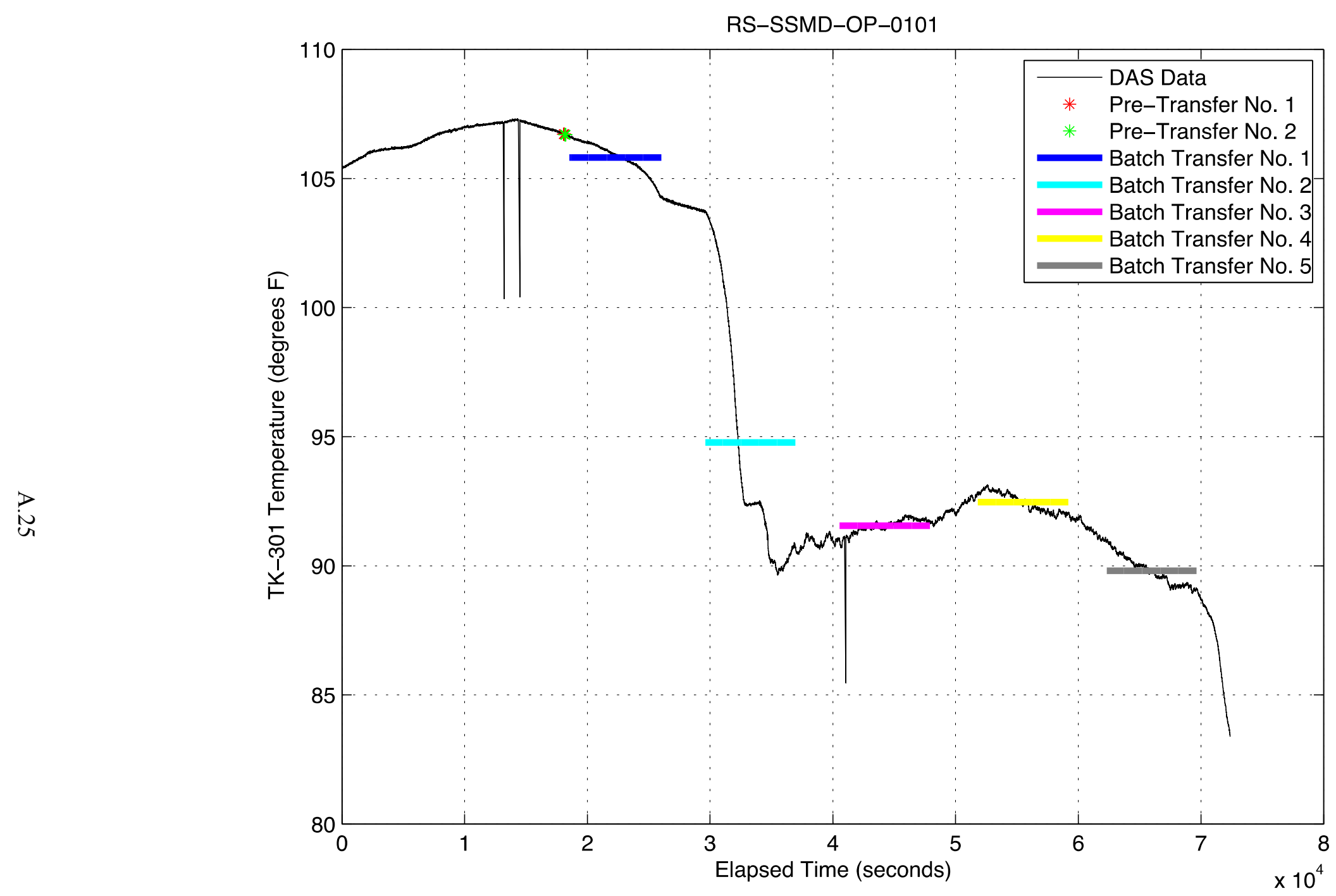

Figure A.23. RS-SSMD-OP-0101 [120-in., V=1, BS=H, SV=H, CV=11.3] 
RS-SSMD-OP-0101

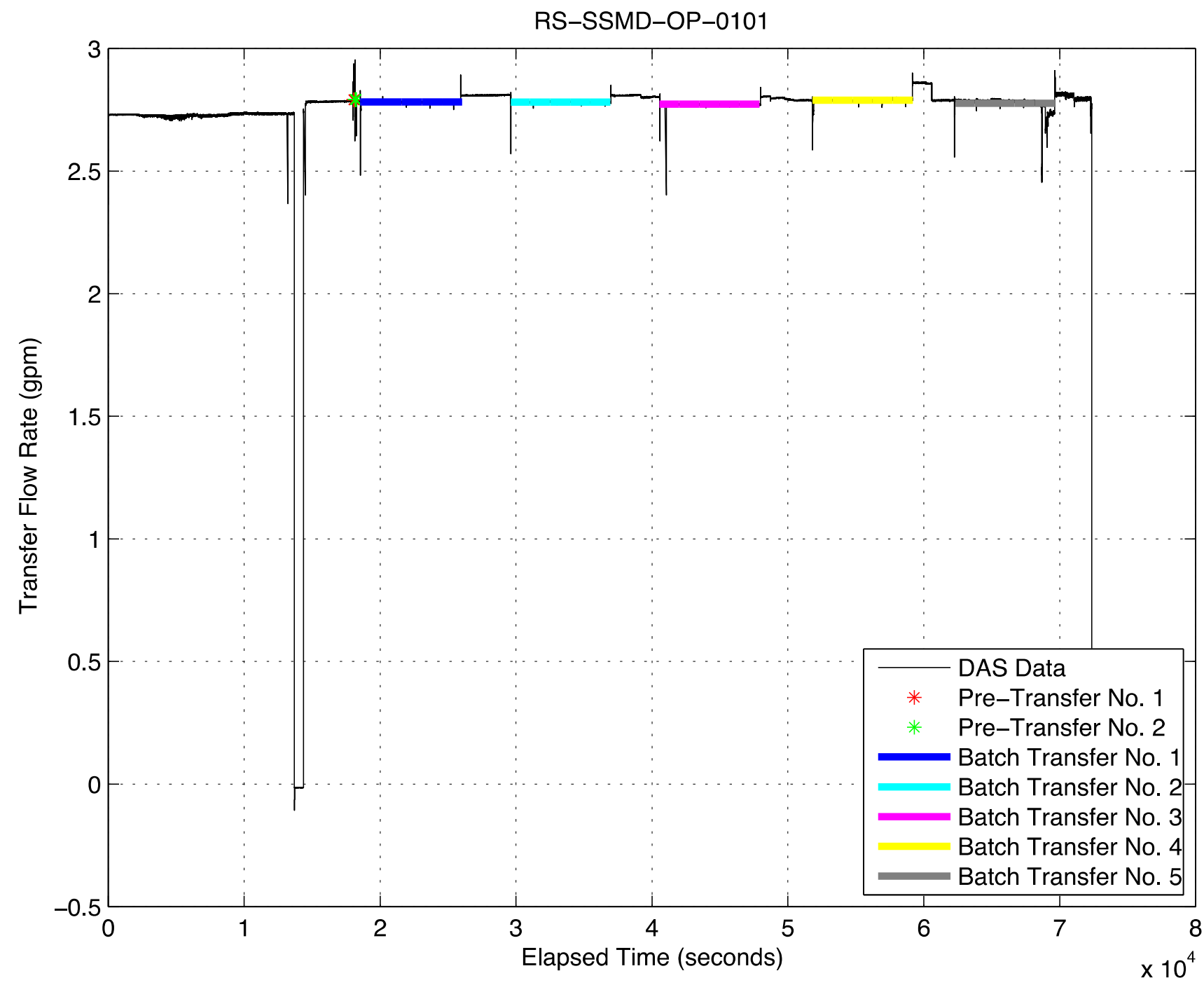

Figure A.24. RS-SSMD-OP-0101 [120-in., $V=1, B S=H, S V=H, C V=11.3]$ 


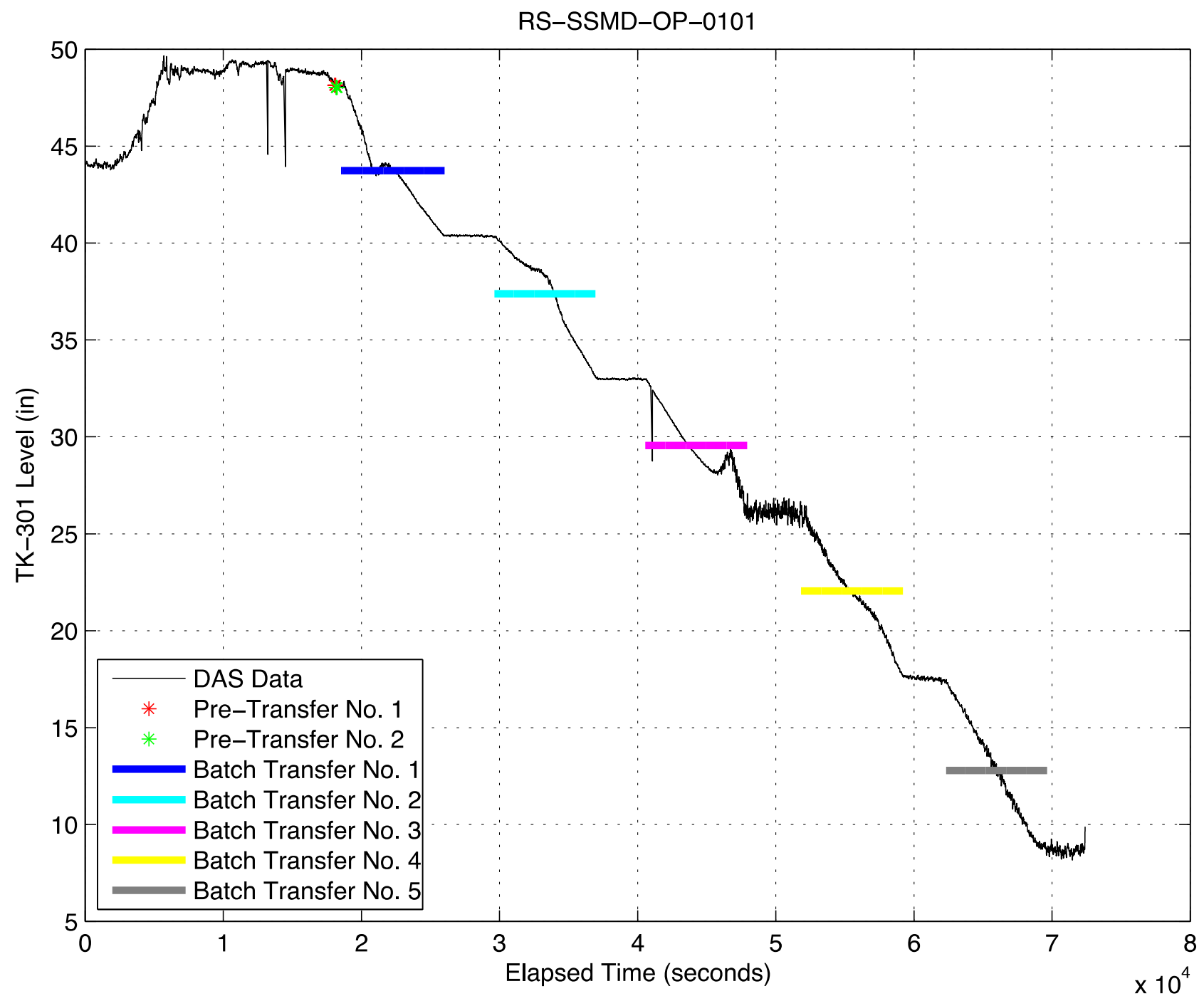

Figure A.25. RS-SSMD-OP-0101 [120-in., V=1, BS=H, SV=H, CV=11.3] 


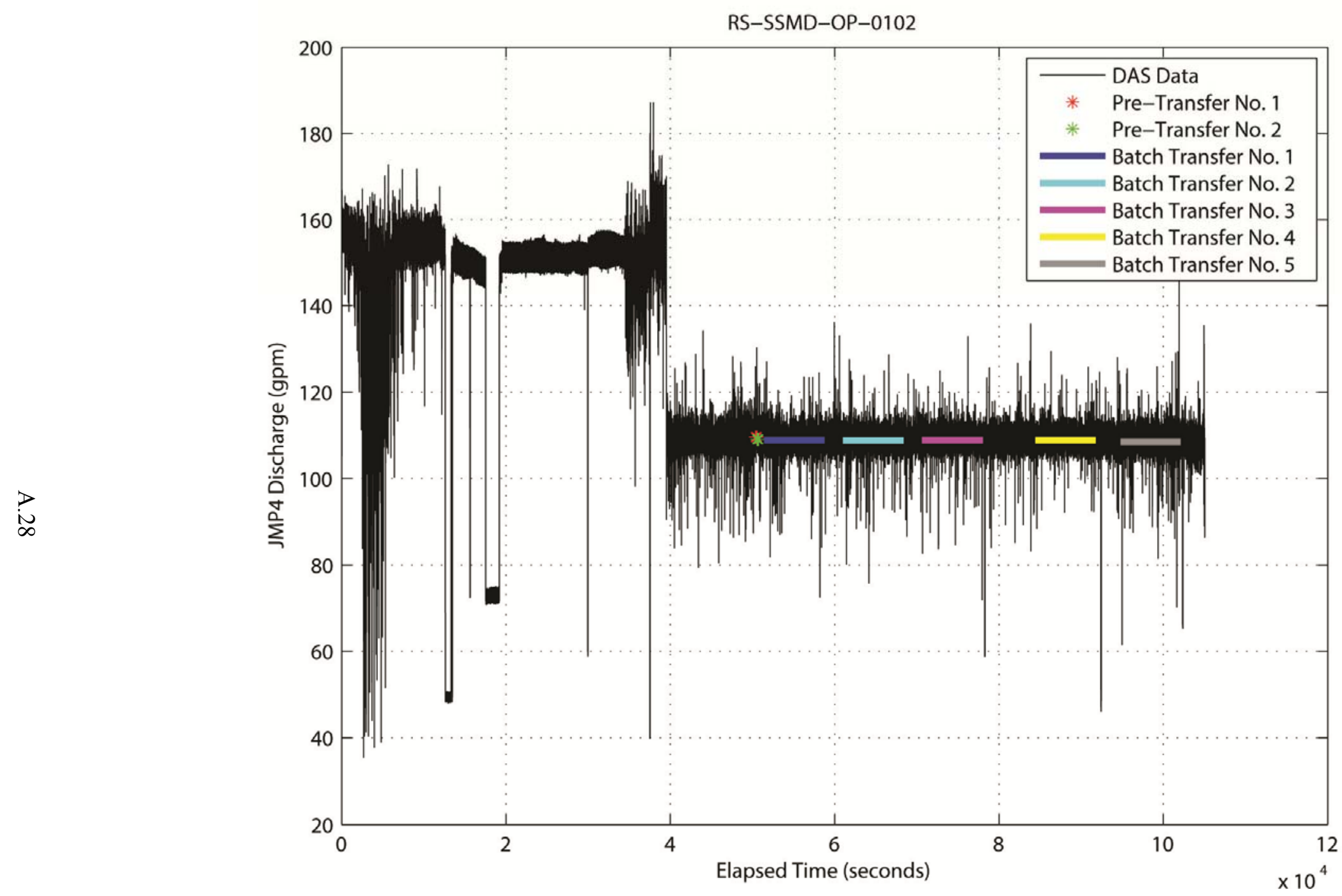

Figure A.26. RS-SSMD-OP-0102 [120-in., $V=3, \mathrm{BS}=\mathrm{H}, \mathrm{SV}=\mathrm{H}, \mathrm{CV}=11.3]$ 


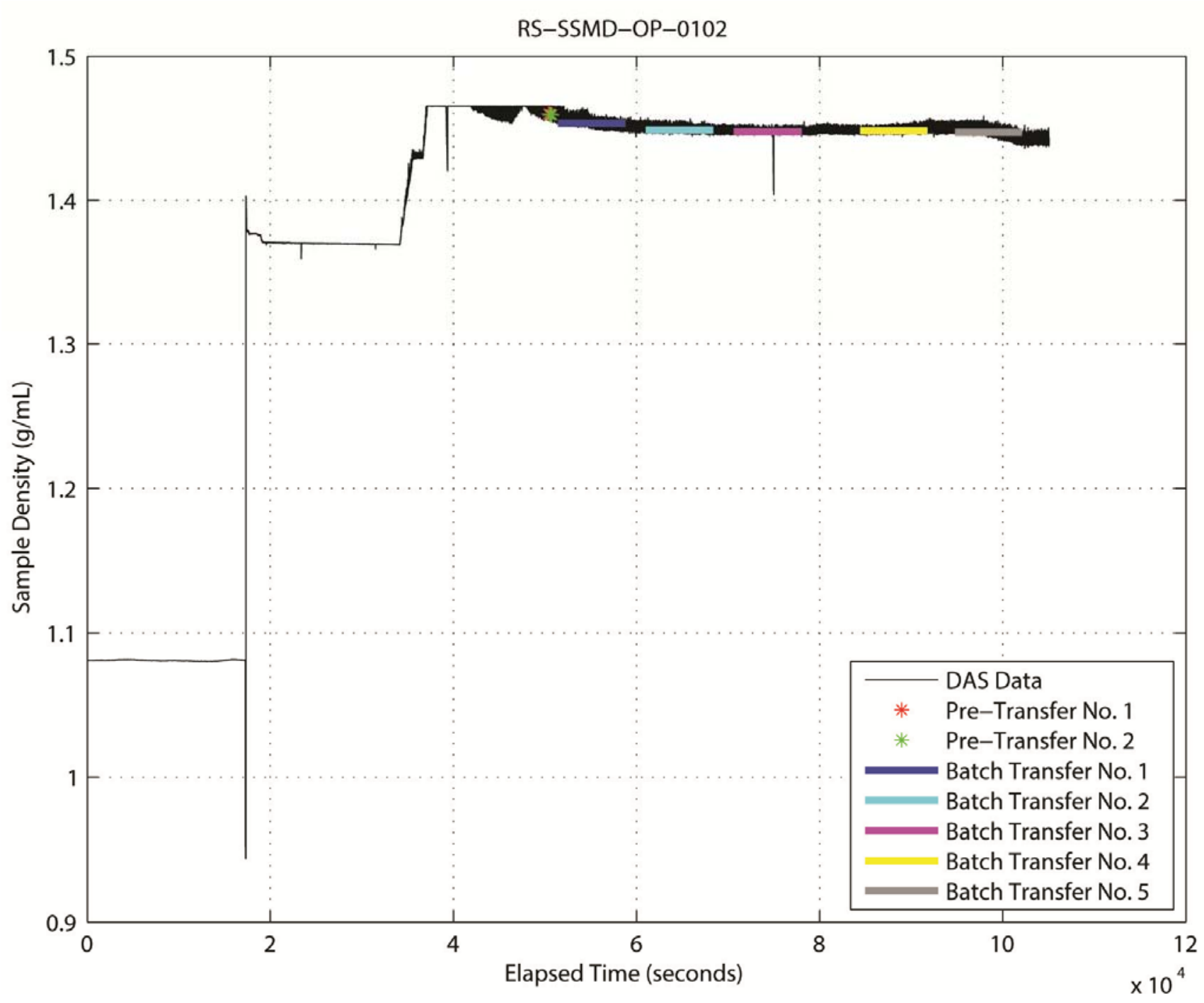

Figure A.27. RS-SSMD-OP-0102 [120-in., V=3, BS=H, SV=H, CV=11.3] 


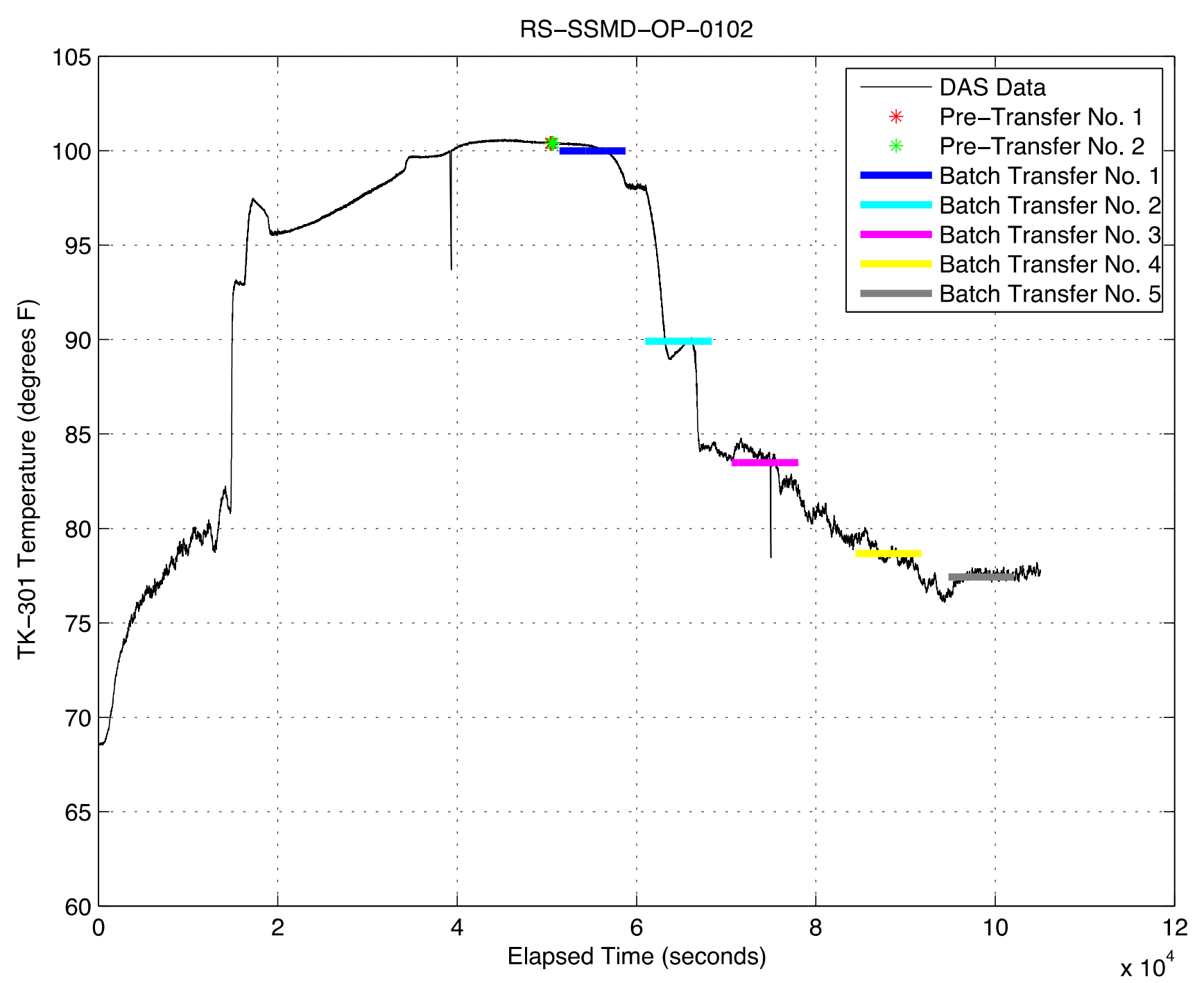

Figure A.28. RS-SSMD-OP-0102 [120-in., V=3, BS=H, SV=H, CV=11.3] 


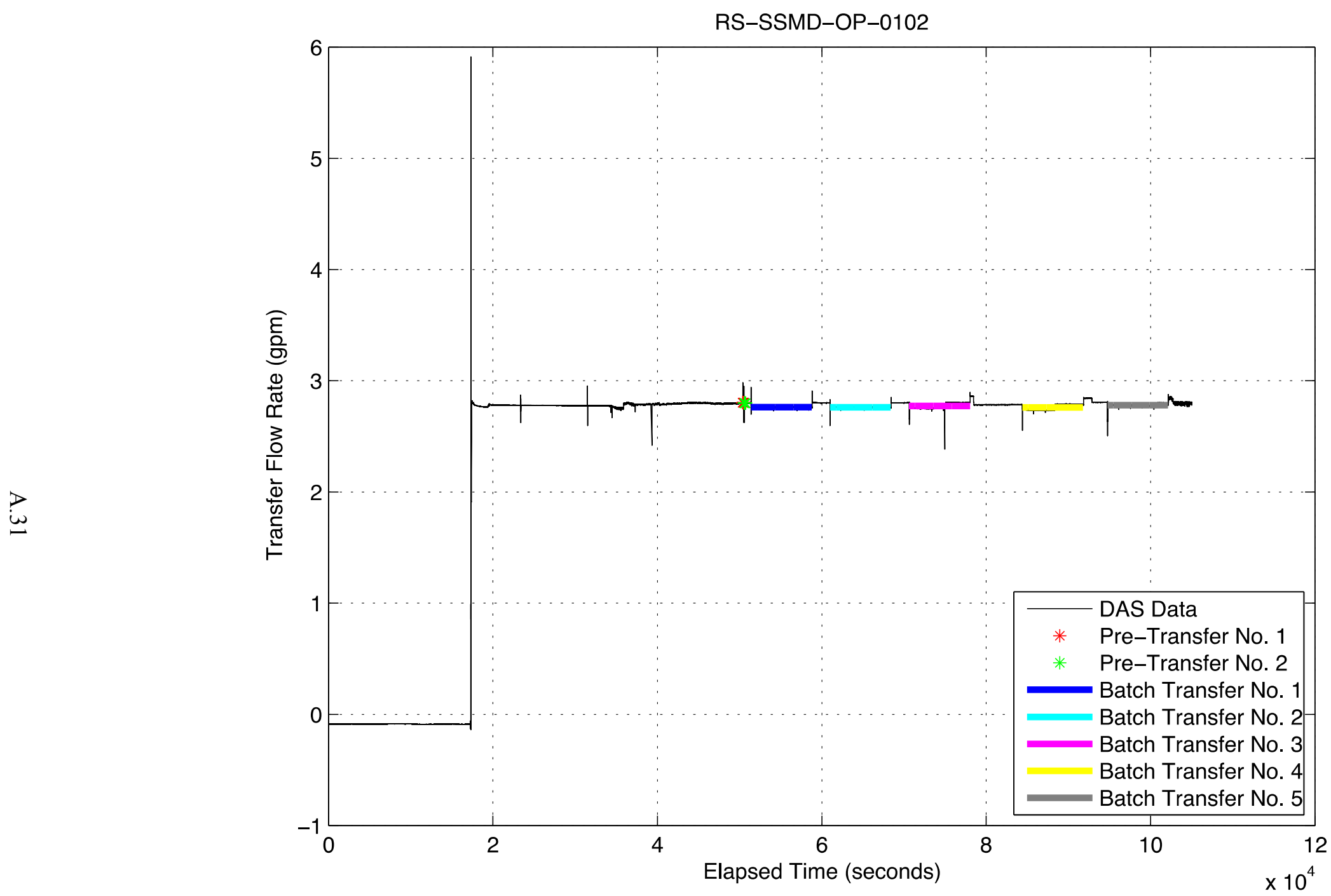

Figure A.29. RS-SSMD-OP-0102 [120-in., $V=3, B S=H, S V=H, C V=11.3]$ 


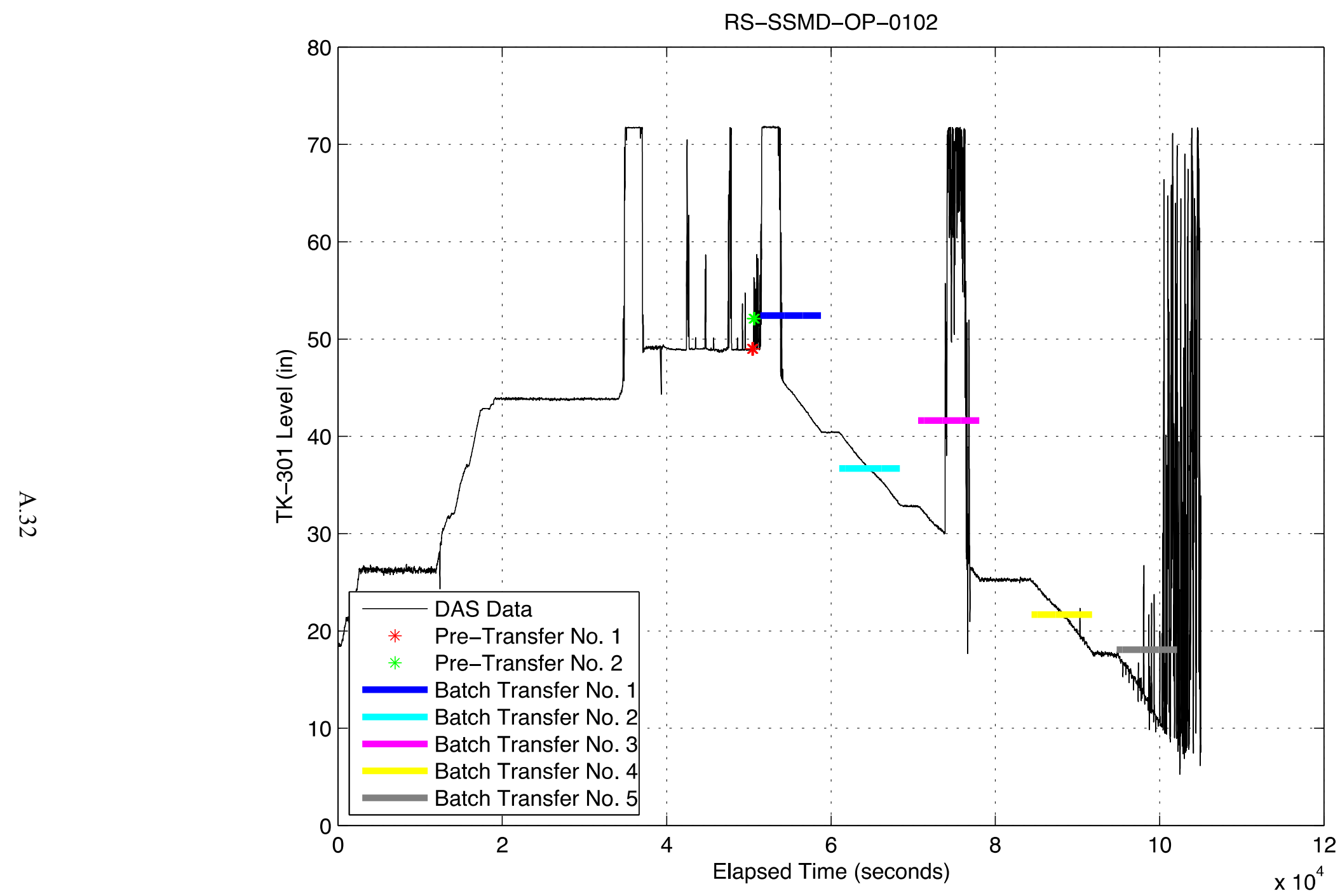

Figure A.30. RS-SSMD-OP-0102 [120-in., V=3, BS=H, SV=H, CV=11.3] 


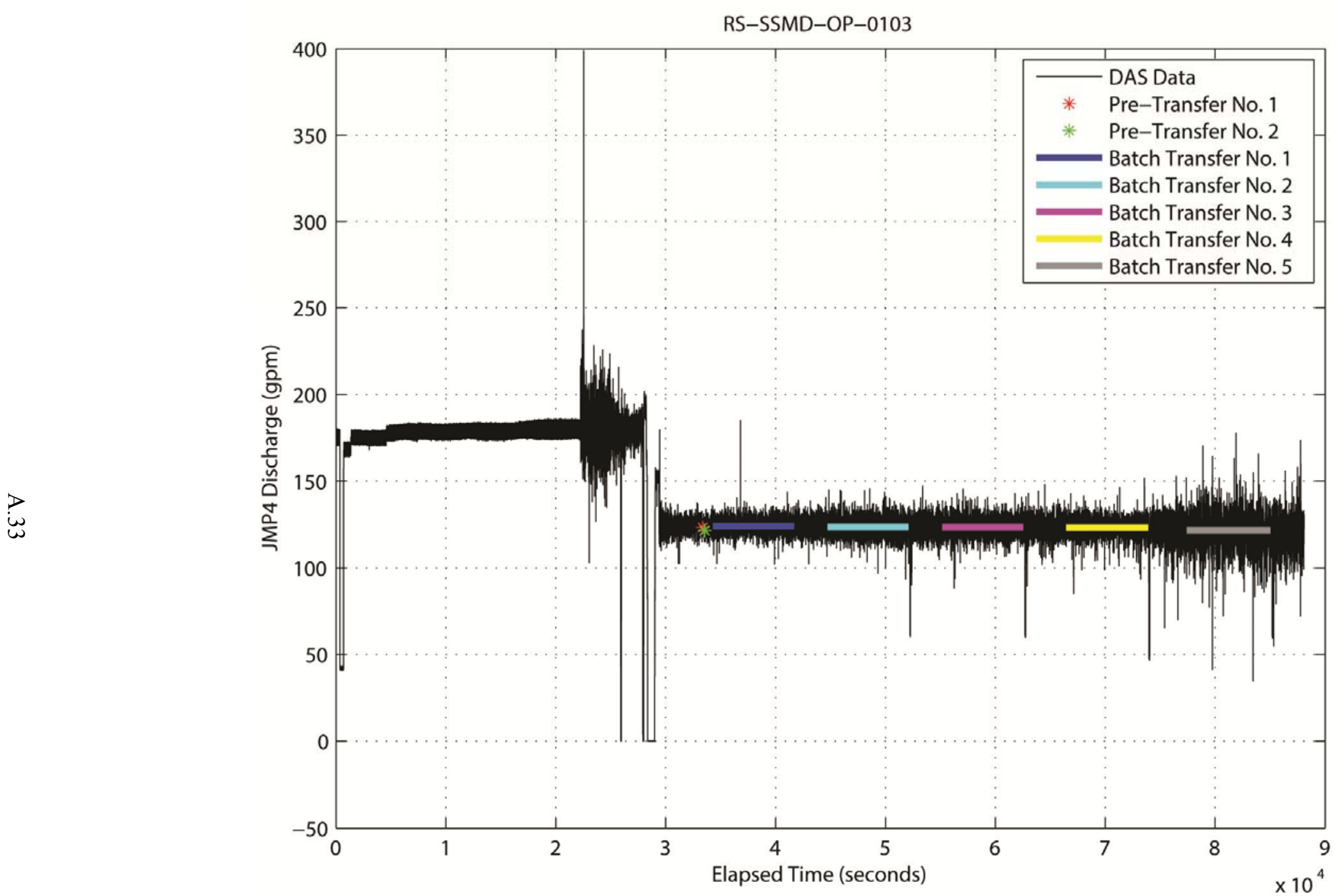

Figure A.31. RS-SSMD-OP-0103 [120-in., V=5, BS=H, SV=H, CV=11.3] 
RS-SSMD-OP-0103

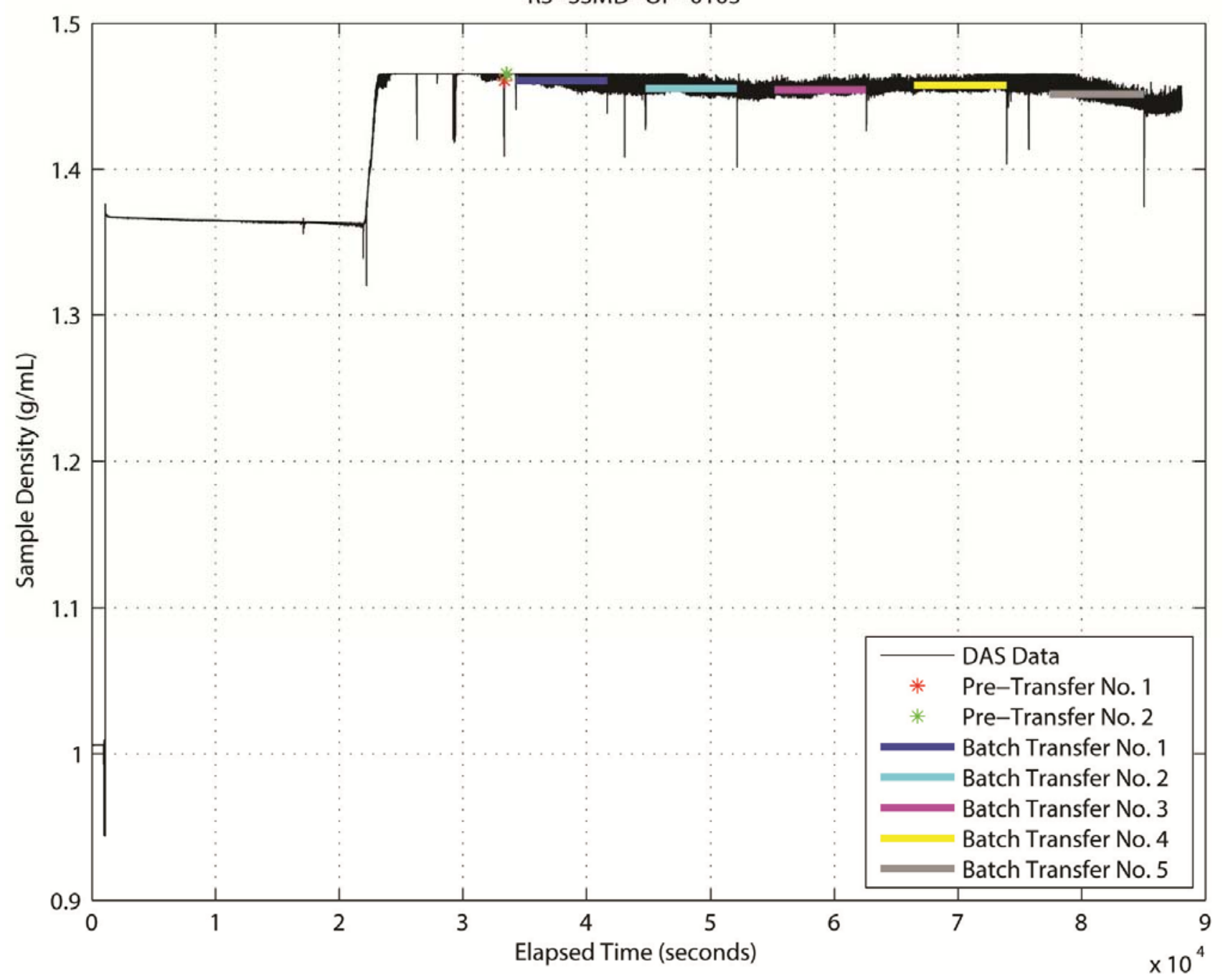

Figure A.32. RS-SSMD-OP-0103 [120-in., V=5, BS=H, SV=H, CV=11.3] 


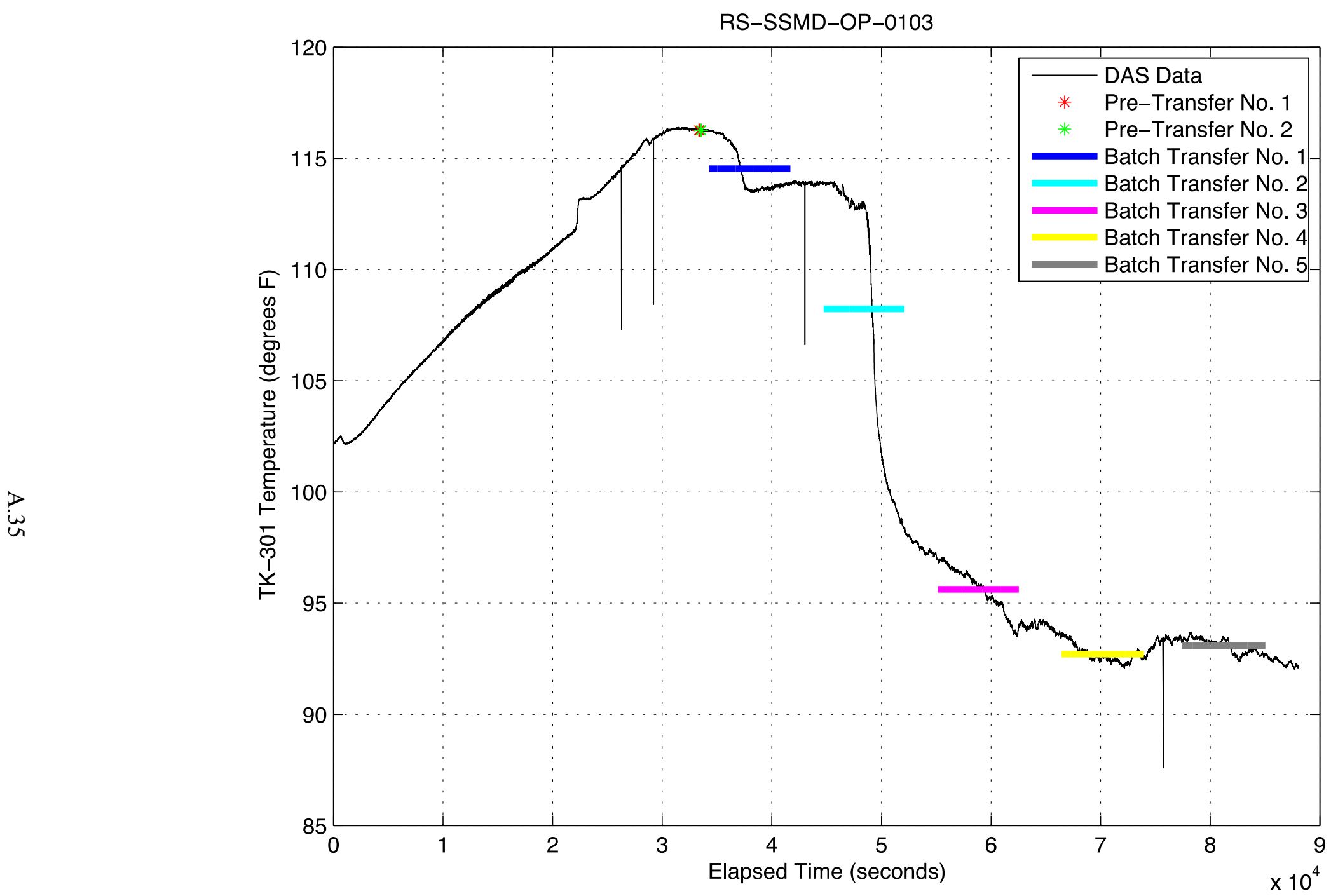

Figure A.33. RS-SSMD-OP-0103 [120-in., V=5, BS=H, SV=H, CV=11.3] 


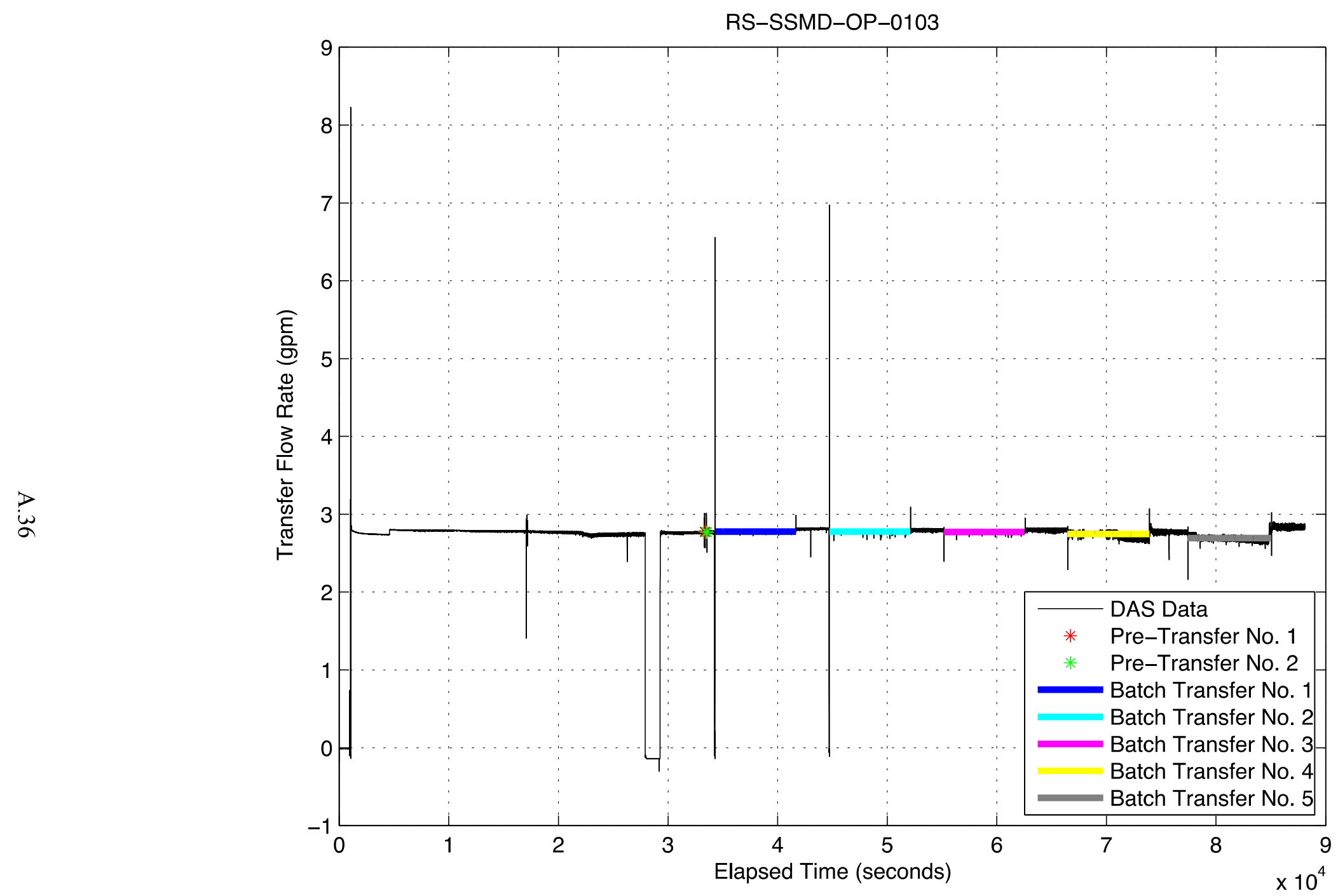

Figure A.34. RS-SSMD-OP-0103 [120-in., V=5, BS=H, SV=H, CV=11.3] 


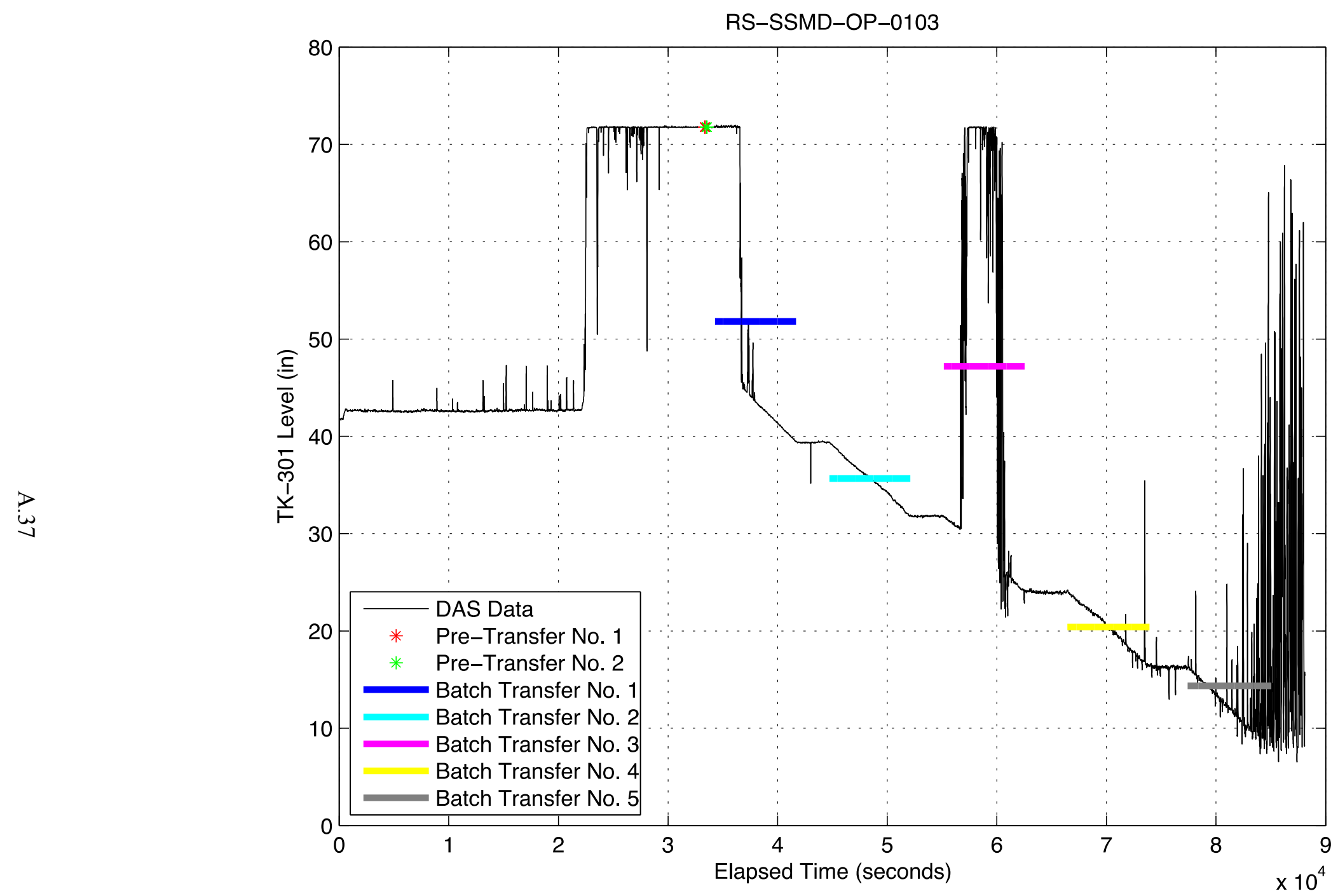

Figure A.35. RS-SSMD-OP-0103 [120-in., V=5, BS=H, SV=H, CV=11.3] 


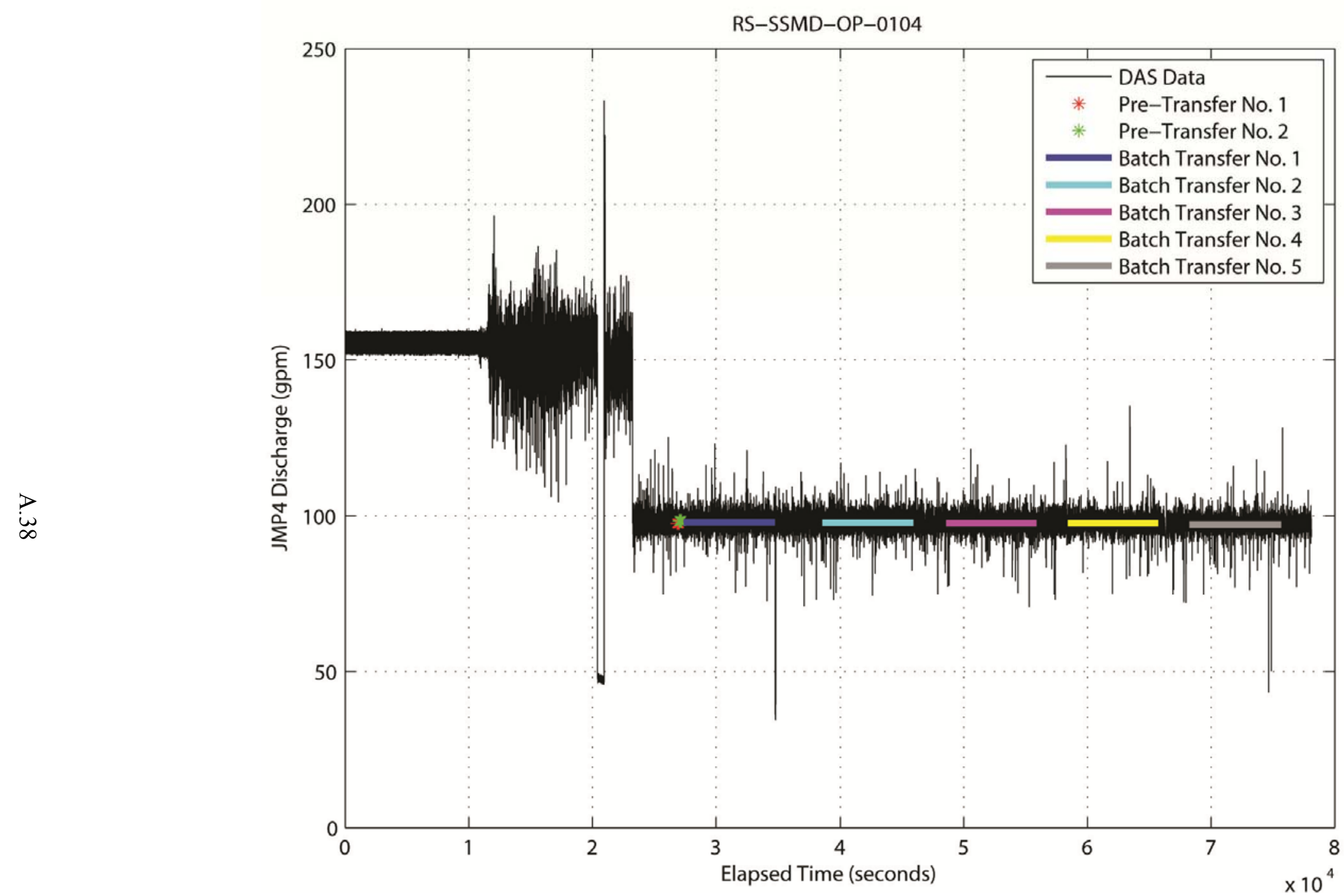

Figure A.36. RS-SSMD-OP-0104 [120-in., V=2, BS=H, SV=H, CV=11.3] 


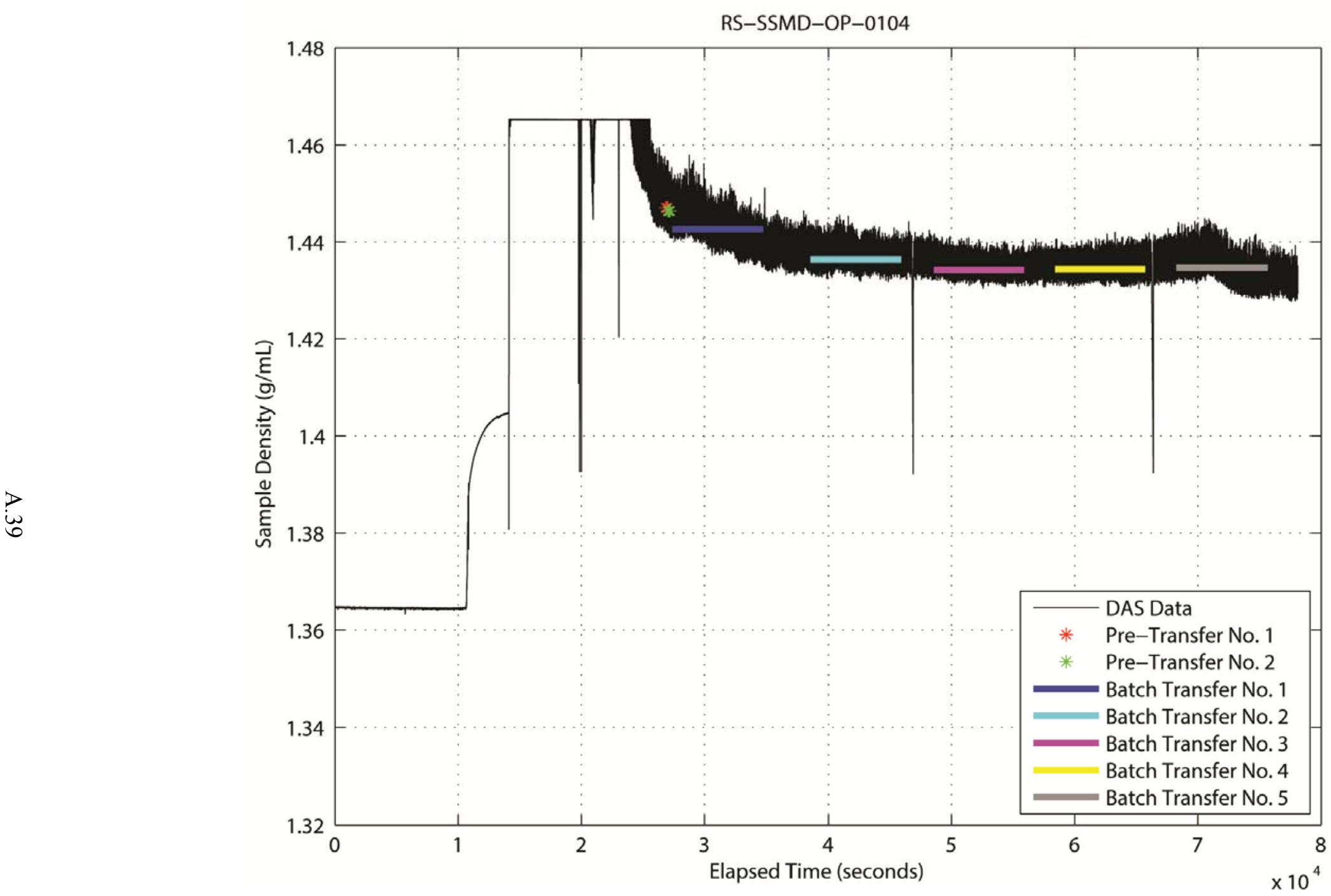

Figure A.37. RS-SSMD-OP-0104 [120-in., $V=2, B S=H, S V=H, C V=11.3]$ 


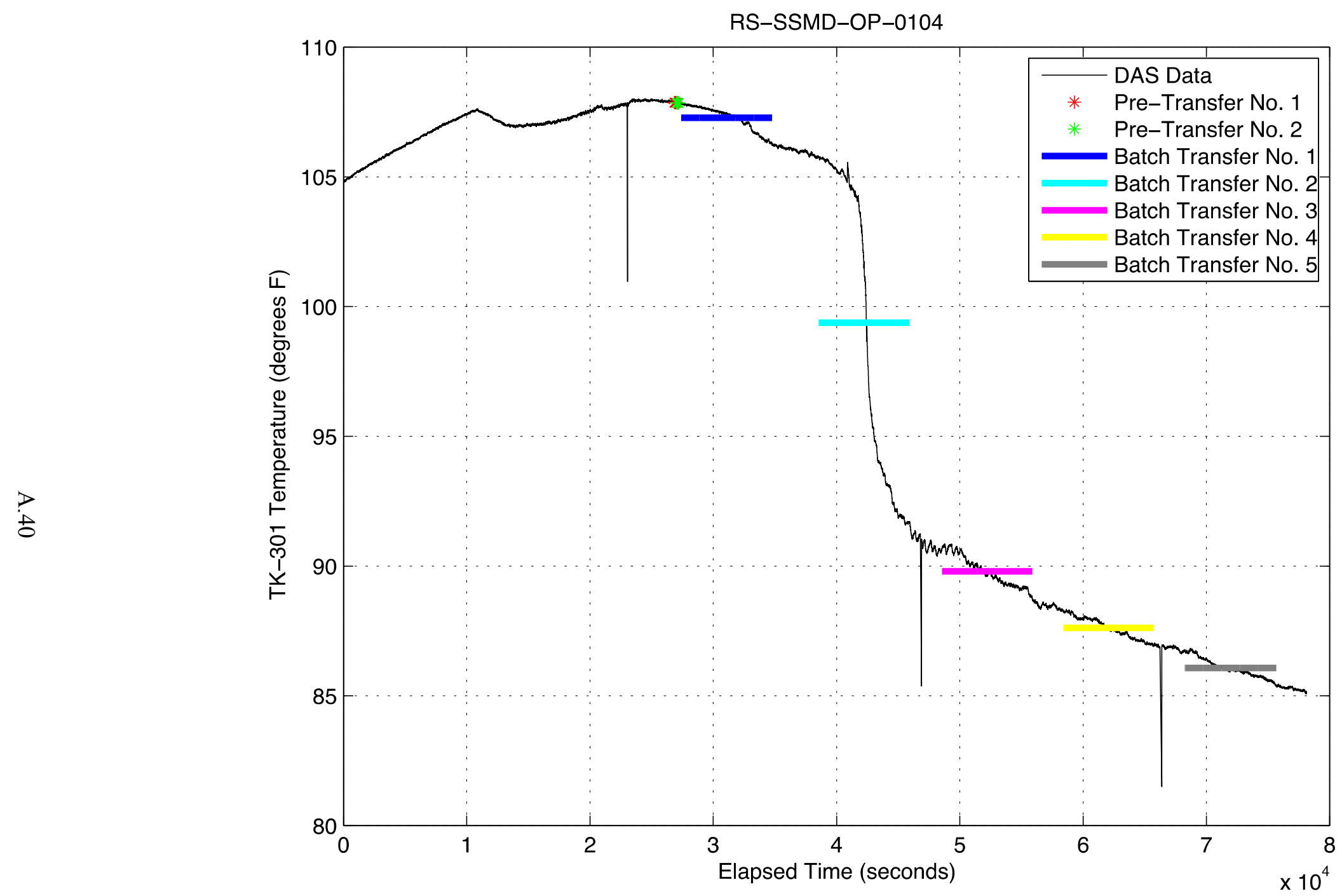

Figure A.38. RS-SSMD-OP-0104 [120-in., V=2, BS=H, SV=H, CV=11.3] 


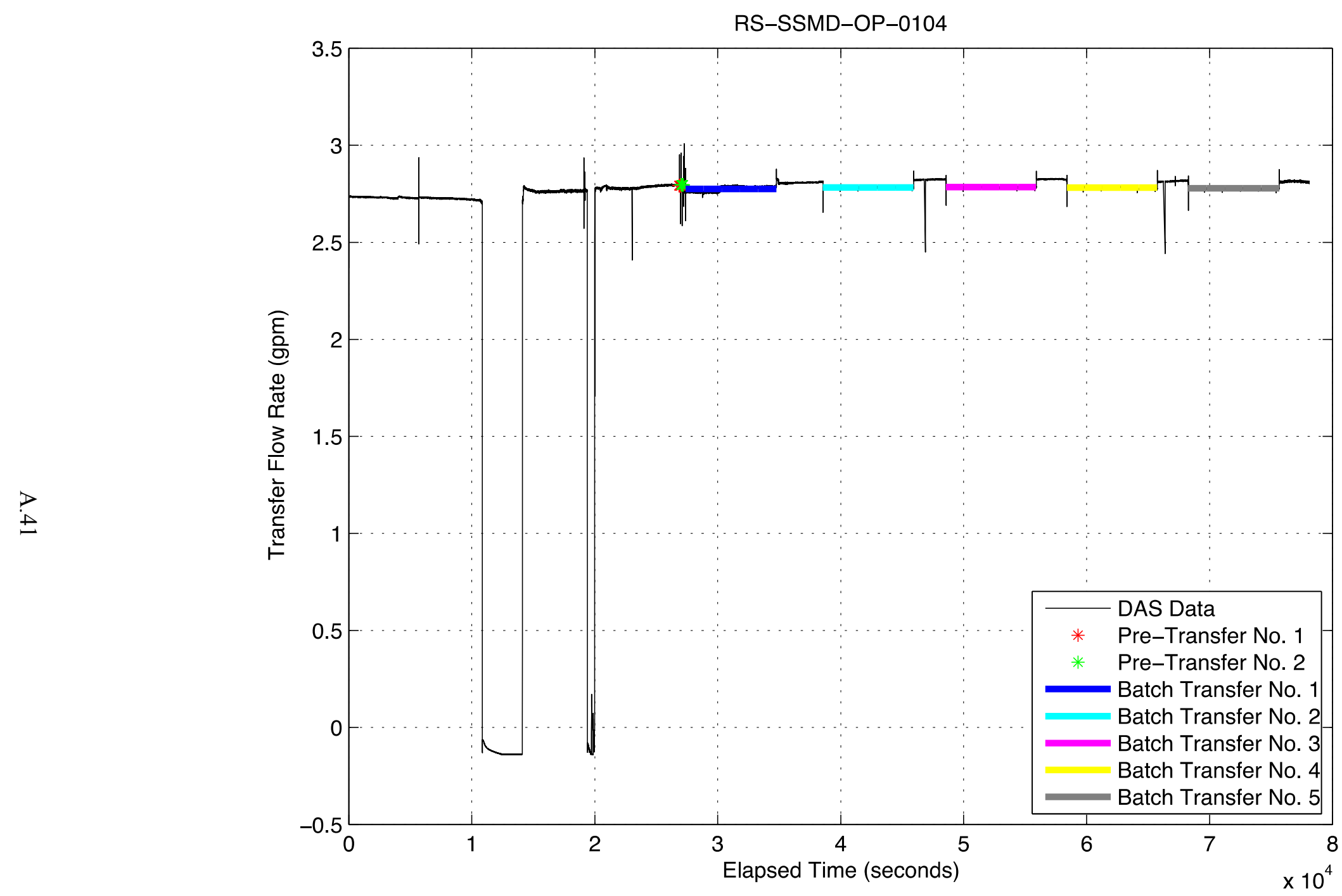

Figure A.39. RS-SSMD-OP-0104 [120-in., $V=2, B S=H, S V=H, C V=11.3]$ 


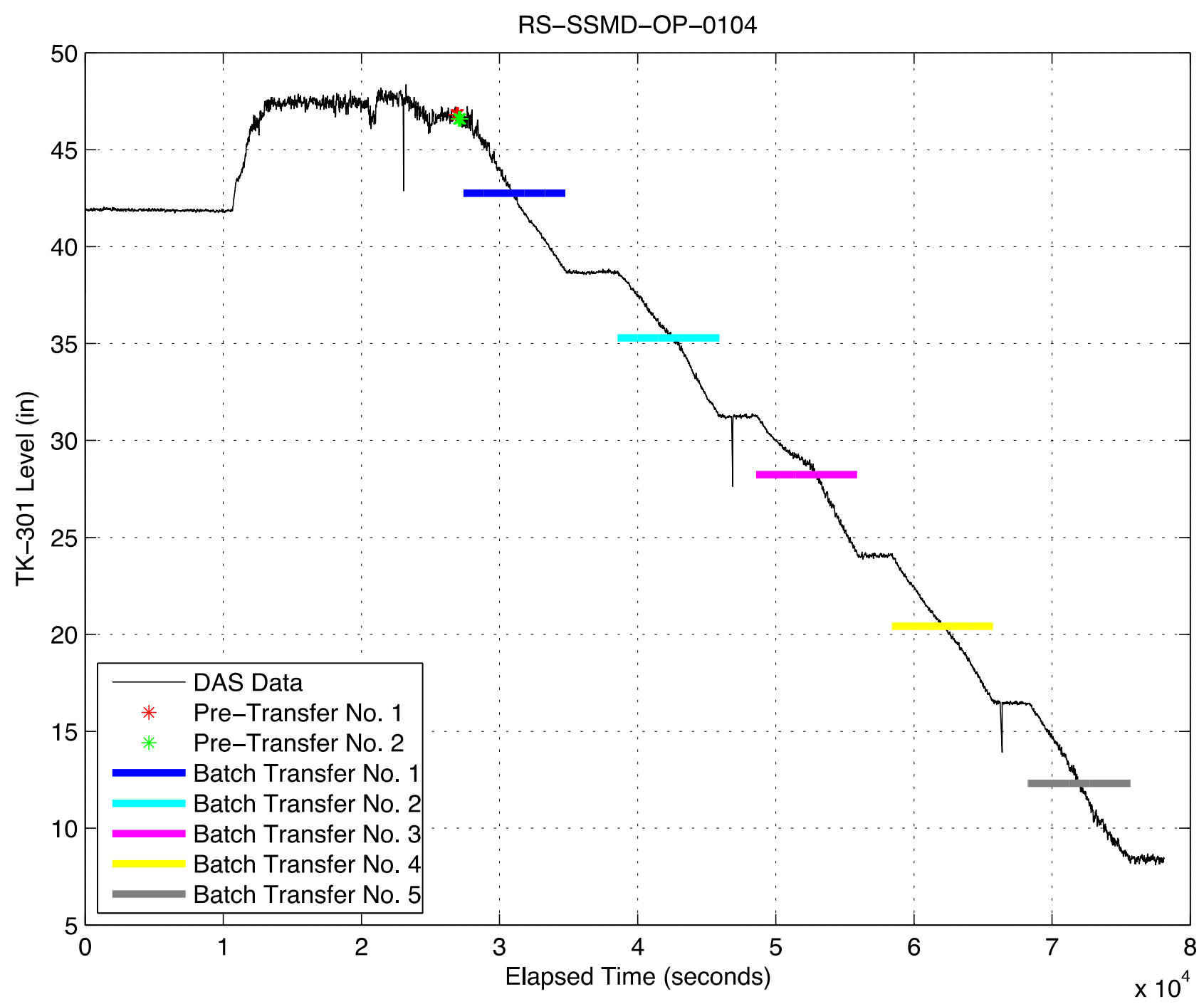

Figure A.40. RS-SSMD-OP-0104 [120-in., V=2, BS=H, SV=H, CV=11.3] 


\section{Reference}

Kelly SE, RX Milleret, and TA Wooley. 2013. One System Waste Feed Delivery Mixing Performance and Solids Accumulation Test Report. RPP-53931, Rev. A, Washington River Protection Solutions, Richland, Washington. 

Appendix B

\section{ParaFlow Predictions}





\section{Appendix B}

\section{ParaFlow Predictions}

The results in this appendix were previously discussed in Rector et al. (2012). The objective of that work was to use high-performance multiphase flow simulations with ParaFlow to resolve design, operational, safety, and optimization issues for high-level waste transport processes. That paper presented simulation results for scaled tests of two tank-mixing applications: the Hanford Waste Feed Delivery (WFD) tank and pulse jet mixing in the Hanford Waste Treatment Plant (WTP). Select results for the WFD tank that are relevant to the current study are included in this appendix.

The ParaFlow computer program, developed at Pacific Northwest National Laboratory (PNNL), has been designed to simulate solid-liquid multiphase resuspension and mixing in chemical processing systems. The solution procedure is based on a new lattice kinetics algorithm, also developed at PNNL, which scales efficiently on massively parallel computers (Rector and Stewart 2010a). The ParaFlow program has been applied to a variety of multiphase processing systems, including slurry pipelines, ultrafiltration, pulse jet mixing, and jet pump tank mixing (Rector et al. 2009; Rector and Stewart 2010b).

\section{B.1 Waste Feed Delivery Tank Mixing}

The waste from each Hanford storage tank is transferred to a WFD tank in preparation for delivery to the WTP. The waste in the WFD tank is mixed and sampled prior to delivery and it is important that these samples are representative of the entire tank contents. That is a challenge because as rotating jet pumps suspend the solids from the bottom sediment layer, the suspended solids concentrations vary in three dimensions as a function of time. The goal of the study was to provide a sufficiently accurate prediction of the suspended solids behavior to guide both the sampling and extraction processes.

A series of scaled experiments has being conducted as part of Small Scale Mixing Demonstration testing to better understand the re-suspension behavior of different types of waste (Woodworth and Townson 2010; Jackson 2011). Single-particle simulations were performed for both the 120-inch and 43.2-inch-diameter scaled tanks. The simulant was a suspension of $6 \mathrm{wt} \% \mathrm{ZrO}_{2}$ particles with a 5.7 specific gravity. Simulations were performed for the 43.2-inch tank for nozzle flow rates jet velocities of $6.5 \mathrm{gpm}(17 \mathrm{ft} / \mathrm{s}), 7.5 \mathrm{gpm}(19 \mathrm{ft} / \mathrm{s})$, and $8.5 \mathrm{gpm}(22 \mathrm{ft} / \mathrm{s})$. The nozzle flow rates/jet velocities for the 120-inch tank were $70 \mathrm{gpm}(22 \mathrm{ft} / \mathrm{s}), 80 \mathrm{gpm}(25 \mathrm{ft} / \mathrm{s})$, and $90 \mathrm{gpm}(28 \mathrm{ft} / \mathrm{s})$.

The existence of a cloud height is seen in the measured vertical density profile taken near the center of the tank at riser 30 during scaled mixing experiments. The density data is presented in the left side of Figure B.1 for the 43.2-inch tank and Figure B.2 for the 120-inch tank. Data for several different jet pump flow rates are included. The ParaFlow simulation results are presented in the plots on the right side of these figures. The reduction of density at the top of the curve indicates the existence of a depletion zone. The 43.2-inch tank data shows only a small region of partial depletion. However, the depletion region for the 120-inch tank at lower flows indicates a substantial depletion region, consistent with a distinct cloud height. 
Test Data

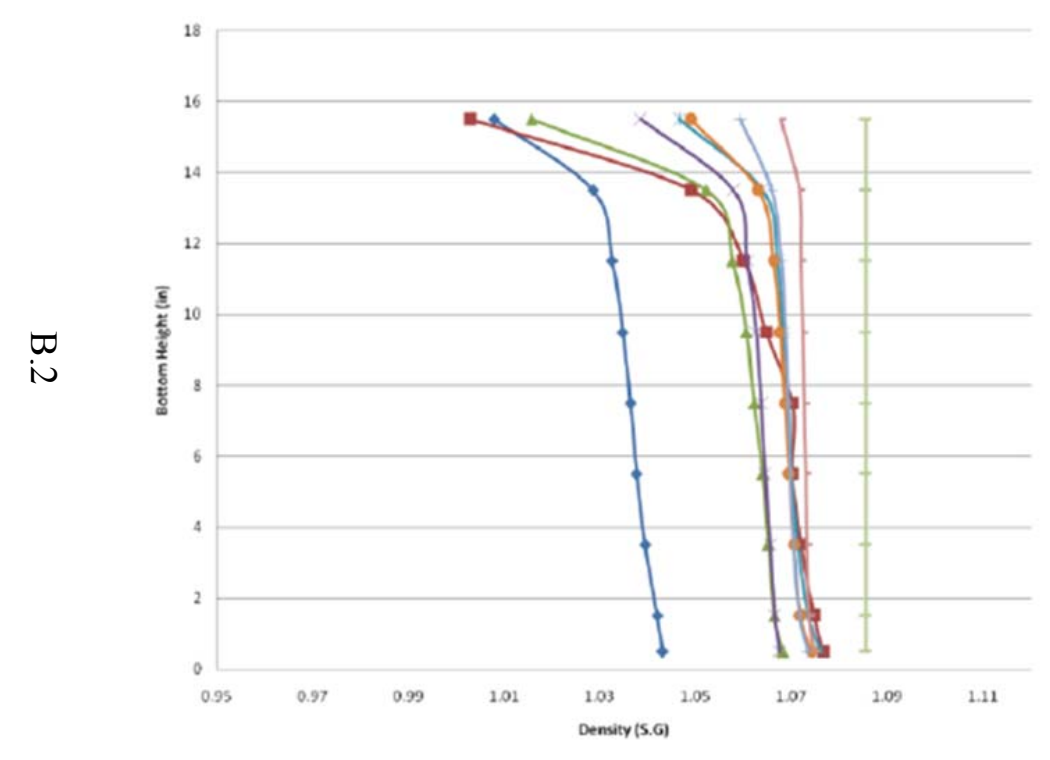

ParaFlow Prediction

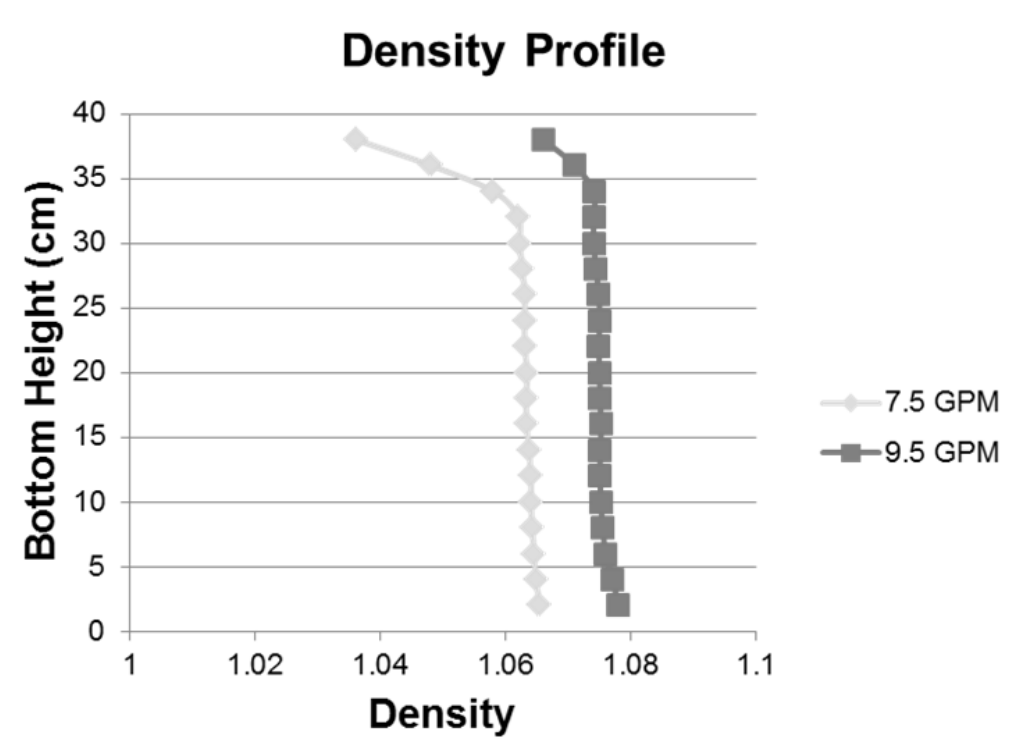

Figure B.1. ParaFlow Predictions of Homogeneous Mixing within Cloud $-\mathrm{ZrO}_{2}$ Simulant, 43-inch Vessel 
Test Data

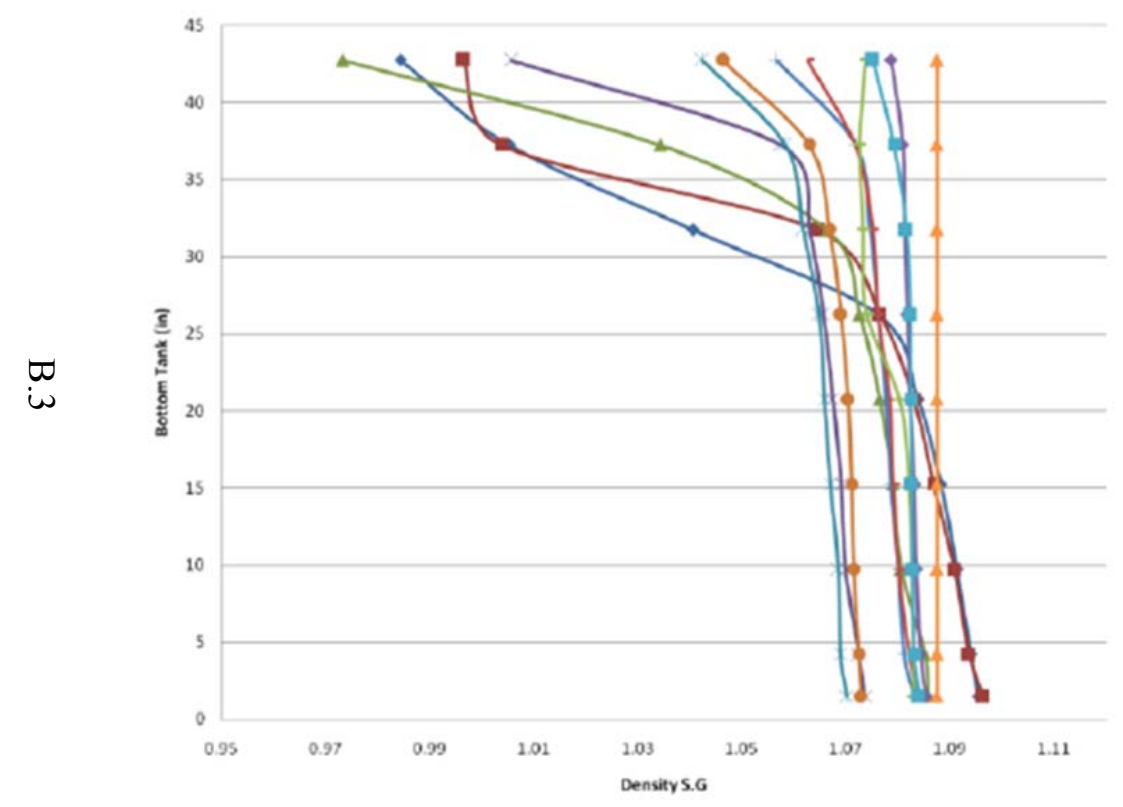

ParaFlow Prediction

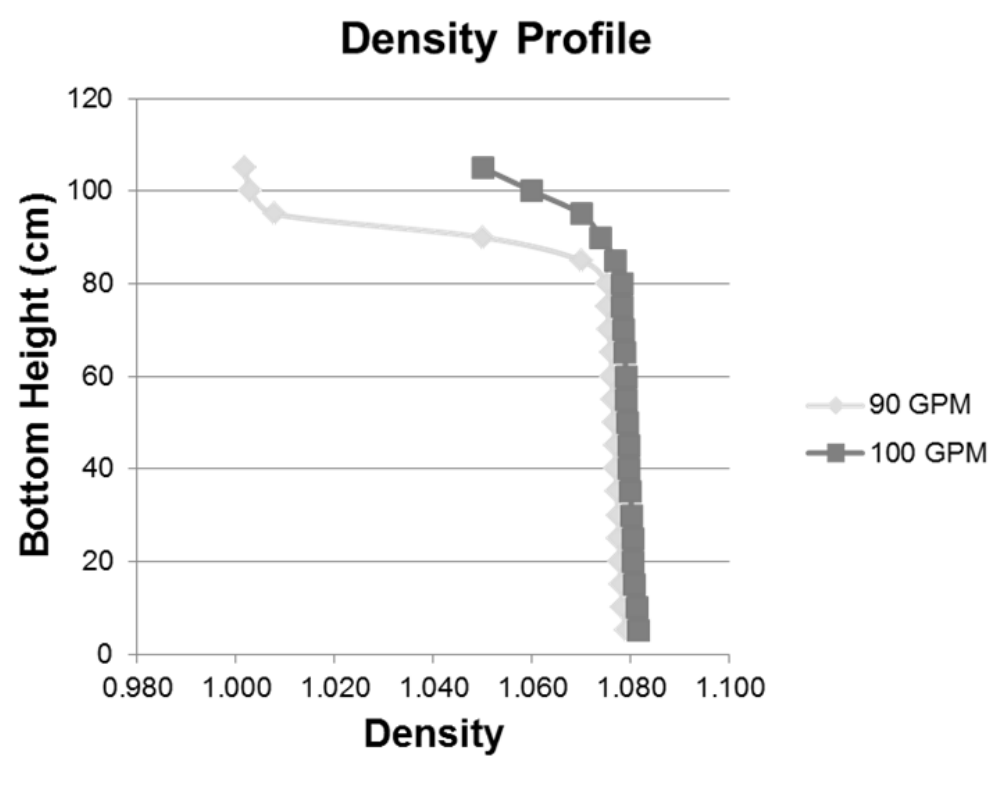

Figure B.2. ParaFlow Predictions of Homogeneous Mixing within Cloud $-\mathrm{ZrO}_{2}$ Simulant, 120 -inch Vessel 


\section{B.2 Waste Feed Delivery Tank Transfer}

The ParaFlow simulation for the 80-gpm case with $\mathrm{ZrO}_{2}$ particles was modified to withdraw material near Riser 30, near the center of the tank, at an elevation above the jet nozzles. The slip surface at the top of the liquid moved down at a rate equivalent to the volumetric withdrawal rate. The transfer ceased when one-sixth of the tank contents was removed.

The tank average specific gravity at the beginning of the simulation is approximately 1.052 . The concentration profile shown in Figure B.3 indicates that the fluid level has dropped (the top blue band is air) and that the suspended solids now occupy almost all of the fluid region. The lower cloud height increases the solids concentration, resulting in an averaged mixture density at the withdrawal point of just over 1.06 at the beginning of the transfer. As the suspension is removed, the cloud height does not change appreciably throughout the simulation. The cloud height appears to be more a function of the jet speed and simulant type than slight changes in solids concentration. The reduction in solids is uniformly mixed throughout the cloud region, reducing the mixture density until a final averaged withdrawal density of approximately 1.048 is reached.

The average density of the transfer stream was measured as a function of time for each batch transfer experiment for the 120-inch vessel and is presented in top left plot in Figure B.3 for the 80-gpm case and bottom left plot in the same figure for the 90 -gpm case. The vertical lines indicate the beginning and end of each batch transfer. Note that in both cases the initial mixture density exceeds the tank average, indicated by the yellow line, and then decreases as the solids are removed from the concentrated cloud.

The simulated density of the mixture at the removal point in the tank is presented as the grey symbols overlain on each of the measured data plots in Figure B.3 for the first batch transfer only. The simulation results follow the data in both cases. The slope is more gradual in the 90-gpm case because the cloud height is near the top of the liquid level and the cloud concentration is close to the tank average. In both cases, the sediment formation was small relative to the suspended solids.

The right-hand plot in Figure B.3 pictorially relates the pre-transfer concentrations (i.e. time $=0$ ) from the SSMD test data and ParaFlow predictions. The test data is shown as open symbols with blue for small scale, red for large scale tests. The open triangles represent the SSMD test data transfer location concentration as inferred from the vertical density gradients of Figure B.1 and Figure B.2 (denoted as "vertical profile"), while the open diamonds are for the actual measured density at the transfer location prior to batch transfer (denoted as "prior to batch xfer"; two test conditions for the large scale test tank are from the left-side plots of Figure B.3). Inconsistency is noted between these two methods ("vertical profile" and "prior to batch xfer"). The solid symbols are the ParaFlow predictions at the respective tank scales as denoted by color, and there are very similar results for the large scale tank at the two jet velocities evaluated with the "prior to batch xfer" SSMD results. 

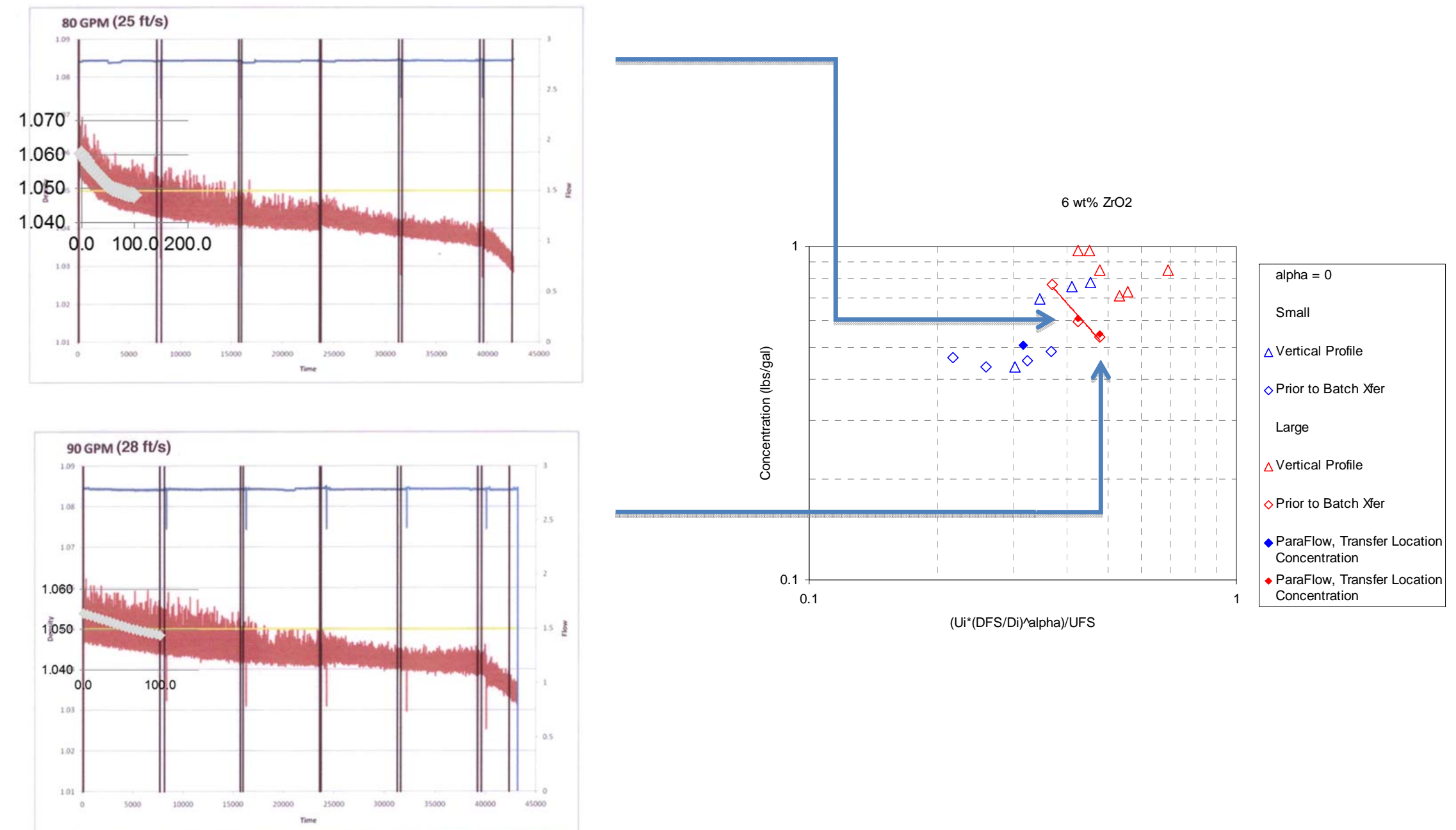

$($ Ui*(DFS/Di)^alpha)/UFS

Figure B.3. ParaFlow Predictions of Transfer UDS Concentration for $\mathrm{ZrO}_{2}$ Simulant $(\alpha=0)$ 


\section{B.3 References}

Jackson V. 2011. Small Scale Mixing Demonstration Sampling and Batch Transfers Initial Results Report. RPP-49740 (RPT-SSMD-EG-0005, Rev. A), EnergySolutions, Richland, Washington.

Rector DR and ML Stewart. 2010a. "A semi-implicit lattice method for simulating flow." Journal of Computational Physics 229(19):6732-6743.

Rector DR and ML Stewart. 2010b. "Modeling of Leaching Filter Pressure Drop and Fouling Behavior." Presented at the 2010 Waste Management Conference, March 7-11. 2010, Phoenix, Arizona.

Rector DR, ML Stewart, and J Bao. 2012. "Modeling of HLW Tank Solids Resuspension and Mixing Processes." Presented at the 2012 Waste Management Conference, February 27-March 1, 2012, Phoenix, Arizona.

Rector DR, ML Stewart, and AP Poloski. 2009. "Modeling of Sediment Bed Behavior for Critical Velocity in Horizontal Piping." Presented at the 2009 Waste Management Conference, March 1-5, 2009, Phoenix, Arizona.

Woodworth R and PA Townson. 2010. Small Scale Mixing Demonstration Initial Results Report. RPP-47557 (RPT-SSMD-EG-0003, Rev. 0), EnergySolutions, Richland, Washington. 


\section{Distribution}

No. of

Copies

ONSITE

2 DOE Office of River Protection

CK Liu

WR Wrzesinski

H6-60

H6-60

6 Washington River Protection Solutions

SE Kelly

KP Lee

RX Milleret

SA Saunders

M Thien

TA Wooley
$\mathrm{H} 4-02$

H4-02

H4-02

H4-02

H4-02

H4-02
No. of

Copies

5 Pacific Northwest National Laboratory

JA Fort

K7-15

PA Gauglitz

DR Rector

K7-15

K7-15

PP Schonewill

P7-25

BE Wells 




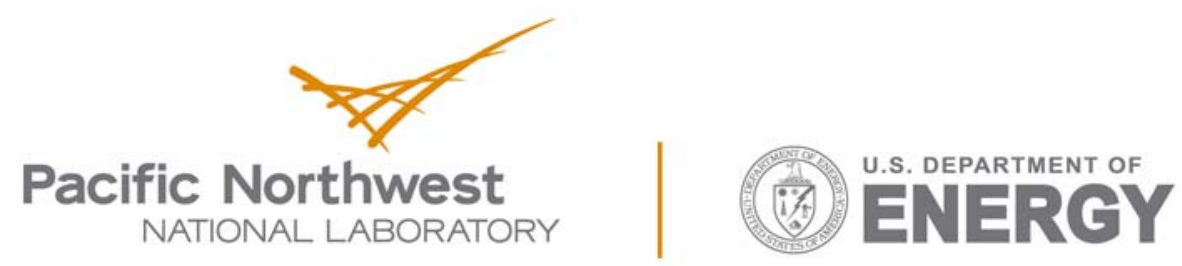

Proudly Operated by Battelle Since 1965

902 Battelle Boulevard

P.O. Box 999

Richland, WA 99352

1-888-375-PNNL (7665)

www.pnnl.gov 